

$$
\begin{aligned}
& 5080116 \\
& \begin{array}{r}
39.360 \\
(48.7)
\end{array} \\
& A^{\frac{123}{400}}
\end{aligned}
$$


Digitized by the Internet Archive in 2018 with funding from Wellcome Library

https://archive..org/detail's/b29289191 


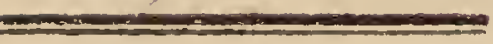

A RBORES MIRABILES,

$\S \%$

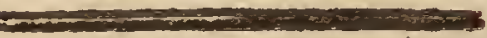




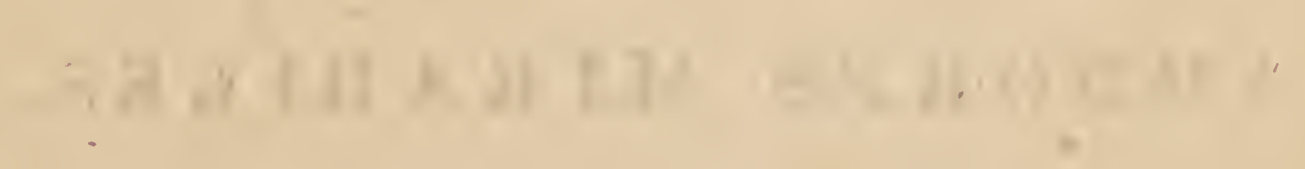




\section{ARBORES MIRABILES:}

$\mathbf{O R}$,

\section{A DESCRIPTION}

OF THE MOST

\section{$R E M A R K A B L E, T R E E S$,}

\section{PLANTS, AND SHRUBS,}

IN ALL PARTS OF THE WORLD.

Illustrated with several curious Anecdotes of their wonderful

Properties, and at the same time manifesting Infinite

Wisdom in the Formation of those valuable Pro-

ductions, so beneficial to all Mankind.

TAKEN FROM THE JOURNALS OF

EMINENT TRAVELLERS, HISTORIANS, AND NATURALISTS.

\section{BY JOSEPH TAYLOR.}

"And out of the ground marle the Lord God to grow every tree that is pleasant to the sight, and good for food."-Genesis ii.9.

"Not a tree,

A plant, a leaf, a blossom, but contains

A folio volume. - We may read, and read,

And read again; and still find something new,

Something to please, and something to instruct, E'en in the bumble weed."

\section{LONDON :}

PRINTED BX AND FOR W. DARTON, 58, HOLBORN HIL, 



\section{ANECDOTES}

\section{$O F$ \\ REM A R A BLE TREES.}

\section{The Upas, or Poison Tree:}

"Where seas of glass with gay refiection smile, Round the green coast of Java's palmy isle; A spacious plain extends its upland scene, Rocks rise on rocks, and fountains gush between. Soft hreathes the breeze, - - eternal summers reign, And showers prolific bless the soil in vain! No spicy nutmeg scents the vernal gales,No towering plantain shades the mid-day valesNo grassy mantle hides the sable hillsNo flow'ry chaplet crowns the trickling rillsNo step retreating on the sand impress, Invites the visit of a second guest.

Fierce in dread silence on the blasted heath Fell Upas sits!"

DARTIN.

A description of a tree in the island of Java, called the Upas, or Poison tree, is given ta the public by a surgeon belonging to the Dutch Last India Company, of the name of Foersch, who was stationed at Batavia, in the year 1774. Surprising as these accounts may be, they are accompanied with so many public facts, and names of persons and places, that it is somewhat difficult to conceive them fabulous. 
The Upas grows about seven leagues fror Batavia, in a plain surrounded by rocky mountains, the whole of which plain, containing a circle of ten or twelve miles round the tree, is totally barren. Nothing that breathes or vegetates can live within its influence. The bird that flies over it drops down dead. The beast that wanders into it expires. The whole dreadful area is covered with sand, over which lie scattered loose flints and whitèned bones.

This tree may be called the Emperor's great military magazine. In a solution of the poisonous gum which exudes from it, his arrows and offensive weapons are dipped; the procuring, therefore, of this poisonous gum, is a matter of as much attention as of difficulty. Criminals are only employed in this dreadful service. Of these several every year are sent with a promise of pardon and reward if they procure it. Hooded in leather cases, with glass eyelet holes, and secured as much as possible from the full effluvia of the air they are to breathe, they undertake this melancholy journey, travelling always with the wind. About one in ten escapes, and brings away a little box of this direful commodity!

\section{The Fountain Tree.}

in one of the Canary Islands, grows a tree which furnishes water to the inhabitants and beasts of the whole place. 
"6 The district in which this tree stands is called Tigulatre, near to which, and in the cliff, or steep rocky ascent, surrounding the whole island, is a narrow gutter or gulley, which commences at the sea, and continues to the summit of the cliff, where it joins or coincides with a valley which is terminated by the steep front of a rock.

" On the top of this rock, grows a tree, called, in the language of the ancient inhabitants, Garse, (sacred or holy tree) which for many years has been preserved sound, entire and fresh. Its leaves constantly distil such a quantity of water, as is sufficient to furnish drink to every living creature in Hierro; nature having provided this remedy for the drought of the island. It is situated about a league and a half from the sea. Nobody knows of what species it is, only that it is called Til. It is distinct from other trees, and stands by itself. The circumference of its trunk is about twelve spans, the diameter four, and in height from the ground to the top of the highest branch forty spans: the circumference of all the branches together, is one hundred and twenty feet. The branches are thick and extended; the lowest commence about an ell from the ground. Its fruit resembles the acorn, and tastes something like the kernel of a pine apple, but is softer and more aromatic. The leaves of this tree resemble those of the laurel, but are larger, wider, and more curved; they come forth in 
perpetual succession, so that the tree always remains green. On the north side of the trunk, are two large tanks, or cisterns, of rough stone, or rather one cistern divided, each half being twenty feet square, and sixteen spans in depth. One of these contains water for the drinking of the inhabitants; and the other that which they use for their cattle, washing, and such like purposes. Every morning, near this part of the island, a cloud or mist arises from the sea, which the south and easterly winds force against the forementioned steep cliff, so that the cloud, having no vent but by the gutter, gradually ascends it, and from thence advances slowly to the extremity of the valley, where it is stopped and checked by the front of the rock, which terminates the valley, and then rests upon the thick leaves and wide-spreading branches of the tree, from whence it distils in drops, during the remainder of the day, until it is at length exhausted, in the same manner that we see water drip from the leaves of trees after a heavy shower of rain. This tree yields most water in those years when the Levant or easterly winds have prevailed for a continuance, for by these winds only the clouds or mists are drawn hither from the sea.

"A A person lives on the spot near where this tree grows, who is appointed by the Council to take care of it, and its water; and is allowed a house to live in, with a certain 


\section{A DROPFING TREE.}

salary. He every day distributes to each family of the district, seven pots or vessels full of water, besides what he gives to the principal people in the island."

Glas's History of the Canary Islands.

\section{Tree yielding Water, in America.}

In Cockburn's Voyages we find the following account of a dropping tree, near the mountains of Vera Paz, in America.

" On the morning of the fourth day we came out on a large plain, where were numbers of fine deer, and in the middle stood a tree of an unusual size, spreading its branches over a vast compass of ground. Curiosity led us up to it; we had perceived, at some distance off, the ground about it to be wet, at which we began, to be somewhat surprised, as well knowing there had no rain fallen for near six months. past, according to the certain course of the season in that latitude: that it was impossible to be occasioned by the fall of dew on the tree, we were convinced, by the sun's having power to exhale all moisture of that nature a few minutes after its rising. At last, to our great amazement, as well as joy, we saw water dropping, or, as it were, distilling fast from the end of every leaf of this wonderful, (or had it been amiss, if I had said miraculous) tree; at least it was so with respect to us, who had been labonring four 
days through extreme heat without receiving the least moisture, and were now almost expiring for the want of it.

"We could not help looking on this as liquor sent from heaven to comfort us under our great extremity. We catched what we could of it in our hands, and drank very plentifully of it, liking it so well, that we could harcly prevail with ourselves to give it over.

" A matter of this nature, could not but excite us to make the strictest observations concerning it; and accordingly we staid under the tree near three hours, and found we could not fathom its body in five times. We observed the soil where it grew to be very stony; and upon the nicest inquiry we could afterwards make, both of the ratives of the country, and the Spanish inhabitants, we could not learn that there was any such tree known throughout New Spain, nor perhaps all America over.'

\section{The Tallow Tree.}

The Tallow Tree grows in great plenty in China, and produces a substance much like our tallow, and serving for the same purposes.

It is about the height of a cherry tree; its leaves in form of a heart, of a deep shining red colour, and its bark very smooth. Its fruit is enclosed in a kind of pod or cover, 
like a chesnut, and consists of three round white graius, of the size ano form of a small nut, erch having its peculiar capsule, and within that, a little stone - This stone is encompassed with a white pulp, which has all the propertics of truc tallow, as to consistence, colour, and even smell; and accordingly the Chinese make their candles of it, which would doubtless be as gooul as those in Hurope, if they knew how to purify their vegetable, as well as we do our animal tallow, and make their wicks as fine. All the preparation they give it, is to melt it down, and mix a little oil with it, to make it softer and more pliant. It is true their candles marie of it, yield a thicker smoke, and give a dimmer light than our's; but these defects are owing in a great measure to the wicks, which are not of cotton, but only a little rod or switch of dry light wood, covered with the pith' of a rush, wound round it, which being very porous, serves to philtrate the minute parts of the tallow, attracted bythe burning stick, and which by this means is kept burning.*

How various are the productions of the vegetable world! How infuite must be the wisdom which originally designed, and thus uniformly produces all these excellencies! And how great the goodness, which thus amply provides for the necessities of his creatures, and affords them so much use with so much beauty! One would scarcely expect

* Du Halde's History of China. 
the vegetable world to produce any thing so near to the animal, as the present tree affords: but naturalists observe, that the limits are scarce discernable, which divide the different orders of beings.-Some animals approach very nigh to some human creatures: some plants again approach as near to the animals: and some fossils are removed by a very insensible distance from vegetables. - How far man may be removed from angels, we know not; but certain it is, that the true Christian, who is renewed in the image of his God, participating of the divine nature, may well hope, that the perfections and happiness of angels. will one day be his.

\section{The Cotton Tree.}

There are three sorts of cotton trees; one creeps on the earth, like a vine: the second is thick, like a bushy dwarf tree; and the third, is as tall as an oak. All the three after they have produced very beautiful flowers, are loaded with a fruit as large as a walnut, whose outward coat is entirely black. This fruit, when it is fully ripe, opens and discovers a down extremely white, and which is called Cotton. They separate the seeds from that by a mill, and then spin the cotton, and prepare it for all sorts of fine work and conveniences of every kind. With this they likewise make muslin, and sometimes mix. 
the cotton with wool, and sometimes with silk and gold itself.

The tree which produces this useful and valuable merchandize grows commonly in several places of the Levant, and of the East and West Indies, especially in the Antilles. Its fruit is of an oval form, about the size of a nut, which, through the heat of the sun, opens in sereral places, and discovers the cotton through the clefts. The cotton of the first sort of plant which creeps on the ground, is esteemed the best, -its produce near Smyrna is greater than any where else: they sow the seeds (which are like little beans, and found in each of the fruit) in June, and gather it in October; and the soil is so favourable, that they can have three crops in a year. There are ordinarily brought from Smyrna ten thousand bales of cotton annually; and yet there is at least as much more spent in the manufactures of the country.*

To such plants and trees we owe those beautiful vestments of linen and cotton, which contribute so much to the satisfáction of living. Who that beholds these vestments shining in their snowy whiteness, would imagine they were formed from such originals! But what is too minute in the Creator's hands, to produce the most admirable effects? A serious and contemplative mind sees God in every thing: every object we behold, the food by which we are sustained, the raiment.

* Chambers's Dictionary. 
wherewith we are cloathed, suggest thoughts of piety and gratitude; and if we attend to the silent voice of meditation, we shall (in Shakespeare's strong language)

"F Find, tongues in trees, books in the ruming brooks;

Sermons in stones, and good in every" thing,"

\section{The Cocoa Tree.}

The Cocoa, by some called the Indian Palm, is a large tree, a native of the Indies, of one single trunk, which is never more than 2 foot in diameter, but rises to the height of fifty, and naturally prunes itself. From its top spring some slender branches with leaves, sometimes twenty feet in length, whose weight makes them hang down, though they are very thin, and form an agreeable shade, with a head naturally cut in a round form.

While the trunk is green, it contains white pith, like curdled milk, extremely tender and delicious, which one need not be afraid to eat to excess. The wood is then spungy, and cuts very easily; the Indians, without fear of damaging it, make notches in it at certain distances, by which they mount to the top of the tree with incredible swiftness. But some time after it is felled, it grows very hard, as we see in those pieces which are brought to us. It becomes good fire wood, and is also made into masts, planks, poles, swords, and.arrows, which are so hard 
as to pierce iron cuirasses. It has three sorts of bark ; the first and second are used to pack up merchants' goods, the third is so fine that paper is made of it, and it serves for many uses beside. At the top, and immediately under the place where the branches spring out, shoot out a number of husks, a little flatted, of the bigness and length of a man's arm. They consist of two or three coats, which break as the fruit they contain pushes out and enlarges, then a cluster appears, to which are fixed eighty or a hundred small cocoa nuts, whereof only thirteen or fourteen come to perfect maturity. Clusters of different ages are to be seen upon the same tree; some are in blossom, while others have their fruit alieady formed, or are ready to be gathered. The Indians do not always delay cutting the nuts till they are come to full ripeness; experience has made them sensible that this fruit has its particular virtues at any time that it is gathered.

When the nut is yet green, although of the bigness of two fists, almost a pint of liquor is drawn from it, clear and fresh as the purest spring water; besides being the most agreeable liquor that can be drank, it perfectly quenches the thirst, refreshes the blood, and cures ardent fevers; when taken hot it stops the flux of blood; when a little farther ad.. vanced, the liquid within thickens, and cuts with a spoon like cream. It hardens insensibly; first it takes the consistence, colour, and 
nearly the taste of our nuts, then it becomes: like the filbert or almond, but of a much more delicate flavour; the Indians rasp it to mix with their rice, and, when they add sugar and cinnamon, it becomes a most delicate dish. The oil which is drawn trom it is extremely soft, and, only on account of its plenty, becomes cheap, and is applied to the most common uses, which occasions a great consumption of it. The nut is commonly of the figure and bigness of an oval melon, though, sometimes, longer; it has a triple bark; the outermost is very brown and close, the second, when dry, forms a sort of flax, the third is a very thin skin which runs perfectly white, and every body, even the principal persons in the country, wear caps made of it; but, be. fore that second bark becomes dry, through ripeness, they season it like Spanish cardoons, and the inside of the nut is used for bread. There is nothing fitter to be spun, or which is of greater use; and after being carded, that sort of stuff is made of it called ccorcee. And, of what remains, tow, ropes, and cables are made, fitter for ships, than any produced from other materials, for, the bark agreeing with salt water, grows green again in the sea, and keeps ships at anchor in great safety, not so much by its strength, as by jts verdure and pliableness,' which makes it stretch like wax, and humour the motion of the vessel. Lastly, of the shell, immediately enclosing the fruit, cups, drinking vessels, 
and other ornaments are made, which be. come very valuable on account of the figures designed on them by the Indians, with admirable art, and the rich furniture wherewith they are mounted. Art and experience have taught the natives of the country the manner of drawing wine from this tree, to which Providence seems to have given the virtues of all other plants. For this purpose they cut off a flower, or an entire husk, and, at that place, fix a pitcher hermetrically sealed, to the tree, that the air may not touch the liquor, which distils continually. When the the vessel is full, they boil it, and the fire gives it the taste and quality of wine, although, before, it was like milk. When the Indians want good vinegar, they expose that liquor to the sun; and in order to make strong spirits, distil it by the alembic. They likewise make sugar of it, which they call jacra; but, as it is brown, they do not esteem it, having plenty of the white sort. The pith which runs through the trunk comes out at the superior extremity, sometimes in a point, sometimes in a round ball, enclosed in a husk: this is called palmite; within is a white substance, divided by leaves, which shut very close upon one another; they serve for several uses; when eat raw, they have an excellent taste. They are also put in soup, like cabbage, and sometimes used in sallad, like lettuce; and, lastly, when left to dry, they become the finest paper in the Indies; 
but, by taking away the palmite, the loss of the tree is endangered.

It now only remains to mention the leaves of the Cocoa, which are no less curious and useful than the other parts of the tree. We have mentioned their length before; they are shaped like a writing pen; the Indians have a way of preparing and rendering them pliable as cotton; some make cloaths of them; others cover their houses with them. The merchants use them in package, and the seamen make sails of them. This tree is so common in many courtries of the Indies, that there are whole forests of them.

Of all trees that grow upon the face of the earth, none is more serviceable than the $\mathrm{Co}$ coa; it, alone, can supply the necessities of mankind; its pith, liquor and fruit, are sufficient to support the Indians, who are naturally sober; and the wood is used in building ships, houses, and making arms; its leaves supply the place of slates, tiles, and sails for ships; in short, its different barks are the materials of the different cloathing of the country.

Certainly no reasonable being, when he contemplates a tree like this, whereon so many different qualities are bestowed by the hand of Providence, adapted to so many uses, but must be naturally led to adore Him whose power hath made it. 


\section{The Tea Tree.}

This tree is a native of China, of very slow growth; it has a black, woody, irregular, branched root, and rises to a fathom high, or somewhat more. The bark is of a chesnut colour, dry, thin, and weak, greyish on the stem, and a little greenish on the extremities of the twigs; yet it is firm, and sticks closely to the wood, and is covered with a very thin rind, which sometimes loosens of itself as the bark grows dry. Under the rind, the bark is greenish, and smells like hazel tree leaves, and has a bitter, nauseous, and astringent taste. The branches and twigs are numerous, irregular, slender, of different sizes, but rather short, and bave none of those rinds, which denote the annual increase of other trees. Its leaves are very thick set, without any regularity, and are in substance, like those of the morella cherry tree, but when young, they resemble, except in colour, the spindle tree, with red berries, called euonymus. The larger leaves are two inches long, and one broad, or but little less; from a small beginning, they become roundish and broad, and then taper into a sharp point; they are serrated, or indented, the teeth being a little bent, hard, obtuse, and set close together, but of different sizes. They have one very conspicuous nerve in the middle, which is answered by a deep furrow 
on the other side. Every leaf is branched or each side into five, six, or seven transverse ribs. The branches contain many flowers, of an inch or more in diameter, not unlike our wild roses, and have but little smell: these flowers continue growing till late in the winter, and a few generally fall short of the largeness and beauty of the rest : this flower contains many white and very small stems, like those of the rose aforesaid, with yellow heads, shaped like a heart; and these flowers are succeeded by a great plenty of fruit, which is commonly tricapsular, like the seed vessels of the racinus, composed of the round capsula; of the bigness of wild plums; each of these capsulæe contains a husk, a nut and a seed.

The method of gathering the leaves is one by one, lest they should be torn. The first gathering begins at the middle of the first moon, immediately before the vernal equinox; these leaves are scarcely full opened, being only of two or three days growth; but they are accounted the best, fetch the best price, and are called the flower of the tea; but, by the Chinese, veui boui, or bohea tea. The second gathering begins about a month after, and the last gathering is in $J$ une; the leaves of the gatherings are sorted into three several classes, according to their size and goodness, and sold accordingly. After the leaves are gathered, they are the same day carried to the work-house, and roasted over a slow fire in an iron pan; and, that they may be tho- 
roughly and equally dried, the roaster keeps them continually stirring with his hands, then takes them out, with a shovel like a fan, and commits them to the rollers, who roll them with the palms of their hands in small parcels, till they are equally cooled, and the sharp yellow and greenish juice is quite discharged. They are then poured upon a mat, and sorted a second time into different classes according to their goodness, and those that are less curled or burnt are taken out.

It is said that the Dutch were the first im. porters of tea into Europe, about the year 1606, for which they exchanged dried sage with the Chinese; and though the English did certainly about the same time gain a knowledge of this plant, we do not find that the government took any cognizance of it till the Restoration, when in 1660, a duty of eight pence per gallon was laid on the liquor made, and sold in all coffee-houses.

Now therefore this, as well as all other plants, may be considered as an instance of God's divine love to men, who thus causes the earth to yield her increase, grass for the oxen, and herb for the service of man; who, when he created our first párents, did not leave them to rove in an empty void world, but gave his almighty command, that those trees and herbs should be for their sustenance, saying, "Behold I have given you every herb bearing seed, which is upon the face of all the earth, and every tree in the which 
is the fruit of the tree yielding seed, to you it shall be for meat."

\section{The Coffee Tree.}

The Coffee 'Tree is a native of the $\mathrm{In}$ dies, grows surprizingly quick, and its body is naturally of an upright form; its leaves are somewhat like those of the common bay, but curl at the end and hang downwards. The blossoms first appear in July, when they show themselves in bunches at the joints, near the ends of the branches; they are much like the flowers of the Jessamine, but have the addition of some yellow apices, which are loose on the top of the blossom, and a style which shnots out near half an inch above it. The fruit appears about $\mathrm{Oc}$ tober, which hangs on the tree till the next July before it is ripe: it is then gathered and prepared for the market, or for propagating other plants.

Coffee is, perhaps, one of the greatest blessings, among those that are not really necessaries of life, that Providence has in. dulged to mankind, considering its beneficial qualities in use as well its agreeable properties, should be among the most elegant plants, in foliage; in blossom, and in fruit also.

*Genesis, chap. i. 2\%. 
It is a pleasant, wholesome, and cheap beverage, and of great use in many disorders; and a further demonstration (if it were necessary) of the goodness of the Almighty in providing so many, blessings for the com. fort of mankind.

\section{The Anacardium, or Cashew-nut Tree.}

This tree grows naturally in the West Indies, and arrives at the height of twenty feet, in those places of which it is a native, but cannot be preserved in Britain without the greatest difficulty. The fiuit of this tree is as large as an orange; and is full of an acid juice, which is frequently made use of in making punch. To the apex of this fruit grows a nut, of the size and shape of a hare's kidney, but much larger at the end which is next the fruit than at the other. The shell is very hard; and the kernel, which is sweet and pleasant, is covered with a thin film. Between this and the shell, is lodged a thick, blackish, inflammable liquor, of such a caustic nature in the fresh nuts, that if the lips chance to touch it, blisters will immediately follow. The kernels are eaten raw, roasted, or pickled. The caustic liquor just mentioned, is esteemed an excellent cosmetic with the West India young ladies, but they must certainly suffer a great deal of pain in its ap. plication; and as fond as our British females 
are of a beautiful face, it is highly probable they would never submit to be flayed alive to obtain one. When any of the former fancy themselves too much tanned, by the scorching rays of the sun, they gently scrape off the thin outside of the stone, and then rub their faces all over with the stone. Their faces immediately swell and grow black; and the skin being poisoned by the caustic oil above mentioned, will, in the space of five or six days, come entirely off in large lakes, so that they cannot appear in public in less than a fortnight; by which time the new skin looks as fair as that of a new bom child. The negroes of Brazil cure themselves effectually of disorders in the stomach, by eating the yellow fruit of this tree; the juice of which being acid, cuts the thick tough humours, which obstructed the free circulation of the blood, and thus removes the complaint. This cure, however, is not voluntary; for their masters, the Portuguese, deny them any other sustenance: and letting them loose to the woods, where the cashew-nuts grow in great abundance, leave it to their option to perish by famine, or sustain themselves with this fruit. The milky juice of this tree, will stain linen of a good black, which cannot be washed out. 


\section{The Plane Tree.}

A remarkable instance of one being placed in a bad situation, making an effort to come at better nourishment.

A mong the ruins of Newabby, formerly a monastery in Galloway, there grows on the top of a wall, a Plane tree, about twenty feet-in height. Straitened for nourishment in that barren situation, it several years ago directed roots down the side of the wall, till they reached the ground ten feet below; and now the nourishment it afforded to those roots during the time of their descending is amply repaid, having every year since that time made vigorous shoots. From the top of the wall to the surface of the earth, these roots have not thrown out a single fibre, but are now united in a single root.

Here again, is infinite wisdom displayed. An animal would not have acted with more judgment, in endeavouring to extricate himself from an uncomfortable situation, than the above tree in shooting its fibres towards a better soil. May we not here justly exclaim with the Psalmist, "Lord how won. derful are all thy works, in wisdom hast thou made them all!" 


\section{The Oleracee, or Cabbage Palm Tree.}

This is the most beautiful, and, perhaps, the tallest, of all trees. It is a native of India. The trunk is perfectly straight, and marked with rings at the vestigiz of the footstalks of the leaves, Near the ground it is about seven feet in circumference, but tapers as it ascends, and attains the height of one hundred and seventy, or two hundred feet. The bark is of an ash colour till within twenty-five or thirty feet of the extremity of the tree; when it alters at once to a deep sea green, which continues to the top. About five feet from the beginning of the green part upwards, the trunk is surrounded with its numerous branches in a circular manner, all the lowermost spreading horizontally with great regularity; and the extremities of many of the higher branches bend wavingly downwards, like so many plumes of feathers. These branches, when full grown, are twenty feet long, more or less, and are thickly set on the trunk alternately, rising gradually superior one to another. Their broad curved sockets so surround the trunk, that the sight of it, whilst amongst these, is lost, which appears again among the very uppermost branches, and is there enveloped in an upright green conic spire, which beautifully terminates its great height. The abovementioned branches are somewhat 
round underneath, and slightly grooved on the upper side. They are likewise decorated with a very great number of green pinnated leaves. Some of these are near three feet long, and an inch and a half broad, growing narrow towards their points, as well as gradually decreasing in length towards the extremities of the branches. As there are many thousand leaves upon one tree, every branch bearing many scores upon it, and every leaf being set at a small and i qual distance from one another, the beauty of such a regular lofty group of waving foliage, susceptible of motion, by the most gentle gale of wind, is not to be described. The middle rib, in each leat is strong and prominent, supporting it on the under side, the upper appearing smooth and shining. The pithy part of the leaf being scraped off, the inside texture appears to be so many longitudinal thread-like filaments. These being spun in the same manner as they do hemp or flax, are used in making cordage of every kind, as well as fishing nets, which are esteemed stronger than those usually made from any other material of the like nature.

Upon removing the large leaves, or branches, which surround the top of the trunk a little way above the beginning of the green bark just mentioned, what is called the Cabbage, is discovered lying in many thin, snowwhite, brittle flakes, in taste resembling an almond, but sweeter. This substance, which 
cannot be procured without destroying the tree, is boiled, and eaten with mutton by the inhabitants of the West Indies, in the same manner as turnips and cabbage are with us; though it must appear the height of extravagance and luxury to fell so stately a tree, which would be an ornament to the most magnificent palace in Europe, to gratify the taste of any epicure, especially as there is but a very small part of it eatable. What is called the Cabbage-flower, grows. from that part of the tree where the ash-coloured trunk joins the green part already described. Its first appearance is a green, husky spathe, growing to above twenty inches long, and about four broad; the inside being full of small white, stringy filaments, full of alternate protuberant knobs, the smallest of these resembling a fringe of coarse white thread knotted: these are very numerous, and take their rise from larger footstalks; and these footstalks, likewise, are all united to different parts of the large parent stalk of all. As this husky spathe is opened, while thus young, the farinaceous yellow seed in embryo, resembling fine saw-dust, is very plentifully dispersed anong these stringy filaments, which answer the use of apices in other more regular flowers: these filaments being cleared of this dust, are pickled, and esteemed among the best pickles, either in the West Indies, or in Europe. But if this spathe is not cut down and opened whilst thus young; if it be suffer- 
ed to continue on the tree, till it grows ripe and bursts; then the enclosed part, which whilst young and tender is fit for pickling, will by that time have acquired an additional hardness, become soon after ligneous, grow bushy, consisting of very many small leaves, and in time produce a great number of small oval thin-shelled nuts, about the bigness of unhusked coffee berries. These, being planted, produce young cabbage trees.

The sockets, or grooves, formed by the broad part of the footstalks of the branches, are used by the negroes as cradles for their children. On the inner side of the very young footstalks are tender pellicles, which when dried, it is said, make a writing paper. The trunks serve as gutterings; the pith makes a sort of sago, and the nut yields oil, by decoction.

\section{The Magney, or Mati Tree.}

This tree yields to none in point of utility. It grows copiously in New Spain, and affords water, wine, oil, vinegar, honey, syrup, threar, rieedles, \&c. The inhabitants plant more or less of them next to every house; it grows as. well in the fields, provided it has proper attendance and care. It has broad and thick leaves, with sharp points, which serve for needles: and the points being torn off, there follows out of the leaf, a tough kind of 
hair fit for sewing. The branch is cut off when still young and tender, and a cavity being left in the tree, a liquor comes out like water, fresh and sweet: if boiled, it acquires the quality of wine; in length of time it turns to vinegar, and if continued longer bolling, and strained, it resembles honey; but if only half boiled, it is not unlike a syrup. In short, there are nineteen several services which this tree, though but small, yields to the inhabitants. The leaves serve for covering their houses, and a fine yarn may be spun out of them for their vestments. (Dut of its roots strong and thick ropes are made, and it is further remarkable, that each plant, though small, (being cut off very young) produces at least fifty barrels of liquor, each containing two Spanish arobes.

\section{The Ebony Tree.}

The Ebony tree is a native of the Indies. It rises with a shrubby stalk, three or four feet high, which puts out several side branches garnished with hoary leaves at each joint, composed of five.narrow spear-shaped lobes, which join at their tails to the footstalk, and spread out like the fingers of a hand. The branches are terminated by thick spikes of large purple flowers, which are of the butterDy or pea bloom kind.

Ebony wood is exceedingly hard and hea- 
vy, susceptible of a very fine polish, and on that account used in mosaic and inlaid works, toys, \&c. 'There are divers kinds of ebony; the most usual among us are black, red and green, all of them the produce of the island of Madagascar. The island of St. Maurice, belonging to the Dutch, likewise furnishes part of the ebonies sold in Europe. The islanders take care to bury their trees, when cut down, to make them the blacker, and to prevent their splitting when wrought. Black ebony is much preferred to that of other colours. The best is a jet black, free of veins and rind, very massive, astringent, and of an acrid and pungent taste. Its rind, infused in water, is used for many medicinal purposes. It yields an agreeable perfume when laid on burning coals: when green, it readily takes fire, from the abundance of its fat. If rubbed against a stone, it becomes brown. The Indians make statues of their Gods, and sceptres for their princes of this wood. It was first brought to Rome by Pompey, after he subdued Mithridates. It is now much less used among us than arciently, since the discovery of so many ways of giving other hard woods a black colour.

\section{The Baobab Tree.}

This tree is a native of Africa, and the largest production of the whole vegetable 
kingdom. The trunk of this tree is not very high, seldom exceeding from twelve to fifteen feet from the root to the branches; some are from twenty-five to twenty-seven feet in diameter. Many are supposed to be coeval with Noah's deluge. 'The lowest branches extend almost horizontally; and as they are very large, and about sixty feet in length, their own weight bends the extremity of them to the ground, so that the head of the tree, which is, moreover, pretty round, wholly hides the trunk, and forms a hemispherical mass of verdure of about one hundred or one hundred and thirty feet in diameter.

The leaves are about five inches long, and two broad, pointed at both extremities, and there are generally seven fixed in the manner of a fan, to one pedicle. The size of the roots corresponds to that of the trunk and the branches. That in the middle forms a pivot, which penetrates a great way into the earth; the rest spread near the surface. The flowers are in proportion to the bigness of the tree. After the fall of the petals and staminæ, the ovary ripens into an oblong fruit, pointed at both ends, about fifteen or eighteen inches long, and five or six broad, covered with a kind of greenish down, under which is a ligneous rind, hard, almost black, two or three lines in thickness, and marked with twelve or fourteen rays, which divide it lengthways in to sides. This fruit adheres to the tree by a cylindrical pedicle two feet long, and an inch 
in diameter. It contains a kind of pulp, or whitish, spongy, juicy substance, of an acrid taste: when the fruit is fresh, this pulp seems to form only one mass; but, as it dries, it shrinks and divides itself into a great number of poheara, or bodies with several faces, each of which contains a shining brown seed, of the shape of a kidney bean, five lines long, and three broad. The pulp that surrounds it is easily reducible to a powder, which is brought to Europe for sale.

The rind of the fruit, and the fruit itself, when it is spoiled, serves the negroes to make soap; they burn it and mix the ashes with palm oil that is beginning to grow rancid.

It is usual with the negroes of Africa, when -they leave their country, to carry with them the seeds of those pot-herbs of which they make most use, among, which they never. fail to take a portion of this powder, which they keep dry in little cotton bags; this not only gives a flavour to their repast, but also keeps up a free perspiration in their bodies, which preserves their health, and allays the too great heat of blood.

The negroes make a very singular use of this monstrous tree. It is said to be subject to the rot. When the natives find a tree in this condition, they enlarge the cavity, and form it into a dark chamber, or rather deep cave, which they destine for the tombs of those whom they judge unworthy of the

$$
\text { - } 12
$$


usual honours of sepulture. Such are their guiriots: by that name are meant their poets, musicians, drummers, and buffoons; they have them of both sexes. These hirelings preside at their balls and dances, the libertinism of which they greatly animate by their buffooneries. The negroes are very much afraid of these people, and pay great respect to them, and to all that have superior knowledge to their own, treating them as sorcerers or demons, which are not understood by them in an ill sense, but for sublime geniuses. They honour them while they live; but after death this fearful respect is changed into horror. They will suffer them neither to be laid in the earth nor thrown into the sea or any river; they imagine that the ground in which they should be buried would be enchanted, that it would divert the rains, and produce nothing; and that the water into which they should be thrown would nourish no more fish. They therefore suspend thern in these hollow trunks shutting up the entry with a board: the bodies, thus hung up, dry, and become a kind of mummy, without the assistance of perfumes and embalming. A striking proof of the power of ignorance and superstition. 


\section{The great Chesnut Tree}

UPON IMOUNT RTNA.

The chesnut tree sometimes grows to an immense size; the largest in the known world are those which grow upon Mount Etna, in Sicily.

This celebrated tree exceeds the size of other trees so much, that it cannot fail to excite the greatest admiration. It has its name from the following circumstance. Jean of Arragon spent some time in Sicily on her way from Spain to Naples. While here, she visited Mount AEtna, attended by her principal nobility, and happening to be overtaken by a storm, they took shelter under this tree, whose branches were sufficiently extensive to cover them all.

A celebrated traveller reports this tree to be one hundred and sixty feet in circumference, but quite hollow within, which however affects not its verdure: for the chesnut tree, like the willow, depends upon its bark for subsistence, and by age loses its internal part. As the cavity of this enormous mass is very considerable, the people have built a house in ii, where they have an oven for drying nuts, almonds, chesnuts, \&c. of which they make conserves. They frequently supply themselves with wood from the tree which encircles their house, so that it seems likely, in a short time, to go to ruin through 
the ingratitude and thoughtlessness of its inhabitants.

Besides this, there are abundance of other trees of the same species in the neighbour: hood, very remarkable for their size, all very beautiful and straight, and almost as smooth as polished marble. One of these measured thirty-eight. feet in circumference, and there were a number of others nearly of the same size. Among these there were seven standing together, which have received the name of the seven brethren; another is denominated the ship, from the general figure of its top, which has some slight resemblance to a ship. Its diameter is twenty-five feet, so that the circumference cannot be less than seventy five feet. The chesnut trees thrive very well in this country, and are carefully cultivated by the inhabitants. They are worked into hoops for casks, and a considerable trade is caried on in this article.

\section{Valuable Properties of the Chesnut Tree.}

At Tortworth in Gloucestershire is a chesnut tree fifty-two feet round. It is proved to have stood there ever since the year 1150 , and was then so remarkable, that it was called the great chesnut of Toriworth. It fixes the houndary of the manor, and is probably near one thousand years old. As an ornamental tree, the chesnut, though unequa! 
to the oak, the beech, and the esculus, has a degree of greatness belonging to it, which recummends it strongly to the gardener's attention. Its uses have been highly extolled, and it may deserve a considerable share of the praise which has been given it. As a substitute for the oak it is preferable to the elm : for doorjambs, window-frames, and some other purposes of the house.carpenter, it is nearly equal to the oak itself; but is very apt to be shakey, and there is a deceitful brittleness in it which renders it unsafe to be used as beams, or in any other situation where an uncertain load is required to be borne. It is universally allowed to be excellent for liquor casks, as not being liable to shrink, nor to change the colour of the liquor it contains: it is also strongly recommended as an underwood for hop-poles, stakes, \&c. Its fruit too is valuable, not only for swine and deer, but as human food: bread is said to have been made of it. Upon the whole, the chesnut, whether in the light of ornament or use, is most undoubtedly an object of great admiration.

\section{The Banian Tree.}

The Religiosa, or Banian tree, is a native of several parts of the East Indies. It hath a woody stem, branching to a great height, and vast extent, with heart-shaped entire leaves, ending in acute points. Of this tree the 
following lines of Milton contain a description equally beautiful and just.

"There soon they chose

The fig-tree; not that tree for fruit renown'd,

But such as at this day to Indians known

In Malabar or Decan, spreads her arms,

Branching so broad and long, that in the ground

The bended twigs take root, and daughters grow

About the mother tree, a pillar'd shade,

Higl over arch'd and echoing waiks between;

There oft the Indian herdsman, shmming heat,

Shelters in cool, and tends his pasturing herds

At loop-holes cut through thickest shade."

Paradise Lost, Book ix. 1. 1100.

The banian tree, or Indian fig, is perhaps the most beautiful of nature's productions in that genial climate, where she sports with the greatest profusion and variety. Some of these trees are of amazing size and great extent, as they are continually increasing, and, contrary to most other things in animal and vegetable life, they seem to be exempted from decay. Every branch from the main body throws out its own roots; at first in small tender fibres, several yards from the ground; these continually grow thicker until they reach the surface; and there striking in, they increase to large trunks, and become parent trees, shooting out new branches from the top; these in time suspend their roots, which, swelling into trunks, produce other branches: thus continuing in a state of progression as long as the earth, the first parent of them ail, contributes her sustenance. The Hindoos are peculiarly fond of the banian tree; they look upon it as 
an emblem of the Deity, from its long duration, its out-stretching arms, and overshadowing beufficence; they almost pay it divine nonours, and

"Find a fane in crery sacred grove."

Near these trees the most esteemed pagodas are generally erected: under their shade the brahnins spend their lives in religious solitude; and the natives of all casts and tribes are fond of recreating in the cool recesses, beautiful walks, and lovely vistas of this umbrageons canopy, impervious to the hottest bcams of a tropical sun.

A remarkable large tree of this kind grows on an island in the river Nerbedda, ten miles from the city of Baroche, in the province of Guzerat, a flourishing settlement lately in the possession of the Wast India company, but ceded by the government of Bengal, at the treaty of peace concluded with the Mahrattas in 1783, to Mabdajec Scindize, a Mahratta chief. It is distinguished by the name of Cubbee Burr, which was given in honour of a famous saint. It was once much larger than at present; but high floods have carried awry the banks of the island where it grows, and with them such parts of the tree as had thus far extended their roots: yet what remains is about two thousand feet in circumference, measured round the principal stems; the over-hanging branches, not yet struck down, cover a much larger space. The chief trunks 
of this single tree (which in size greatly exceed our English elms and oaks,) amount to three hundred and fity; the smaller stems, forming into stronger supporters, are more than three thousand; and every one of these is casting out new branches and hanging roots, in time to form trunks, and become the parents of a future progeny. Cubbeer Burr is famed throughout Hindostan for its great extent and surpassing beauty : the Indian armies generally encamp around it; and at stated seasons, solemn jatamas, or Hindoo festivals, are held there, to which thousands of votaries repair from various parts of the Mogul empire. It is said, that seven thousand persons find ample room to repose under its shade. The English gentlemen, on their hunting and shooting parties, used to form extensive encainpments, and spend weeks together under this delightful pavilion, which is generally filled with green woodpigeons, doves, peacocks, and a variety of feathered songsters, crowded with families of monkeys performing their antic tricks; and shaded by bats of a large size, many of them measuring upwards of six feet from the extremity of one wing to the other. This tree not only affords shelter, but sustenance, to all its inhab!tants, being covered amid its bright foliage with small figs of a rich scarlet, on which they all regale with as much delight as lords of the creation on their more costly fare in their parties. 
Mr. Tickell, in his epistle from Avignon, has the following fine simile, taken from this curious tree.

The fair descendants of thy* sacred bed

Wide brancbing, o'er the western world shall spread,

Like the fam'd Banjan tree, whose pliant shoot

To earthward bending, of itself takes root,

Till, like their mother piant, ten thousand stand

In verdant arches on the fertile land:

Beneath her shade the tawney Indians rove,

Or hunt at large through the wide-echoiug grove.

\section{The Beech Tree}

Grows in many different parts of the kingdom. In stateliness and grandeur of outline, the beech vies with the oak. Its foliage is peculiarly soft and pleasing to the eye; its branches are numerous and spreading, and its stem waxes to a great size. The bark of the beech is remarkably smooth, and of a silvery cast; this, added to the splendour and smoothness of its foliage, gives a striking neatness and delicacy to its general appearance. The beech, therefore, standing singly, and suffered to form its own natural head, is highly ornamental; and its leaves varying their hue as the autumn approaches, renders it, in this point of view; still more desirable. In point of actual use, the beech follows next to the oak and the ash : it is almost as necessary to the cabinetmakers and turners (especially about the me-

* Qucen Caroline. 
tropolis) as the oak is to the ship-builder, or the ash to the plough and cartwright. The natural soil and situation of the beech is upon dry, chalky, or limestone heights. It grows to a great size upon the hills of Surry and Kent, as also upon the declivities of the Cotswold and Stroudwater hills of Giloucestershire, and flourishes exceedingly upon the bleak banks of the Wye, in Hereford and Monmouthshires, where it is much used in mak ing charcoal. In situations like those, and where it is not already prevalent, the beech, whether as a timber-tree, or as an underwood, is an object worthy the planter's attention.

The mast, or seeds, yield a good oil for lamps; and are a very agreeable food to squirrels, mice, and swine. The fat of swine fed with them, however, is soft, and boils away, unless hardened by some other food. The leaves, gathered in autumn, before they are much injured by the frosts, make much better mattrasses than straw or chaff, and last for seven or eight years. The nuts, when eaten by the human species, occasion giddiness and head-ach; but when well dried and powdered, they make wholesome bread. They are sometimes substituted for coffee. The poor people in Silesia use the expressed oil instead of butter. 


\section{The Sugar Maple Tree.}

The Sugar Maple Tree grows in the greatest abundance throughout Kentucky, in -America, and is known to be the hardiest, and most difficult to destroy of all the trees in their forests, the beech not excepted. The old trees produce the most and the richest juice, and trees which have been used for this purpose for years are known to be better than fresh trees. It is a common remark in that country; that whenever they meet with a black tree of this sort, they are sure it will prove a rich one. The blackness proceeds from the incisions made in the bark by the pecking of the parroquet, and other birds, in the season of the juice rising, which, oozing out, dribbles down its sides, and stains the bark, which, in the course of time, becomes black.

The season of tapping (as it is called) this tree, is about the middle of February, in Kentucky; but not until the latter end of the month, about Pitsburgh, in the remote parts of Pennsylvania, on the head branches of the Susquahana and Delaware, and in the state of New York. Frosty mornings, and bright sunshine are necessary to produce copious exudations. The season continues in this climate about six weeks, when the juice is found to be too thin and poor to make sugar, but it is still capable of making molasses, 
spirits by distillation, vinegar, and an agreeable table beer.

The business of making the sugar is mostly managed by women and boys: the men generally have nothing more to do with it than to tap the trees, prepare the sheds, and different apparatus; so that the agricultural employments are very little obstructed by this business, which produces so important an article for domestic uses. The perfection to which the people of Kentucky have brought their sugar; has induced many people in the upper parts of the states of New York and Pennsylvania to make a business of it during the season the juice is running: and considerable quantities have been sent to the markets of Philadelphia and New York, not inferior to the best clayed French, and Spanish sugars.

\section{The Liriodendron, or Tulip Tree.}

This tree is a native of most parts of America. It rises with a large upright trunk, branching forty or fifty feet high. The trunk, which often attains to a circumference of thirty feet, is covered with a grey bark. The branches, which are not very numerous, of the two years old wood are smooth and brown; while the bark of the summer's shoots is smoother and shining, and of a bluish colour. They are very pithy; their young wood is green, and, when broken, emits a strong scent. 
The leaves grow irregularly on the branches, on long footstalks. They are of a particular structure, being composed of three lobes, the middlemost of which is shortened in such a manner that it appears as if it had been cut off and hollowed at the middle. The two others are rounded off. They are about four or five inches long; and as many broad; they are of two colours; their upper surface is smooth, and of a stronger green than the lower. They fall off pretty early in autumn, and the buds for the next year's shoots soon after begin to swell, and become dilated, insomuch that by the end of December, those at the ends of the branches will become near an inch long, and half an inch broad. The outward laminæ of these leaf-buds are of an oval figure, have several longitudinal veins, and are of a bluish colour. The flowers are produced with us in July, at the ends of the branches; they somewhat resemble the tulip, which occasions its being called the tulip tree. The number of petals of which each is composed, like that of the tulip, is six ; and these are spotted with green, red, white, and yellow, thereby making a beautiful mixture. The flowers are succeeded by large cones, which never ripen in England.

The tulip tree, in those parts of America where it grows common, affords excellent timber for many uses; particularly the trunk, which is frequently hollowed, and made into a canoe sufficient to carry many people; and E. 2 
for this purpose no tree is thought more proper by the inhabitants of those parts. With us, it may be stationed among trees of forty feet growth.

A remarkably fine tree of the above descrip. tion is now in a flourishing state at Waltham Abbey, in Essex, and is much resorted to by curious visitants, during the time it is in blossom.

\section{The Cinnamon Tree.}

The Cinnamomum, or Cinnamon Tree, is a native of Ceylon. It hath a large root, and divides into several branches, covered with a bark, which on the outer side is of a greyish brown, and on the inside has a reddish cast. The wood of the root is hard, white, and has no smell. The body of the tree, which grows to the height of twenty or thirty feet, is covered, as well as its numerous branches, with a bark, which at first is green, and afterwards red. The leaf is longer and narrower than the common bay tree; and it is threenerved, the nerves vanishing towards the top. When first unfolded, it is of a flame colour: but after it has been for some time exposed to the air, and grows dry, it changes to a deep green on the upper surface, and to a lighter . on the lower. The flowers are small and white, and grow in large bunches at the extremity of the branches; they have an agreeable smell, something like that of the lily of 
the valley. The fruit is shaped like an acorn, but is not so large.

The cinnamon is the under bark of the tree. The best season for separating it from the outer bark, which is grey and rugged, is the spring, when the sap flows in the greatest abundance. It is cut into thin slices, and exposed to the sun, and curls up in drying. The old trees produce a coarse kind of cinnamon: the spice is in perfection only when the trees are not older than three or four years. When the trunk has been stripped of its bark, it receives no farther nourishment; but the root is still alive, and continues to throw out fresh shoots. The fruit of this tree is shaped like an acorn, but is not so large. Its seed, when boiled in water, yields an oil, which swims at top, and takes fire. If left to cool, it hardens into a white substance, of which candles are made; which have an agreeable smell; and are reserved for the use of the king of Ceylon. The cinnamon is not reckoned excellent unless it be fine, smooth, brittle, thin, of a yellow colour, inclining to red, fragrant, aromatic, and of a poignant, yet agreeable taste. The connoisseurs give the preference to that, the pieces of which are long, but slender. That which comes to us is generally mixed with the cassia bark: but this last is easily distinguished, Cinnamon splinters in breaking, and has a roughness along with its aromatic flavour, while the cassia breaks over smooth, and has a mucilagenous taste. Cinnamon is 
a very elegant and useful aromatic, more grateful both to the palate and stomach than most other substances of this class. The leaves of this tree, either recent or dried, are so strongly impregnated with an aroma, as to, afford a good succedaneum for the bark both in cookery and medicine. Distilled, they give an excellent simple and spiritous water, and an essential oil. Powdered, they are a good aromatic species, or mareschal perfume.

\section{The Camphora, or Camphor Tree.}

This tree grows naturally in the woods of the western parts of Japan, and in the adjacent islands. The root smells stronger of camphor. than any other part, and yields it in greater plenty. The bark of the stalk is outwardly somewhat rough, but in the inner surface smooth and mucous, and therefore easily separated from the wood, which is dry, and of a white colour. The leaves stand upon slender footstalks, have an entire uridulated margin, running out into a point: have the upper surface of a lively and shining green, the lower herbaceous and silky, and are furnished with a few lateral nerves, which stretch arch-wise to the circumference, and frequently terminate in small warts; a circumstance, peculiar to this species of tree. The flowers are produced on the tops of the footstalks, which proceed from the arm-pits of the leaves; but 
not till the tree has attained considerable age and size. The flower-stalks are slender, branched at the top, and divided into very short pedicles, each supporting a single flower. These flowers are white, and consist of six petals, which are succeeded by a purple and shining berry of the size of a pea, and in figure somewhat top-shaped. It is composed of a soft pulpy substance, that is purple, and has the taste of cloves and camphor, and of a nucleous, or kernel, of the size of a peppercorn, that is covered with a black, shining, oily cortical, of an insipid taste.

The camphor, though solid, is the essential oil of this tree, and is obtained from it by distillation in the East Indies.

In China, some of these trees are found above one hundred cubits in height, and so thick, that twenty persons cannot enclose them. The tree is there called tchang: and it is said that the trunk, when old, emits sparks of fire, but of so subtle a nature, as not even to injure the hair of those who are near it. Common camphor costs only a penny the ounce at Pekin. The method used by the Chinese for obtaining camphor is as follows. They take some branclies fresh from the tchang, chop them very small, and lay them to steep in spring water for three days and three nights. After they have been soaked in this manner, they are put into a kettle, where they are boiled for a certain time, during which they keep constantly stirring 
them with a stick made of willow. When they perceive that the sap of these small chips adheres sufficiently to the stick in the form of a white frost, they strain the whole, taking care to throw away the dregs and refuse. This juice is afterwards poured gently into a new earthen bason, well varnished, in which it is suffered to remain one night. Next morning it is found coagulated, and formed into a solid mass. To purify this first preparation, they procure some earth from an old earthen wall, which, when pounded, and reduced to a very fine powder, they put into the bottom of a bason made of red copper; over this layer of earth they spread a layer of camphor, and continue thus until they have laid four strata. The last, which is of very fine earth, they cover up with the leaves of the plant po-ho, or penny-royal; and over the whole they place another bason, joining it very closely to the former, by means of a kind of red earth that cements their brims together. The bason, thus prepared, is put over a fire, which must be managed so as to keep up an equal heat: experience teaches them to observe the proper degree. But above all, they must be very attentive lest the plaister of fat earth which keeps the basons together, should crack or fall off, otherwise the spirit would evaporate and ruin the whole process. When the basons have been exposed to the necessary heat, they are taken off, and left to cool; after 
which they are separated, and the sublimated camphor is found adhering to the cover. If this operation be repeated two or three times, the camphor is found purer, and in larger pieces. Whenever it is necessary to use any quantity of this substance, it is put between two earthen vessels, the edges of which are surrounded with several bands of wet paper. These vessels are kept for about an hour over an equal and moderate fire; and when they are conl, the camphor is found in its utmost perfection, and ready for use. This method of procuring camphor, even from the heart of the tree, may be practised in all seasons of the year: which would not he the case, were it ex tracted like other resinous substances that only flow during a certain short space of time. Besides, by lopping the branches of the camphor tree, less hurt is done to it than by making incisions, which are always hazardous.

\section{The Sassafras Tree.}

This tree is a native of North America. It has a shrub-like straight stem, garnished with both oval and three-lobed, shining, deciduous leaves, of different sizes, from three to six inches long, and near as broad, with small yellowish flowers, succeeded by blackish berries, but not in this country. This tree grows to about thirty feet in height. The branches are not very numerous. Its bark is smooth, 
and of a red colour, which beautifully distinguish it in winter; whilst the fine shining yreen of its leaves constitutes its greatest beauty in summer. In these, indeed, there is a variety, and a very extraordinary one. Some are large, and of an oval figure; others are smaller, and of the same shape; while others again are so divided in to three lobes, as to resemble the leaves of some sorts of the fig-tree. In America the Sassafras generally stands single in the woods, and along the fences round the fields. It flowers in May, before the leaves come out; and being entirely covered with them, it is distinguished at a great distance by their beautiful yellow colour.

The root of the sassafras has a fragrant smell, and a sweetish, aromatic, sub-acrid taste; the bark tastes much stronger than any other part, and the small twigs stronger than the large pieces. It is a warm aperient and corroborant, and frequently employed with good success for purifying and sweetening the blood and juices. For these purposes, infusions are made from the rasped root or bark, and drank as tea, but generally called salop. It was formerly made great use of in medicine, and is now sometimes recommended.--Sassafras yields in distillation an extremely fragrant oil, of a penetrating pungent taste, so ponderous (notwithstanding the lightness of the drug itself) as to sink in water. Rectified spirit extracts the whole taste and smell of sassatras; and elevates nothing in evaporation: 
hence the spiritous extract proves the most elegant and efficacious preparation, as con taining the virtue of the root entire.

The bark of this tree is used by the women in Pennsylvania and other parts of North America, in dying worsted a fine lasting orange colour. The wood is made use of for posts belonging to the inclosures, for it is said to last a long time in the ground: but it is likewise said, that there is hardly any kind of wood which is more attacked by worms than this, when it is exposed to the air without a cover; and that in a short time it is quite worm-eaten through and through. On cutting some part of the sassafras tree, or its shoots, and holding it to the nose, it has a strong, but pleasant smell. Some people peel the root, and boil the peel with the beer which they are brewing, because they believe it wholesome. For the same reason the peel is put into brandy, either whilst it is distilling, or after it is made. Professor Kalm informs us, that a decoction of the root of sassafras in water, drank every morning, is used with success in the dropsy. When part of a wood is destined for cultivation, the sassafras trees are commonly left upon it, because they have a very thick foliage, and afford a cool shade to the cattle during the great heats. Some people get their bed-posts made of sassafras wood, in order to expel the bugs; for its strong scent, it is said, prevents those vermin from settling in them. For two or three 
years together, this has the desired effect, or about as long as the wood keeps its strong aromatic smell; but, after that time, it has been observed to lose its effect. In Pennsylvania, some people put chips of sassafras into their chests, where they keep all sorts of woollen stuffs, in order to expel the moths, (or larvæ, or caterpillars of moths or tinies) which commonly settle in them in the summer. 'The root keeps its smell for a long while: professor Kalm saw one which had lain in the drawer of a table five or six years, and still preserved the strength of its scent. The people also gather its flowers, and use them as tea.

\section{The Persen, or Alligator Pear Tree.}

In the West Indies this tree is universally cultivated by all ranks of people. It rises to a considerable height, with a straight trunk, of which the bark and wood are of a greyish colour. The leaves are long and oval, pointed, of a substance like leather, and of a beautiful green colour. The flowers are produced in large knots or clusters at the $\epsilon x$ tremities of the branches, and consist each of six petals, disposed in the form of a star, and of a dirty white, or yellow colour, with an agreeable odour, which diffuses itself to a considerable distance. The fruit is pear-shaped, and from one to two pounds in weight. On 
removing a green skin or covering, is found a yellow butyraceous substance; and in the heart a large round seed or stone, which is unequal in the surface, and exceedingly hard and woody. This fruit is ripe in August and September, and constitutes one of the most agreeable articles of diet for six or eight weeks to the negroes. These pears, with a little salt, and a plantain or two, afford a hearty meal. They are served up at the tables of white people as a choice fruit. When the pear is ripe, the yellow or eatable substance is firmer than butter, and tastes somewhat like butter, or marrow : hence it is called by some, the vegetable marrow. But, however excellent this fruit is, when ripe, it is very dangerous when pulled and eaten before maturity. Dr. Wright says, he has repeatedly known it to produce fever and dysentery, which were removed with difficulty. The leaves of this tree are made into pectoral decoctions by the common people, and the large stone is used for marking linen. The cloth is tied or held over the stone, and the letters are pricked out by a needle, through the cloth, and into the seed. The stain is of of a reddish brown, which never washes out. The buds of this tree are likewise said to be useful in medicine. The wild boars eat greedily of these pears, which give their flesh a luscious and most agreeable flavour. The bark is known in the shops by the name of cassio lignea, and has a very near resem. 
blance to cinnamon, and resembles it more in its aromatic flavour than in its external appearance, and is very frequently substituted for the more expensive article cinnamon.

\section{The Reus Vernix, or Poison Ash.}

The Poison Ash grows naturally in Virginia, Pennsylvania, Carolina, and Japan, rising with a strong woody stalk to the height of twenty feet and upwards; though in this country it is seldom seen above twelve, by reason of the plant's being extremely tender. The bark is brown, inclining to grey; the branches are garnished with winged leaves, composed of three or four pair of lobes, terminated by an odd one. The lobes vary greatly in their shape, but for the most part they are oval and spear-shaped. The tootstalks become of a bright purple towards the latter part of summer, and, in autumn, all the leaves are of a beautiful purple before they fall off. Professor Kalm says, " an incision being made into the tree, a whitish yellow juice, which has a nauseous smell, comes out between the bark and the wood. This tree is not known for its good qualities, but greatly so for the effect of its poison; which, though it is noxious to some people, yet does not in the least affect others; and, therefore, one person can handle the tree as he pleases, cut it, peel off its. 
bark, rub it, or the wood, upon his hands, smell it, spread the juice upon his skin, and make more experiments, with no inconvenience to himself. Another person, on the contrary, dares not meddle with the tree, while its.wood is fresh, nor can he venture to touch a hand which has handled it, nor even to expose himself to the smoke of a fire which is made with this wood, without soon feeling its bad effects; for the face, the hands, and frequently the whole body, swells excessively, and is affected with very acute pain. Sometimes bladders or blisters arise in great plenty, and make the sick person look as if he was infected with the leprosy. In some people, the external thin skin peels off in a few days, as is the case when a person has: scalded or burnt any part of his body. Nay, the nature of some persons will not even. allow them to approach the place where the tree grows, or to expose themselves to the wind when it carries the effluvia, or exhala. tion, of this tree with it, without letting them feel the inconvenience of the swelling just described. Their eyes are sometimes shut up for one or two, or more days together, by the swelling. I know (says the Professor) two bro. thers, one of whom could, without danger, handle this tree in what manner he pleased, whereas the other could not come near it without swelling. I have known old people who were more afraid of this tree than of a viper, and I was aquainted with a person, 
who, merely by the noxious exhalations of if, was swelled to such a degree, that he was as stiff as a log of wood, and could only be turned about in sheets. In some places this tree is rooted out, on purpose that its poison may not affect the workmen. The natives are said to distinguish this tree in the dark, by its extreme coldness to the touch, and the inspissated juice of this tree is said to be the fine varnish of Japan.

\section{The Olea Europea, or Common Olive Tree.}

The Europea, or common Olive Tree, rises with upright solid stems, branching numerously on every side, twenty or thirty feet high; spear-shaped, stiff, opposite leaves, two or three inches long, and half an inch or more broad; and at the axillas, small clusters of white flowers, succeeded by oval fruit.

This species is the principal sort cultivated for its fruit; the varieties of which are numerous, varying in size, colour, and quality.

It is a native of the southern warm parts of Europe, and is cultivated in great quantities in the South of France, Italy, and Portugal, for the fruit, to make olive oil, which is in so great repute, and is transported to all parts, to the great advantage of those countries where the trees grow in the open ground: The green fruit is also in much esteem for 
pickling; of which we may see plenty in the shops.

Olive trees are easily propagated by shoots, which, when care has been taken to ingraft them properly, bear fruit in the space of eight or ten years. Those kind of olives which produce the purest oil, and bear the greatest quantity of fruit, are ingrafted on the stocks of inferior kinds.

Different names are assigned by the French to the different varieties of the olive tree; and of these they reckon nineteen; whilst in Florence are cultivated no fewer than thirty-two.

Olive shoots are ingrafted when in flower. If the operation has been delayed, and the tree bears fruit, it is thought sufficient to take off a ring of bark; two fingers breadth in extent, above the highest graft. In that case, the branches do not decay the first year: they afford nourishment to the fruit, and are not lopped off till the following spring.

Olive trees are commonly planted in the form of a quincunx, and in rows, at a considerable distance from one another. Between the rows it is usual to plant vines, or to sow. some kind of grain. It is observed, that olives, like many other fruit trees, bear well only once in two years. The whole art of dressing these trees consists in removing the superfluous wood; for it is remarked, that trees, loaded with too much wood, prow. 
duce neither so much fruit, nor of so good a quality.

Olives have an acrid, bitter, and extremely disagreeable taste: pickled (as we receive them from abroad) they prove less disagreeable. The Lucca olives, which are smaller than the others, have the weakest taste; the Spanish, or larger, the strongest: the Provence, which are of a middling size, are generally the most esteemed.

When olives are intended for preservation, they are gathered before they are ripe. The art of preparing them consists in removing their bitterness, in preserving them green, and in impregnating them with a brine of aromatised sea-salt, which gives them an agreeable taste. For this purpose, different methods are employed. Fomerly they used a mixture of quick lime, with six pounds of newly sifted wood ashes; but of late, instead of the ashes, they employ nothing but a lye. This, it is alleged, softens the olives, makes them more agreeable to the taste, and less hurtful to the constitution. In some parts of Provence, after the olives have lain some time in the brine, they remove them, take out the kernel, and put a caper in its place. These olives they preserve in cxcellent oil; and when thus prepared, they strongly stimulate the appetite in winter. Olives, perfectly ripe, are soft, and of a dark red colour. They. are then eaten without any preparation, ex 
cepting only a seasoning of pepper, salt, and oil, for they are extremely tart, bitter, and corrosive.

The oil is undoubtedly that part of the produce of olive trees which is of the greatest value. The quality of it depends on the nature of the soil where the trees grow, on the kind of olive from which, it is expressed, on the care which is taken $\mathrm{z}$ gathering and pressing of the fruit, and likewise on the separation of the part to be extracted. Unripe olives give an intolerable bitterness to tho oil; when they are over-ripe, the oil has an unguinous taste. It is, therefore; of importance to choose the true point of maturity. When the situation is favourable, those species of olives are cultivated which yield fine oils: otherwise, they cultivate such species of trees as bear a great quantity of fruit, and they extract oil from it for the use of soaperies, and for lamps.

They gather the olives about the months of November and December. It is best to put them, as soon as possible, into baskets, or into bags made of wool or hair, and to press them immediately, in order to extract a fine oil. Lhose who make oil only for soaperies, let them remain in heaps for some time in their storehouses; when afterwaris pressed, they yield a inuch greater quantity of oil. Those even who extract oil to be used in food, sometimes allow them to ferment in heaps, that they may have more oil; but this is exw 
tremely hurtful to the quality of the oil, and is the reason why fine oil is so very rare. In order to have the oil in its purity, they allow it to deposit its sediment, and then pour it off into another vessel. The oil extracted from the pulp only of the olives is the most perfect which can be obtained, and will keep for several years; but that which is extracted from the kernel only, or from the nut, or from the whole olive, ground in the common way, in public mills, has always more or fewer defects, loses its limpidity in a certain time, and is very apt to become rancid. Care must be taken, likewise, to keep the oil in proper vessels, well shut. After all, in the course of time, olive oil loses its qualities, becomes disagreeable to the taste and smell, diminishes in fluidity, and at length thickens considerably.

The refuse of the first pressing, when squeezed a second time, yields an oil, but thicker and less pure than the former. What remains after the second pressing, when mixed with a little water, and placed in a pan over the fire, produces by pressure a third oil, but of a very inferior quality.

The sediment, or foecis, of new oil, is an excellent remedy in rheumatic affections. In Paris the wax used for shoes is commonly made of the dregs of defecated oil and smoke black.

Oil of olives is an ingredient in the compow sition of a great many balsams, ointments, 
plasters, \&c. It is of an emollient nature, and reckoned an effectual cure for the sting of wasps, bees, and other insects. It is of no use in painting, because it never dries completely. The best soap is made of it, mixed with Alicant salt-ivort, and quick lime.

The wood of the olive tree is beautifully veined, and has a pretty agreeable smell : it is in great esteem among cabinet-makers, on account of the fine polish which it assumes. It is of a resinous nature, and consequently excellent for burning.

As the laurel branch is the symbol of glory, so the olive branch, covered with leaves, has, from the most ancient times, been the emblem of concord, the symbol of friendship and peace.

\section{The Toluifera, or Balsam of Tolu-Tree.}

This tree grows in Spanish America, in the province of Tolu, behind Carthagena, whence we are supplied with the balsam, which is brought to us in little gourd shells. The balsam is obtained by making incisions in the bark of the tree, and is collected into spoons, which are made of black wax, from which it is poured into proper vessels.

This balsam is of a reddish yellow colour, transparent, in consistence thick and tenacious: by age it grows so hard and brittle, that it may be rubbed into a powder be- 
tween the finger and thumb. Its smell is extremely fragrant, somewhat resembling that of lemons; its taste is warm and sweetish, and on being chewed, it adheres to the teeth. Thrown into the fre, it immediately liquifies, takes flame, and disperses its agreeable odour. Though it does not dissolve in water, yet if boiled in it for two or three hours in a covered vessel, the water receives its odoriferous smell: water also suffers a similar impregnation from the balsam by distillation. With the assistance of mucilage, it unites with water, so as to form a milky solution. This balsam possesses the same general virtues with the balsam of Gilead, and that of Peru, and is less heating and stimulating, and may therefore be made use of with more safety.

This useful tree, grows to a considerable height: it sends off numerous large branches, and is covered with a rough, thick, greyish bark: the leaves are elliptical or oval, entire, pointed, alternate, of a light green colour, and stand upon short strong footstaks, the flowers are numerous, and the fruit is a round berry.

\section{The Candchouc, India Rubber, or Syringe Tree.}

In Cayenne, and other parts of South America, the Syringe Tree is a native, and 
possesses the most singular properties.No substance is yet known which is so pliable, and at the same time so elastic. This substance oozes out, under the form of a vegetable milk, from incisions made in the tree, and is chiefly gathered in time of rain, because, though it may be collected at all times, it flows then most abundantly. The means employed to inspissate and indurate it are kept a profound secret; but it is affirmed, that it thickens and hardens gradually, by being exposed to the air; and as soon as it acquires a solid consistence, it manifests a very extraordinary degree of flexibility and elasticity. Accordingly, the Indians make boots of it, which water cannot penetrate, and which, when smoaked, have the appearance of real leather. Bottles are also made of it, to the necks of which are fastened hollow reeds, so that the liquor contained in them may be squirted through the reeds, or pipes, by pressure. One of these, filled with water, is always presented to each of their guests, at their entertainments, who never fail to make use of it before eating. This whimsical custom led the Portuguese in that country to call the tree that produces this resin pao de xirringa, and hence the name of seringal is given both to the tree and to its resinous production. Flambeaus, an inch and a half in diameter, and two feet long, are likewiss: made of this resin, which give a beautifn! light, have no bad smell, and burn twelve? 
hours. A kind of cloth is also prepared from it, which the inhabitants of Quito apply to the same purposes as our oil cloth and sail cloth. It is formed, in fire, by means of moulds; into a variety of figures for use and orrament; and the process is said to be thus: -The juice, which is obtained by incision, is spread over pieces of clay formed into the desired shape; and as fast as one layer is dry, another is added, till the vessel be of a proper thickness: the whole is then held over a strong smoke of vegetables on fire, whereby it is hardened into the texture and appearance of leather; and before the finishing, while yet soft, is capable of having any impression made on the outside, which remains ever after. When the whole is done, the inside mould is picked out.

The Abbe Clavigero informs us, that the elastic gum is called by the Mexicans, olin, or olli, and by the Spaniards of that kingdom, ale; that it distils from the olquahuitl, which is a tree of moderate size, the trunk of which is smooth and yellowish, the leaves pretty large, the flowers white, and the fruit yellow and rather round, but angular, within which there are kernels as large as filberts, and white, but covered with a yellowish pellicle. That the kernel has a bitter taste, and the fruit always grows attached to the bark of the tree. That when the trunk is cut, the ule which distils from it is white, liquid, and viscous; afterwards it becomes yellow: and 
Fastly of a leaden colour, though rather blacker, which it always retains. The tree, he adds, is very common in the kingdom of Guatimala.

Among us it is made great use of by painters and others, for rubbing out black lead: pencil marks, \&c.

\section{The Caryophyllus, or Clove Tree:}

The Clove Tree resembles, in its bark, the olive; and is about the height of the laurel, which it also resembles in its leaves. No verdure is ever seen under it. It has a great number of branches, at the extremities of which are produced vast quantities of flowers, 'that are first white, then green, and at last pretty red and hard. When they arrive at this degree of maturity, they are, properly speaking, cloves. As they dry, they assume a dark yellowish cast; and, when gathered they become of a deep brown. 'The season for gathering the cloves is from October to February. The boughs of the tree are then strongly shaken, or the cloves beat down with long reeds. Large cloths are spread to receive them, and they are afterwards either dried in the sun, or in the smoke of the bamboo cane. The cloves which escape the notice of those who gather them, or are purposely left on the tree, continue to grow till they are about an inch in thickness; and these falling off, produce new plants, which to not bear in less than eight or ten years. 
Those, which are called mother-cloves, are inferior to the common sort; but are preserved in sugar by the Dutch; and, in long voyages, eat after their meals, to promote digestion.

The clove, to be in perfection, must be full sized, heavy, oily, and easily broken; of a fine smell, and of hot aromatic taste, so as almost to burn the throat. It should make the fingers smart, when handled, and leave an oily moisture upon them, when pressed. In the East Indies, and in some parts of Europe; it is so much admired, as to be thought an indispensable ingredient in almost every dish. It is put into their food, liquors, wines, and enters likewise the composition of their perfumes. Considered as medicines, cloves are very hot, stimulating aromatics: and possess, in an eminent degree, the general virtues of substances of this class. Their pungency resides in their resin; or rather in a combina. tion of resin with essential oil: for the spiritous extract is very pungent; but if the oil and resin contained in this extract are separated from each other by distillation, the oil will be very mild, and any pungency which it does retain, proceeds from some small portion of adbering resin, and the remaining resin will be insipid. No plant, or part of any plant, contains such a quantity of oil as cloves do. From sixteen ounces Newman obtained by distillation, two ounces and two drams; and Hoffman obtained an ounce and a half of oil from two ounces of the spice. The oil is: 
specifically heavier than water. Cloves acquire weight by imbibing water; and this they will do at a considerable distance. The The Dutch, who trade in cloves, make a considerable advantage by knowing this secret. They sell them always by weight; and when a bag of cloves is ordered, they hang it, for several hours before it is sent in, over a vessel of water, at about two feet distance from the surface. This will add many pounds to their weight, which the unwary purchaser pays for on the spot. This is sometimes practised in Europe, as well as in the spice islands: but the degree of moisture must be more carefully watched in the latter; for there a bag of cloves will, in one night's time, attract so much water, that it may be pressed out of them hy, squeezing them with the hand.

The clove tree is a native of the Moluccs. islands, particularly of Amboyna, where it is principally cultivated. It is never propagated in Europe. At Amboyna the Company have allotted the inhabitants 4000 parcels of land, on: each of which they were allowed to dwell; and about the year 1720 , compelled to plant about 125 trees, amounting in all to 500,000. Each of these trees; produces annually, on an average, two pounds of cloves; and consequently the collective produce must weigh more than a million. The culivator is paid with the species that is constantly returned to the company, and receives some unbleached cottons, which are brought from Córromandel.

$$
\text { G. } 2
$$




\section{The Kooker-boom, or Quiver Tree.}

The Kooker-boom, or Quiver Tree, is a native of the southern parts of Africa, and is a species of the agave, or American aloe. It rises to the height of twenty-five or thirty feet; its trunk is smooth, and the bark white. When young, and the trunk is not more than four or five feet long, it terminates with a single tuft of leaves, which spread and form a crown, from the midst of which all its flowers issue. As it grows older, it pushes out lateral branches, perfectly regular and symmetrical, each of which has, at its extremity, a crown, similar to that of the young plant. The kooker-boom thrives much better on mountains than on the plain. Instead of long roots penetrating deep into the earth, like those of other trees, it has but a very slight one, by which it is fixed to the soil. Accordingly three inches of mould are sufficient to enable it to grow upon the very rocks, and attain its utmost beauty: but its root is so feeble a support, that the largest may be thrown down by a single kick of the foot. The hordes on the West make their quivers of the trunk of this tree; when young, from whence it derived its name given by the planters. 


\section{The Linden, or Lime Tree.}

This tree is generally supposed to be a native of Britain. It flourishes-best on the sides of hills, is easily tiansplanted, and grass grows well beneath it. The leaves are heartshaped, with the apex produced, and serated. on the edges; the flowers grow in a thin. umbel, from three to nine together, of a whitish colour, and a fragrant smell, very grateful to bees. The wood is soft, light, and smooth; close grained, and not subject to the worm, and of a spongy texture. It is used for making lasts and tables for shoemakers. It also makes good charcoal for gunpowder, and for designers. It is used by turners, carvers, and leather-cutters. In some countries, the leaves are dried as a winter food for sheep and goats. Cows eat them in Autumn, but they give a bad taste to the milk. The bark, macerated in water, is made into cordage, ropes, and fishing nets; and mats and rustic garments are also made of the inner rind. The flowers afford the best honey for bees, and the gummy sap or juice, when repeatedly boiled and clarified, produces 2 substance like sugar. 


\section{The Cerbera, or Devil Tree.}

This remarkable tree is a native of the warmer parts of America. It rises with an irregular stem to the height of eight or ten feet, sending out many crooked, diffused branches, which, towards their tops, are garnished with thick succulent leaves, of a lucid. green, smooth, and very full of a milky juice. The flowers come out in loose bunches at the: end of the branches; they are of a cream eolour, having long narrow tubes, and at the top are cut into five obtuse segments, which seem twisted, so as to stand oblique to the tube. The wood of this tree stinks most abominably, and the kernels of the nuts are a deadly poison, to which there is no antidote; so that the Indians will not even use: the wood for fuel.

\section{The Ceratonia (Carob Tree) or: St. John's Bread.}

This tree is a native of Spain, of some parts of Italy, and the Levant. It is an ever green; and, in the countries where it is a: native, grows in the hedges. It produces a. quantity of long, flat, brown-coloured pords, which are thick, mealy; and of a sweetish taste. These pods are many times eaten by. the poorer sort of the inhabitants, when there 
is a scarcity of other food, but they are apt to disagree with the bowels. They are called G. Whan's bread, from an ill-founded assertion of some writers on scripture, that these pods were the locusts St. John eat with his honey in the wilderness. The tree may be propagated in this country, from seeds, which aie to be sown in a moderate hot bed, and the plants inured to the open air by degrees.

\section{The Cercis, or Judas Tree.}

In Italy, and other parts of the South of Europe, this tree grows luxuriantly. They differ in the height of their growth, in different places. In some, they will arrive to be fine trees, of near twenty feet high, whilst in others they will not rise to more than ten or twelve feet, sending forth young branches irregularly from the very bottom. The stem of this tree is of a dark greyish colour, and the branches, which are few and irregular, have a purplish cast. The leaves are smooth, heart-shaped, and roundish, of a pleasant green on their upper surface, hoary underneath, and grow alternately on long footstalixs. The flowers are of a fine purple: they come out early in the spring, in clusters, from the side of the branches, growing upon short footstalks: and, in some situations, they are succeeded by long flat pods, containing seeds, 
which, in very favourable seasons, ripen in England.

The Canadian cercis will grow to the size of the first sort in some places. The branches are also irregular. The leaves are cordated, downy, and placed alternately. The flowers usually are of a palish red colour, and show themselves likewise in the spring, before the leaves are grown to their size. These, too, are often eaten in sallads, and afford an excellent pickle. There is a variety of this species with deep red, and another with purple nowers. The pleasure which these trees will afford in a plantation may be easily conceived, not only as they exhibit their flowers. in clusters, in different colours, early in the spring, before the leaves are grown to such a size as to hide them; but from the difference of the upper and lower surface of the leaves, the one being of a fine green, the other of a hoary cast; so that on the same tree, even in this respect, is shown variety; an improvement whereof is made by the waving winds, which will present them alternately to view.

As these trees will not take root by layers. they must be propagated by seeds, which may be had from abroad. They are generally brought to this country sound and good, and. may be sown in the months of February or March. Common garden mould, of almost every sort. will do very well. Part of the seeds will come up in the spring, and the 
others will remain until the spring following. By proper management, this tree may be trained up a regular stem: the wood of which is of great value; for it polishes extremely well, and is admirably reined with black and green.

\section{The Chamarops, or Palmetto Tree.}

Where are two species of this tree, the most remarkable of which is the glabra, a native of the West Indies, and warm parts of America, also of the corresponding latitudes of Asia and Africa:- It never rises with a tall stem; but when the plants are old, their leaves are five or six feet long, and upwards of two feet broad: these spread open like a fan, having many foldings, and at the top are deeply divided, like the fingers of a hand. This plant the Americans call thatch, from the use to which the leaves are applied. Mr. Adanson describes a species of this tree, which grows naturally at Senegal, whose trunk rises from fifty to sixty feet in height; from the upper end of the trunk issues a bundle of leaves, which, in turning off, form a round head; each leaf represents a fan, of five or six feet in expansion, supported by a tail of the same length. Of these trees, some produce male flowers, which are consequently barren; others are female, and loaded with fruit, which succeed each other uninterrupt. 
edly almost the whole year round. The fruir of these trees, Mr. Adanson affirms to be of the bigness of an ordinary melon, but rounder. It is enveloped in two skins, as tough as leather, and as thick as strong parchment: within, the fruit is yellowish, and full of filaments, fastened to three large kernels in the middle. The negroes are very fond of this fruit, which, when baked under the ashes, is said to taste like a quince.

The little palmetto may be easily raised in this country from seeds brought from America; but, as the plants are tender, they must be constantly kept in a bark stove.

\section{The White Fig, or Plandain Tree.}

The delicious figs, which the inhabitants of Ceylon are so fond of seeing grow round about their cottages, are in high estimation with them. These figs are not of the same sort as those that are natives of Portugal, and are cultivated in Germany, but differ from them torally. Of these there are above twenty different species, all of which have an agreeable sweet taste. They differ much, however, as. well in degree of sweetness, as in magnitude. The fruit of some are nine inches long, some six, others again but half that length; at the same time, they are as thick as the arm of a child that is twelve months old. The skin is yellow throughout the whole substance; 
the inner part, which partakes more of a mealy, than of a watery nature, is perfectly white. About fifty of these figs, more of less, in proportion as they are of a larger or smaller sort, hang ou one stalk. The tree that bears them is not of a woody nature, but consists rather of a spongy substance, and must be watered constantly; and, indeed, the best sort is always found near springs. It bears figs on one stalk only, after which it dies. But in the mean while the stem produces so many young shoots, that you may well afford to give it respite, and in a short time you will have more figs from its new offspring. The leaves of this tree have a beautiful appearance, and are of a very soft texture and substance. They are often above two ells, or four English feet long, and more than an ell in breadth, and serve the country people for plates and dishes at their meals. The inhabitants consider these figs as a capital present, as they are well apprised that the Europeans are very fond of them. The Roln, lawe $i$ is very apt to fall foul on these figs, whilst the country people are asleep in their beds: on which account they are obliged to gather them, almost throughout the whole country, before they are quite ripe. The fruit, when ripe and tender, is physically used by the black doctors, and is found very excellent and efficacious in many disorders. The blos. som is also eatable, and is frequently pickled. Some are of opinion that this was the fruit 
wherewith Eve tempted Adam; and of whose leaves they afterwards made aprons, for which purpose, as we have seen, they were extremely proper. All parts of this tree are useful: good and pleasant wine is made of its fruit, and its leaves are put to various uses. There is a real or imaginary sign of the cross in the fruit; for which reason the Spaniards and Portuguese, will not suffer it to be cut with a knife, but eat it with their teeth.

\section{The Jake, or Sour Sack (Sauer Sack.)}

The Jake Tree, or Sauer Sack, is chiefly found in the island and gardens of Ceylon. The fruit grows on a tolerably large tree, to the thickness of a stout lusty man, hanging on it like a well stuffed sack. It is green, with a cartilaginous rind; on the inside yellow, and divided into a number of partitions; and in each of which there is a kernel, in colnur and. taste perfectly resembling the chesnut. The fruit itself is agreeably sweet, and grows to the size of a large water-bucket, weighing, perhaps, twenty pounds. The Dutch have given it the name of sour sack, to sinuify, that on account of its great size, it rrat be sour sauce for the tree to bear the weight of it. 


\section{The Wintera Aromatica, or Winter. Cinnamon.}

This is one of the largest forest trees upon Terra del Fuego. It often rises to the height of fifty feet. Its outward bark is on the trunk grey, and very little wrinkled; on the branches quite smooth and green. The branches do not spread horizontally, but are bent upwards, and form an elegant head, of an oval shape. The leaves come out without order, of an oval elliptic shape, quite entire, obtuse, flat, smooth, shining, of a thick leathery substance, ever-green; on the upper side of a lively, deep green colour, and of a pale bluish colour underneath, without any nerves, and their veins scarcely visible: they are somewhat narrower near the footstalks, and there their margins are bent downwards. In general, the leaves are from three to four inches long, and between one and two broad; they have very short footstalks, seldom half an inch long, which are smooth, concave on the upper side, and convex underneath. The footstalks for the flowers come out near the extremity of the branches; they are flat, of a pale colour, twice or three times shorter than the leaves: now and then they support only one flower, but are oftener, near the top, divided into three short branches, each with one flower. There is no calyx; but in its place the flower is surrounded with a spatha- 
ceous gem, of a thick, leathery substance, green, but reddish on the side which has faced the sun; before this gem bursts, it is of a round form, and its size is that of a small pea. It bursts commonly so that one side is higher than the other, and the segments are pointed. The corolla consists always of seven petals, which are oval, obtuse, concave, eréct, white, have small veins, and are of an unequal size, the largest scarcely four lines long: they very soon fade, and drop off almost as soon as the gem bursts. The bark of this tree is of a dark brown cinnamon colour, has an aromatic smell, if rubbed; and of a hoi spicy taste, which is lasting on the palate, though imparted slowly. It has the name of winter cinnamon, from a faint resemblance in colour and flavour to that grateful aromatic, though differing from it greatly in every other respect. The bark only is brought to us from the Straits. of Magellan; much celebrated as an antiscorbutic by the first discóverers, but unknown in the practice of physic, no quantity, except as a curiosity, having been brought to Europe. till the return of the ships sent out on the expeditions to the South Seas.

\section{The Magnolia Glauca, or Beaver Tree.}

The Beaver Tree is a native of Pennsylvania, and other parts of America, and is so called, because the root being dainty to these 
animals, are frequently caught by it. Some of these trees drop their leaves early in autumn, though others of the young keep them all the winter. It begins to flower about the end of May, and the scent of its blossom is excellent. When within three quarters of a mile where these trees grow, they are easily discovered by their fragrancy, provided the wind is favourable. The whole air is filled with this pleasing scent. It is beyond description agreeable, we are informed, to travel in the woods while these trees are in flower, which continues for three weeks or longer, according to the quality of the soil they are planted in; and during the whole time of their being in blossom, they spread their odoriferous exhalations. The berries are likewise very fine when ripe, being of a rich red colour, and hanging in bunches on slender stalks.

The natives make great use of this tree for medicinal purposes. The berries, steeped in rum or brandy, and taken every morning, is highly extolled as a remedy for coughs and consumptions. The bark of the tree, like. wise, by being put into brandy, or boiled in. any other liquor, is of great service for many. internal complaints. The following remarkable cure from the virtues of this favourite. tree, is related by a celebrated traveller."An old man had an open sore on his leg, which would notheal, though he had the best advice, and used many remedies. An Indian, 
at last, effected the cure in the following manner. He burnt some of the wood of this tree to char. coal, which he reduced after to a fine powder, he then mixed it with the fresh fat of pork, and rubbed the open places with it several times. This had the desired effect; it dried up the holes, which before were continually open, and the legs of the old man were thus cured, and remained sound to the day of his death."

The wood of this tree is likewise made use of for joiner's planes, and various other purposes.

\section{The White Cedar, or Iuniper Tree.}

This tree grows in the swamps and other parts of America, and, when left to grow up, they are as tall and thick as the largest firtrees, they preserve their green leaves both in winter and summer, and the tall ones have no branches on the lower part of the stem.

The white juniper, or cedar, as it is called by many, is one of the trees which most resist putrefactiun. When it is made use of above ground, it will last longer than under ground, therefore it is employed for many purposes: it makes good fences, and posts which are to be put into the ground.' It likewise makes good canoes. The young trees are made use of for hoops, round barrels, tuns, \&c. because they are thin and pliable; the thick and tall 
trees afford timber and wood for coopers' work: The houses which are built of it surpass, in duration, those which are built of American oak. This tree affords the best kind of shingles, and are preferred to all for several reasons. First, they are more durable than any others made of American wood, (the red.species of this tree excepted.) Secondly, they are very light, so that no strong beams are requisite to support the roof. For the same reason it is unnecessary to build thick walls, because they are not pressed by heavy roofs. When fires break out, it is less dangerous to go under, or along the roofs, because the shingles, being very light, can do little hurt by falling; and they suck the water, being somewhat spongy, so that the roofs can be easily wetted in case of fire, and their fatness prevents the water from injuring them, by its speedy evaporation. When they burn, and are carried about with the wind, they have commonly what is called a dead coal, which does not easily set fire where it alights. The roofs made of these shingles can easily be cut through, if required, because they are thin, and not very hard; for these qualities the people in the country, and in the towns, are very desirous of having their houses covered with white cedar shingles, if the wood can be got. Therefore all churches, and the houses of the more substantial inhabitants of the towns, have shingle roofs. In many of the provinces of New 
York, (where the white cedar does not grow) the inhabitants have their house's roofed with it, and for this purpose great quantites of shingles are annually exported from many parts of New Jersey, to the town of New York, from whence they are distributed throughout the whole province. A quantity of this wood is likewise exported every year to the West Indies, for shingles, pipe-staves, \&ic. \&c.

All the inhabitants are of opinion, that the water in the cedar swamps, is wholesomer than any other drink; it creates a great appetite, which they endeavour to prove by many examples. They ascribe this quality to the water itself, which is filled with the resin of the trees, and to the exhalations which come from the trees, and can easily be smelled. They likewise affirm that this water is always very cold in the hottest seasons; this may be partly owing to the continual shade it is in, and many people go to these cedar swamps, and use the waters for the recovery of their appetite.

\section{The Red Juniper, or Cedar Tree.}

This tree is also; frequently found in Ame. rica, Canada, and other parts. It is so called from its wood being very fine and red within. The Swedes call it red juniper; the English; red cedar; and the French, cedre rouge. At 
its first growth, it bears great similarity to the white cedar tree before described; but after it is grown up; it gets quite different leaves. The berries exactly resemble that of the white, both in colour and shape, but are not so big, though the red cedar grows very tall. They are likewise found on the same ground as the other; sometimes they are stauding together in clusters, especially on the rising banks of rivers, and are sometimes met with on poor, dry, and sandy heaths. Towards Canada, they are seen on the steep sides of the mountains, where they grow promiscuously with the common juniper. Of all the woods in America, this is, without exception, the most durable, and is therefore made use of in all cases where other timber rots. Some people say, that if iron be put into the ground along with a pole of cedar, the iron would be half corroded by rust, in the same time that the wood would be rotten. It is, like the white cedar, made use of for shingles, canoes, yachts, and various other purposes. The heart of this tree is of a fine red colour, and whatever is made of it looks very fine, and has a very agreeable and wholesome smell; but the colour fades by degrees, otherwise the wood would be more frequently made use of by cabinet makers. Its-very pleasant smell, particularly when fresh, induce many people to put the shavings and chips of it among their linen; to secure it against being worm-eaten, and from many 
noxious insects. Many also get bureaus, \&c. made of it, with the same view; but it is only useful for this purpose as long as it is fresh, for it loses its smell after some time and is then no longer good for keeping off insects. The seats of the gentry, in many parts of Philadelphia, has frequently an avenue, with a row of these trees planted on both sides, leading from the high road to their houses, which has a very grand effect. The lower branches are generally cut, and only a fine crown left, whieh in winter, wher most other trees have lost their leaves, adds greatly to their beauty, and makes them look very fine. This tree is of very slow growth, and propagated chiefly by birds, which eat the berries, and void the seeds entire.

\section{The Liquid.Ambar, or Sweet Gum Tree.}

In the woods, and near purling rivulets, in New Jersey, the Liquid Ambar, or Sweet Gum Tree, grows to a great thickness, and its height rivals that of the tallest firs and oaks. As it grows in height, the lower branches die; and drop off, and leave the stem at last quite smooth and straight, with a great crown at the very summit. The seeds are contained in round, dentated cones, which drop off in autumn, and, as the tree is very tall, the high winds carry the seeds away to a great distance. The wood of this tree can 
be made very smooth, because its veins are extremely fine; but it is not hard. Letters carved on it with a knife appear to be engraved; and no wood is more fit for making moulds for casting brass in than this., A very odoriferous rosin or gum (from whence it is named) always flows out of any cut or wound which is made in the tree, which the heat of the sun, in warm parts of the country, causes to flow abundantly.

\section{The Acer Rubrum, or Red Maple Tree.}

In the swampy and wet places, in many parts of America, this tree grows abundantly. Out of its wood, the natives make plates, spinning-wheels, rolls, teet for chairs, and beds, and various other sorts of wooden work. With the bark they dye both worsted and linens, giving them a dark blue colour. This bark likewise makes a good black ink; and when the tree is felled early in the spring, a sweet juice runs out of it, similar to that from the birch tree, which, in Canada, they make both treacle and sugar of. Some of these trees are called the curled maple, on account of the wood being marbled, as it were, within. It is much used by joiners, in that country, for curious work, and is dearer than most other woods used for cabinet work. 'Trees of this description are frequently found, whose outsides are marbled, but their insides not, 
the tree is, therefore, cut very deep before it is felled, to see whether it has veins in every part.

\section{The Thuya, or Desom Tree.}

The inhabitants of Canada make very great use of this tree. It is reckoned one of the most durable of woods. It withstands decay for upwards of a century, and is, therefore, made use of for many purposes, where timber is used under ground, such as posts and pal. lisadoes round the forts in that country, \&c.: also, the ribs and bottom of the bark-boats are taken from this wood, which, while fresh, is particularly pliant, and, by being very light, is proper for these purposes. The thuyæ wood is also reckoned one of the best for the use of lime-kilns; and its branches are used all over Canada for besoms. The twigs and leaves of it being naturally bent together, make it very proper for this purpose. The branches, when first gathered, have a very agreeable scent, which is so powerful, as to be strongly smelled in the houses where these besoms are made use of. And the Indians bring them to the different towns for sale, and, from their great fragrancy, derive emolument from this kind of traffic. The leaves. of this tree are green all the winter, and the virtues of its cones and leaves for medicinal purposes, are held in the highest 
THE GUM TREE.-THE GUAVA.

estimation by all the natives, and many tra. vellers.

\section{The Gum Tree of Dominica.}

Among other valuable trees in the woods of Dominica, is the Gum Tree, which yields great quantities of that article. The circumference of the body of this tree is generally very great, and $j$ ts timber is, on that account, made into canoes; which is done by digging or burning out the inside, and shaping the log into form. 'The gum falls from the body and branches of the tree, in great quantities, in substance like white wax, and was very serviceable to the planters of the island, during the time it was in possession of the French, last war; this gum being used instead of oil, which could not then be had, to burn in the boiling houses when making sugar. The Romish priests of the island likewise use it in their censers at funerals, and other ceremonies of their church, it having a very aromatic smell when burning; and it is supposed to contain virtues which miglst be valuable in medicine, was it better known.

\section{The Guava, as Sensative Tree.}

The Guava Tree, is a native of Dominica, and grows tolerably large and lofty, especially 
those that bear the white guavas. Their timber and branches are very serviceable: and being durable, and of a supple nature, are used for making bows for cattle, yokes, knees for canoes, or boats, baskets, \&c. These trees have a singular property in them, as they are to be seen bearing ripe fruit, fruit just left by the blossoms, and blossoms in full bloom, all growing on the same branch. The blossoms close during the night, but being touched with the hand, or receiving the heat of the sun in the morning, they expand, diffusing the most delightful, fragrant scent.

\section{The Sour Sop Tree.}

The Sour Sop is a fine fruit, large, and much of the shape of a heart. When unripe, it is of a brown colour, and its skin is covered with raised points, like prickles, but they are not sharp. When ripe, it is of a fine green colour, the points then fall off, and the skin is quite smooth. It is a very wholesome fruit, in taste resembling fine cotton dipped in sirup, with a little tincture of acid, of a very agreeable musky flavour, and much recommended in fevers.

The fruit and leaves of the sour sop have a very singular property in them, for the fruit will rot on the ground, without the least visible appearance of worms, although most animals and birds are very fond of it; and the 
leaves being scattered in a room infested with fleas, soon clears it of these troublesome guests, by the strength of the smell of the leaves, which, however, is very pleasant. It is a native of Dominica.

\section{The Citreum, Citrum, or Citron Tree.}

This tree was first brought into Europe from Media. It is of a moderate height, with a branched spreading root, yellowish without, and whitish within. The trunk is slender, the wood whits and hard, and the bark of a pale green colour. The boughs are numerous, long, slender, and tough, and the oldest of them are of a light yellowish green, and armed with pale prickles; but those that are more recent, are of a beautiful green. The top of the branches are tender, and of a brownish red green, as well as the leaves, which are of the size of those of the walnut tree. They are generally blunt, but now and then acuminated, and are three times as long as they are broad: the lower part is not so green as the upper, and the edges are a little serrated. The tree is always cloathed with them, both in winter and summer; and when they are held up against the sun, they appear to have holes in them, or are rather full of rransparent specks. The flowers grow on the tops of the branches, and are rosceate, with feshy petals, which are generally five in 
númber, and stand almost upright; without, they have a reddish blush, but are white within, and placed in a ring. The calyx is small, and divided into five segments, and under the yellow apex there are a great many stamina, and part of the flowers are fruitful, and part barrer. Among the stamina, there is a longish pistil, the rudiment of the fruit, and those flowers that are without never produce any. The shape of the fruit is oblong, but sometimes globular, and scime terminate in a point, while others are blunt. The surface is wrinkled and tuberous, and is often nine inches in length, and upwards. The size is different, as well as the weight. Some will weigh six. nine, and even thirty pounds. The outer rind is tough, thin, bitter, and bot: and the colour is at first green, and then turus to that of gold, when ripe. The inuer, or white rind, is thick, firm, sweetish, with a little acidity. Within, it is divided into several cells, full of an acid juice.' The sceds are numerous, for sometimes an hundred and fifty have been found therein : they are oblong, half an inch in length, and sharp at both enos; they are bitter, yellow without, covered with a streaked skin, and contain a double white kernel. In hot countries, both flowers and fruit may be seen on the tree at the same time, as wel in the spring as in the autumn, but more plentifully in the latter.

The juice of the citron is very useful for many purposes. The acid is agreeable, ex- 
cites an appetite, and helps digestion, when moderately used. It is an excellent remedy against the scurvy, and is a kind of specific to cure that disease. The juice has been known to cure the gums, when even ulcerated with the scurvy. It has also been found very serviceable in burning and malignant fevers. When the juice is mixed with water, and sweetened with sugar, it makes a fine cooling drink, grateful to the palate, and agrees with the sick, as well as those in health. The flowers, as well as theleaves, have an exceedingly fine, refreshing smell. The outer yellow bark has also a very fine aromatic smell, occasioned by the prodigious number of vesicles it has full of essential oil, which, by being cherved, mends the breath, and by its bitterness strengthens the stomach, discusses the wind, and concocts crude humours in the stomach and intestines.

\section{The Malus Limonia, or Lemon Tree.}

The Lemon Tree, we mention here, on account of its affinity with the citron tree. Like that tree, it is moderately tall, though not very full of branches. The leaves are like those of the citron tree, but shorter, and the prickles are more numerous, but less, and venomous. The flowers have much the same smell, and the shape of the fruit is likewise oval, but skorter, and not of so deep 
a yellow. Likewise, the rind is thinner, and they are much more full of juice, which is more acid than that of the citron. Upon which account it is thought by many to be more cooling and efficacious in hot diseases. In short, what has been said of the juice of citrons, may, in most respects, be applied to lemons.

\section{The Aurantia Malus, or Orange Tree.}

This beautiful tree grows abundantly in China, Lisbon, and many other warm countries. It does not grow very tall, but has a thick, woody, branched root, which spreads very much, and is of a yellow colour in the inside. The trunk is hard, white within, of an agreeable smell, and is covered with a greenish, smooth, white bark. The branches are numerous, flexible, and of a beautiful green, with a few thorns thereon. The leaves are somewhat like broad laurel, and are always green, thick, smooth, and ending at each end in a point, with a foliated pedicle, in the shape of a heart. When held up to the light, they appear full of transparent holes. The Nowers grow in bunches, and are roseate, consisting of five white petals, placed in a ring, with many stamina, which have yellow apices, or heads. At the bottom and centre of the cup, there is an orbicular placenta, which sustains a roundish pistil with a long 
tube, that turns into a globous fruit, covered with a rind, which is very well known. There are several kinds of oranges, as the common Seville orange, the sweet Seville orange, the China orange, the horned orange, the curled-leaved orange, the starry orange, \&c. \&c. Many sorts of these oranges are cultivated in England, though more for curiosity than the fruit they produce. The usefulness and deliciousness of this fruit few are unacquainted with, and the peel is an excellent bitter, especially that of the Seville orange. It is an ingredient in tinctures, called stomachic bitters, and is frequently given in a glass of wine before dinner, to create an appetite.

\section{Remarkable Oak Trees.}

The Oak has been long known by the title of honarch of the Woods, and very justly. It was well known and often very elegantly described, by the poets. The following description from Virgil is exquisite.

sf As o'er the aerial Alps, sublimely spread,

Some aged Oak uprear's his reverend liead,

This way and that the furious tempests blow,

To lay the monarch of the mountains low;

Th' imperial plant, though nudding at the sound,

Though all his scattered honours strew the ground,

Safe in his strength, and seated on the rosk,

In naked majesty defies the shock:

High as the head shouts tow'ring to the skies,

so deep the root in hell's foundation lies."

pitt. 
The ancient druids had a most profound veneration for oak trees. Pliny says, that "the druids (as the Gauls call their magicians, or wise men) held nothing so sacred as the misletoe, and the tree on which it grows, provided it be an oak. They make choice of oak groves, in preference to all others, and perform no rites without oak leaves, so that they seem to have the name of druids from thence, if we derive their name from the Greek." Maximus Tyrius says, the Celtæ, or Gauls, worshipped $J$ upiter under the figure of a lofty oak.

This useful tree grows to such a surprising magnitude, that were there not many well authenticated instances of them in our own country, they would certainly appear difficult of belief. In the 18 th volume of the Gentleman's Magazine, we have the dimensions of a leaf twelve inches in length, and seven in bleadth, and all the lcaves of the same tree were equally large.

On the estate of Woodhall, purchased in 1775, by Sir Thomas̀ Bumbold, Bart. late Governor of Madras, an oak was felled; which sold for forty-three pounds, and measured twenty-four feet round.

We are also told of one in Millwood forest, near Chaddesly, which was in full yerdure in winter, getting its leaves again after the Autumn fell off.

In Hunter's Evelyn's Sylva, we have an account of a very remarkable oak, at Green- 
dale, which Gough, in his edition of Camb. den, thus minutely describes. "The Greendale oak, with a road cut thro' it, still bears one green branch. Such branches as have been cut or broken off are guarded from wet by lead. The diameter of this tree at the top, whence the branches issue, is fourteen feet, two inches; at the surface of the gromid, eleven feet and a half; circumference there, thirty five feet; height of the arch, ten, and the width, six feet."

In the Gentleman's Magazine for 1773, we have arr account of one differing very essentially from the common orre; it is frequent abrut St. Thomas, in Devonshire, und is in that country called Licombe oab, from one Widiam Lucombe, whosuccessfully cultivated it near Exeter. It grows as straight and handsome as a fir; its leaves are ever-green, and its wood is as hard as that of the common oak. Its growth is so quick, as to exceed, in twenty or thirty years, the altitude and girth of the common one at one hundred years, It is cultivated in various places, Cornwall, Somersetshire, \&c.

The very remarkable great oak, which stood in Langley wonds, near Downton, was felled on Friday, the ist of December, 1758. This tree, which was the property of the Bisionp of Sulisbury, and sold to Mr. John Misks, timber merchant, at Downton, for forty pounds, was supposed to be near one thousand years growth; it measured six feet, two 
inches diameter at the bottom, contained about ten tons of timber, and was perfectly sound.

\section{Damery's Oak.}

Not far from Blandford, in Dorsetshire, stood, very lately, a tree, known by the name of Damery's Oak. About five or six centuries ago, it was probably in a state of maturity. At the ground, its circumference was sixty-eight feet, and seventeen feet above the ground, its diameter was four yards. As this vast trunk decayed, it became hollow, forming a cavity, which was fifteen feet wide, and seventeen feet high, capable of holding twenty men. During the civil wars, and till after the Restoration, this cave was regularly inhabited by an old man, who sold ale in it. In the violent storm in the year 1703 , it suffered greatly, many of its noblest limbs being torn from it. But it was still so grand a ruin, above forty years after, that some of its branches were seventy-five feet high; and extended seventy-two. In the year 1755 , when it was fit for nothing but fire-wood, it was sold for fourteen pounds. 


\section{Wallace Oak.}

In Torwood, in the county of Stirling, upon a little knoll, stand at this time (1791) the ruins of an oak, which is supposed to be the largest tree that ever grew in Scotland. The trunk of it is now wholly decayed, and hollow; but it is evident, from what remains, that its diameter could not have been less than eleven or twelve feet. What its age may be is matter only of conjecture; but from some circumstances, it is probably a tree of great antiquity. The little knoll it stands on is surrounded by a swamp, over which a causeway leads to the tree, or rather to a circle, which seems to have run round it. The vestiges of this circle, as well as the causeway, hear a plain resemblance to those works which are commonly attributed to the druids. So that it is probable, this tree was a scene of worship belonging to those heathen priests. But the credit of it does not depend on the dubious vestiges of druid antiquity. In a later scene, of greater importancé, (if tradition ever be the vehicle of tiuth) it bore. a great share. When that illustrious bero, William. Wallace, roused the spirit of the Scots nation, to oppose the tyranny of Edward, be often chose the solitude of Torwood as a place of rendezvous for his army. Here he concealed his numbers and his designs, sallying out suddenly on the enemy's garri- 
sons, and retreating as suddenly, when he feared to be overpowered. While his army lay in those woods, the oak which we are now commemorating, was commonly his bead quarters. Here the hero generally slept; its hollow trunk being capacions enough to afford shelter, not only to himself, but to several of his officers. This tree has ever since been known by the name of Wallace tree; by which name it may be easily found in Torwood to this day.

\section{Hern's Oak.}

Among these celebrated trees, we must not forget Hern's Oak, in Windsor forest. Shakespear tells us,

"An old tale goes, that Hern the liunter,

Some time a keeper here in Windsor Forest,

Doth all the winter time, at still of midnight,

Walk rouud about thic onk with ragged horns;

Aud tueu he blast the trees, destroys the cattle,

Makes the milch cow yjeld blood, aud shakes a chain

In hideous dieadful manner."

This tree, as far as we can pay credit to tradition and general opinion, still exists. In the little park at Windsor, is a walk, known by the name of Cuecn Elizabeth's walk. It consists of elms, among which is a single oak taken into the row, as if particularly meant to be distinguished at the time the walk was laid out. This tree is supposed to be Hern's tree. It is a large tree, measuring about. 
twenty-four feet in circumference, and is'still in great vigour. A pit, or ditch, is still shewn near the tree, as Shakespeare describes it, which appears to have been preserved with the same veneration as the tree itself.

\section{Queen Elizabeth's Oak.}

There is an oak, in the grounds of Sir Gerrard Van Neck, at Hevingham, in Suffolk, which carries us likewise in to the times: of Elizabeth. This tree brings such evidence with it, which, if necessary, might carry us into Saxon times. It is now falling fast into the decline of years, and every year robs it of more of its honours. But its trunk, which measures thirty-five feet in circumference, still retains its grandeur, though the ornaments of its boughs and foliage are much reduced. But the grandeur of the trunk consists only in appearance. It is a mere shell. In Queen Elizabeth's time it was hollow; and from this circumstance the tree derives the honour of being handed down to posterity. That princess, who, from her earliest age, loved masculine amusements, used often, it is said, in her youth, to take her stand in this tree, and shoot the deer as they passed. From that time it has been known by the name of Queen Elizabeth's Oak. 


\section{The Fairlop Oak.}

In a glade of Hainhault forest, in Essex, about a mile from Barkingside, stands an oak, which has been known through many centuries, by the name of Fairlop. The tradition of the country traces it half way up the christian æra. It is still a noble tree (1791), though it has suffered greatly from the depredations of tine. About a yard from the ground, where its rough, fluted stem is thirtysix feet in circumference, it divides into eleven vast arms; yet not in the horizontal manner of an oak, but rather in that of a beech. Beneath its shade, which overspreads an area of three hundred feet in circuit, an annual fair has long been held, on the second of July, and no booth is suffered to be erected beyond the extent of its boughs. But as their extremities are now become sapless, and age is yearly curtailing their length, the liberties of the fair seem to be in a very desponding condition. The honour, however, is great; but honours are often accompanied with inconveniences, and Fairlop has suffered from its honourable distinctions. In the feasting that attends a fair, fires are often necessary; and no places seemed so proper to make them in as the hollow cavities formed by the heaving roots of the tree. This practice has browght on a speedier decay on Fairlop than it might otherwise have suffered. 
THE SHIRE OAK.-CHAUCER'S OAKS. 99

\section{The Shire Oak.}

Near Worksop grew an oak, which, in respect both to its own dignity, and the dignity of its situation, deserves honourable mention. In point of grandeur few trees equalled it. It overspread a space of ninety feet from the extremities of its opposite boughs. These dimensions will produce an area capable, on mathematical calculation, of covering a squadron of two hundred and thirty-five horse. The dignity of its station was equal to the dignity of the tree itself. It stood on a point, where Yorkshire, Nottinghamshire, and Derbyshire, unite, and spread its shade over a portion of each. From the honourable station of thus fixing the boundaries of three large counties, it was equally respected through the domains of them all, and was known far and wide, by the honourable distinction of the shire oak, by which 'appellation it was marked among cities, towns, and rivers, in all the larger maps of England.

\section{Chaucer's Oaks.}

The oaks of Chaucer are celebrated, in the snnals of poetry, as the trees under which

"S The laughing, age 
100. THE MAGDALEN, OR GREAT OAK.

They grew in the park at Donnington Castle, near Newbury, where Chaucer spent his life in studious retirement. The largest of these trees was called the king's oak, and carried an erect stem of fifty feet before it broke into branches, and was cut into a beam five feet square. The next in size was called the queen's oak, and survived the calamities of the civil wars in King Charles's time, though Donnington Castle, and the county around it, were so often the scenes of action and desolation. Its branches were very curious; they pushed out from the stem in several uncommon directions, initating the horns of a ram rather than the branches of an oak. When it was felled, it yielded a beam forty feet long, without knot or blemish, perfectly straight, four feet square at the but-end, and near a yard at the top. The third of these oaks was called Chaucer's, of which we have no particulars: in general, only, we are told, that it was a noble tree, though inferior to either of the others.

\section{The Magdalen, or Great Oak.}

Close by the gate of the water-walk, at Magdalen college, Oxford, grew an oak, which perhaps stood there a saplin, when Alfred the Great founded the University. This period only, includes a space of nine hundred years, which is no great age for an 
THE MAGDALEN, OR GREAT OAK. 101

oak. It is, indeed, a difficult matter to ascertain the age of a tree. The age of a castle or abbey is the object of history. Even a common house is recorded by the family that built it. All these objects arrive at maturity in their youth, if we may so speak. But the tree, gradually completing its growth, is not worth recording in the early part of its existence. It is then only a common tree; and afterwards, when it becomes remarkable for its age, all memory of its youth is lost. This tree, however, can almost produce historical evidence for the age assigned to it. About five hundred years after the time of Alfred, William of Wainfleet, Dr. Stukely tells us, expressly ordered his college to be founded near the great oak: and an oak could not, he thinks, be less than five hundred years of age, to merit that title, together with the honour of fixing the scite of a college. When the magnificence of Cardinal Wolsey erected that handsome tower, which is so ornamental to the whole building, this tree might probably be in the meridian of its glory; or rather, perbaps, it had attained a green old age. But it must have been manifestly on its decline at that memorable æra, when the tyranny of James gave the fellows of Magdalen so noble an opportunity of withstanding bigotry and superstition. It was afterwards much injured in Charles the Second's time, when the present walks were laid out. Its roots were dis. turbed, and from that period it declined fast,

x. 2 
and became reduced, by degrees, to little more than a mere trunk. The oldest members of the university can scarce recollect it in better plight.. But the faithful records of history have handed down its ancient dimensions. Through a space of sixteen yards, on every side from its trunk, it once flung its boughs, and under its magnificent pavilion, could shelter with ease three thousand men, though, in its decayed state, it could for many years, do little more than shelter some luckless individual, whom the driving shower had overtaken in his evening walk. In the summer of the year 1788 , this magnificent ruin fell to the ground, alarming the college with its rushing sound. It then appeared how precariously it had stood for many years. Its grand tap root was decayed, and it had hold of the earth only by two or three roots, of which none was more than a couple of inches in diameter. From a part of its ruins a chair has been made for the president of the college, which will long continue its memory.

\section{The celebrated Boddington Oak.}

This oak grows in a rich piece of grass land, called the old Orchard Ground, belonging to Boddington manor farm, lying near the turnpike road, between Cheltenham and Tewkesbury, in the vale of Gloucester.

The stem is remarkably collected and snug 
at the root, the sides of its trunk being more upright than those of large trees in general: nevertheless, its circumference at the ground, as near to it as one can walk, is twenty paces: measuring with a two-foot rule, it is somewhat more than eighteen yards. At three feet high, it measures forty-two feet, and at its smallest dimensions, namely from five to six feet high, it is thirty-six feet.

At about six feet it begins to swell out larger, forming an enormous head, which heretofore has been furnished with huge, and, in all probability, extensive branches: but age and ruffian winds, have robbed it of a principal part of its grandeur, and the greatest extent of arm at present is eight yards from the stem. From the ground to the top of the crown of the trunk is about twelve feet, and the greatest height of the branches, by estimation, is forty feet.

The stem is quite hollow, being, near the ground, a perfect shell, forming a capacious well-sized room, which at the floor measures, one way, more than sixteen feet in diameter. The hollowness, however, contracts upwards, and forms itself into a natura! dome, so that no light is admitted, except at the door, and at an aperture, or window, in the side.

It is still perfectly alive and fruitful, having this year (1795) a fine crop of acorns upon it.

It is observable in this, as in many old trees, that its leaves are remarkably small, 
not larger, in general, than the leaves of the hawthorn.

\section{The Shelton Oak.}

Mr. Gough, in his edition of Camden's Britannia, introduces the following notice of this remarkable tree.

"About a mile and a half from Shrewsbury, where the Pool-road diverges from that which leads to Oswestry, there stands an ancient decayed oak. There is a tradition, that Owen Glendwr ascended this tree to reconnoitre; and finding that the king was in great force, and that the Earl of Northumberland had not joined his son Hotspur, he fell back to Oswestry, and, immediately after the battle of Shrewsbury, retreated precipitately to Wales.

"This tree is now in a complete state of decay, and hollow, even the larger ramifications. It is visited by many people, from the above tradition. A gentleman, last year, was so charmed with this old tree, that he gave it the name of Owen Glendwr's Observatory, and wrote the annexed inscription for a brass plate, to be fixed to the tree.

$$
\text { "On July XXII, }
$$

A. D. MCCCCIIII:

OWEN GLEN DWR ascended this Tree to reconuoitre, on his march to Shrew:-bury,

to join the dariag Hotspur, agains: King Henry IV.;

but, finding his ficiends were defeated, returued from this spot into Walea."? 
The following are the dimensions of the Shelton oak.

Girt at bottom, close to the ground, fortyfour feet, three inches. Ditto, five feet fiom the ground, twenty-five feet, one inch. Ditto, eight feet from the ground, twenty-seven feet, four inches. The height of the tree, to near the top, forty-one feet, six inches. Within the hollow of the tree, at the bottom, there is sufficient room for, at least, half a dozen to take a snug dinner.

\section{The Royal Oak.}

This celebrated fair-spreading tree, stands near the middle of a large house at Boscobel, in the parish of Donnington, in Staffordshire, the boughs whereof were once covered with Ivy; in the thick of which King Charles the Second sat in the day time, with Colonel Careless, and in the night lodged in Boscobel house. Doctor Stukely gives us the following information concerning this remarkable tree, and Boscobel house. The doctor lodged at an inn, called I vesey bank, on the borders of Staffordshire and Shropshire. About a mile off, in a large woud, stands Boscobel house, where the Pendrils lived, who preserved King Charles the Second, after the battle of Worcester, and made famous by the royal oak. The grand-daughter of William Pendril still lives in that house (in 1764). 
The floor of the garret (which is a popish chapel) being matted, prevents any suspicion of a little cavity, with a trap door, over the stair-case, where the king was hidden. His bed was artiully placed behind some wainscot, that shut up very close. At a bow-shot from the house, just by a horse-track, passing through the wood, stood the oak, into which the king, and his companion, Colonel Careless, climbed, by means of a hen-roost ladder, when they judged it no longer safe to stay in the house; the family reaching them victuals with a nut book, during their continuance in that situation.

It happened, that whilst the king and the colonel were in the tree, a party of the enemy's horse, sent to search the house, came whistling and talking along the road. When they were just under the oak, an owl flew out of a neighbouring tree, and hovered along the ground, as if her wings were-broken, and the soldiers morrily pursued it, without making any circumspection.' The tree is now inclosed within a brick wall, the inside whereof is covered with laurel. The oak is almost cut away in the middle by travellers, whose curiosity leads them to see it. Close by the side, grows a young thriving plant, from one of its acorns. The king, after the Restoration, reviewing that place, carried some of the acorns, and set them in St. James's Park, or garden, and used to water them himself. He also gave Pendril an estate of about two 
hundred pounds a year, which still remains in the family.

The present tree is fine and thrifty, and, as we have before observed, is said to have originated from an acorn of the old oak; and the wall, which was ruinous, is rebuilt of brick, and an inscription, in latin, engraven on a brass plate, of which the following is a copy.

Quercus amica Jovi.

Felicissinam hanc arborem, quam in Asylum Potentissimi Regis Caroli II.

Deus Optimus Maximus, per quem

Reges regnant, hic crescere voluit, tam in perpetuam Rei tantæ Memoriam, quam in specimen firmæ in Reges Fidei,

Muro cinctam Posteris commendant

Basilius et Jana

Fitzherbert.

Quor Pietatis monumentam jarn vetustate

collapsum paternarum virtatum Hæerede et avite in Principes Fider Emnlatores, in integrum restiturent

Basilius et Eliza

Fitzherbert.

PIII cal, Juuii An. Hum. Sa!.

M DCCLXXXVII. 


\section{Free Translation.}

Sacred to Jupiter is the Oak.

This most glorious tree, which, for the asylum of the Most powerful King Charles II. God the Greatest and the Best, here caused to flourish. Basil and Jane

Fitzherbert

have surrounded with a wall, that it may be secured to posterity, as a perpetual memorial of so great a King, and $a$ proof of their fidelity towards Mouarchs: which monument of Piety, now decayed through age, is rebuilt by Basil and Elizabeth

Fitzherbert, The Heirs of paternal virtue, and the emulators of their ancestors in their fidelity sowards Princes. 4th J bine, 1787 . 


\section{Sir Philip Sydney's Oak.}

This famous tree grows in Penshurst park, in the county of Kent. It goes by the name of Bear Oak, or, perhaps, Bare Oak, from a supposed resemblance to that which Camden says gave name to the county of Berkshire. The tradition there is, that this very tree was planted on the day that the celebrated Sir Philip Sidney was born.

"That larger tree, that of a nut was set

On his great birth, when all the muses met."

Waller.

Formerly the tenants used to furnish themselves with boughs from this tree, to stick in their hats, whenever they went to meet the Earls of Leicester, as was always the custom to do at the end of the park, when they came to reside at their seat. This fine old oak stands upon a plain about five hundred yards from their venerable mansion, near a large piece of water, called Lancup Well. Ben Jonson and Waller have particularly noticed it; and from the distinguished owners of this place, it may be truly said to stand on classic ground. It seems, however, to be fast hastening to decay;

"Its boughs are moss'd with age, And higli top bald with dry antiquity."

Shakospars. 


\section{BeAUty, StatelY, aNd MaJesty.}

Within the hollow of this tree there is a eat, and it is capable of containing five or six persons with ease. 'The bark round the entrance was so much grown up, that it hus lately been cut away to facilitate the access. The dimensions of the tree are as follow:

Girth close to the ground
Ditto one foot from ditto
Ditto five feet from ditto
Height, taken by shadow
Girth of lowest, but not largest, limb

Feet. Inch.

$\begin{array}{ll}35 & 6 \\ 27 & 6 \\ 24 & 0 \\ 73 & 0\end{array}$

$6 \quad 9$

\section{Beauty, Stately, and Majesty,}

THREE VERY REMARKABLE AND WELLKNOWN OAK TREES.

In the park of John Plumptree, Esq. near Deal; in the county of Kent, are oak trees, the most remarkable for height and size in the kingdom. They are distinguished by appropriate names, but the most remarkable of them are those called Majesty. Stately, and Beauty.-Beauty is sixty-three feet from the ground, whilst the uniformity of its branches, and the regularity of its bark are beautiful beyond conception. The circumference of this tree, five feet from the ground, is fifteen feet, nine inches ; its solid contents, bark not included, twelve ton, twenty-five feet! Stately, at four feet from the ground, 
measures in circumference, eighteen feet, and its solid contents, twelve ton, thirty-three feet, one inch, bark not included! But Majesty, the most wonderful of all these trees, has, eight feet from the ground, a circumference of twenty-eight feet; four inches; and, at twenty-eight from the ground, fifteen feet, six inches. It has one arm which contains sixty-eight feet, eleven inches; another, sixtyfour feet, two inches; a third, sixty feet, nine inches, and several others of nearly equal dimensions. The total contents of this huge bulk of timber are thirty-six tons, twentyeight feet, four inches, bark not included.

As the subject of these beautiful trees is inexhaustible, and our volume being limited we shall conclude the description, with th* following elegant lines on this venerable mo: narch of the woods.

"From a small acorn see the oak arise,

Supremely tall, and towering in the skies !

Queen of the groves, her stately head she rears;

Her bulk increasing with increasing years!

Now moves in pomp, majestic o'er the deep,

While in her womb Britannia's thunders sleep;

With fame and conquest graces Albion's shore,

And guards the island, where she grew before." 


\section{The Swietenia Mahagoni, or Mahogany Tree,}

Is a native of the warmest parts of America, and grows also in the island of Cuba, Jamaica, Hispaniola, and the Bahama Islands. It abounded formerly in the low lands of Jamaica; but it is now found only on hills, and places difficult of access. This tree grows tall and straight, rising often sixty feet from the spur to the limbs; and is about four feet in diameter. The foliage is a beautiful deep green, and the appearance made by the whole tree very elegant. The flowers are of a reddish or saffron colour, and the fruit of an oval form, about the size of a turkey's egg: Some of them have reached to a monstrous size, exceeding one hundred feet in height. In felling these trees the most beautiful part is commonly left behind. The negro workmen raise a scaffolding of four or five feet from the ground, and hack up the trunk, which they cut into balks. The part below, extending to the root, is not only of larger diameter, but of a closer texture, than the other parts, most elegantly diversified with shades or clouds, or dotted like ermine with spots: it takes the highest polish, with a singular lustre. This part is only to be come at by digging below the spur, to the depth of two or three feet, and cutting it through; which is so laborious an operation, that few attempt it, 
except they are curious in the choice of their wood, or to serve a particular purpose. The mahogany tree thrives in most soils; but varies in texture and grain, according to the nature of the soil. On rocks it is of a smaller size, but very hard and weighty, and of a close grain, and beautifully shaded; while the produce of the low and richer lands is observed to be more light and porous, of a paler colour, and open grain; and that of mixed soils, to hold a medium between both. This constitutes the difference between the Jamaica wood and that which is collected from the coast of: Cuba, and the Spanish main : the former is found mostly on rocky eminences; the latter is cut in swampy soils near the sea coast. The superior value of the Jamaica wood, for beauty of colouring, firmness, and durability, may therefore be easily accounted for ; and a large quantity of balks and planks is brought from the Spanish Ame. rica coasts to Jamaica, to be shipped from thence to Great Britain. This wood is generally hard, takes a fine polish, and is found to answer better than any other sort, in all kinds of Cabinet ware. It is a very strong timber, and was frequently used as such in Jamaica in former times. It is said to be used sometimes in ship building; a purpose for which it would be remarkably adapted, if not too costly; being very durable, capable of resisting gun-shots, and burying the shots without splintering. 
THE

WONDERFUL PROPERTIES

OF

\section{PLANTS and HEFBS.}

The power of moving from one place to another hath by many been thought to constitute their difference; and indeed, in most cases, it is the obvious mark by which we distinguish an animal from a vegetable: but Lord Kames hath given several very curious instances of the locomotive power of plants: some of which, he says, would do honour to an animal.

Upon the slightest touch the Sensative Plant shrinks back, and folds up its leaves, similar to a snail; which, on the slightest touch, retires within its shell. There is a species of the sensative plant lately discovered, which, if a fly perch upon one of its flower-leaves, it closes instantly, and crushes the insect to death. There is not an article in botany more admirable than a contrivance, visible in many plants, to take advantage of good weather, and to protect themselves against bad. They open and close their flowers and leaves in different circumstances: some close before sun-set, some after; some open to receive rain, some close to avoid it. 
The petals of many flowers expand in the sun; but contract at night, or on the approach of rain. After the seeds are fecundated, the petals no longer contract. All the trefoils may serve as a barometer to the husbandman; they always contract their leaves on an impending storm. Some plants follow the sun, others turn from it. Many plants, on the sun's recess, vary the position of their leaves, which is styled the sleep of plants. A singular plant was lately discovered in Bengal. Its leaves are in continual motion all day long; but when night approaches, they fall down from an erect posture to rest.

A plant has a power of directing its roots for procuring food. The red whortle-berry, a low ever-green plant, grows naturally on the tops of our highest hills, among stones and gravel. This shrub was planted in an edging to a rich border, under a fruit wall. In two or three years it over-ran the adjoining deep-laid gravel walk, and seemed to fly from the border, in which not a runner appeared. An effort to come at food, in a bad situation, is extremely remarkable in the following instance. Among the ruins of New Albey, formerly a monastery, in Galloway, there grows on the top of a wall, a plane tree, about twenty feet high. Straitened for nourishment in that barren situation, it several years ago directed roots down the side of the wall, till they reached the ground ten feet below : and now the nourishment it afforded 
to those roots during the time of their descending, is amply repaid, having every year, since that time, made vigorous shoots. From the top of the wall to the surface of the earth these roots have not thrown out a single fibre, but are now united in a single root.

Plants, when forced from their natural position, are endowed with the power to restore themselves. A hop-plant, twisting round a stick, directs its course from south to west, as the sun does. Untwist it, and tie it in the opposite direction, it dies. Leave it loose in. the wrong direction, it recovers its natural direction in a single night. Twist the branch of a tree, so as to invert its leaves, and fix it in that position, if left in any degree loose, it untwists itself gradually, till the leaves be restored to their natural position. What better can an animal do for its welfare? A root of a tree meeting with a ditch in its progress, is laid open to the air. What follows? It alters its course, like a rational being, dips into the ground, surrounds the ditch, rises on the opposite side to its wonted distance from the surface, and then proceeds in its original direction. Lay a wet sponge near a root laid open to the air; the root will direct its course to the sponge. Change the place of the sponge; the root varies its direction. Thrust a pole in to the ground at a moderate distance from a scandent plant; the plant directs its course to the pole, lays hold of it, and rises on it to its natural height. A honeysuckle 
proceeds in its coursè till it he too long for supporting its weight; and then strengthens itself by shooting into a spiral. If it meet with another plant of the same kind, they coalesce for mutual support, the one screwing to the right, the other to the left. If a honeysuckle.twig meets with a dead branch, it screws from the right to the left. 'The claspers of briony shoot into a spiral, and lay hold of whatever comes in their way for support. If, after completing a spiral of three rounds, they meet with nothing, they try again, by altering their course.

By comparing these and other instances of seeming voluntary motion in plants, with that share of lite wherewith some of the inferior kind of animals are endowed, we can scarce hesitate at ascribing the superiority to the former: that is, putting sensation out of the question. Muscles, for instance, are fixed to one place as much as plants are; nor have they any power of motion, besides that of opening and shutting their shells; and in this respect, they have no superiority over the motion of the sensative plant: nor doth their action discover more sagacity, or even so much, as the roots of the plane tree, mentioned by Lord Kames. 
The wonderful Contrivance of Nature for the Preservation of a Plant that grows on the River Rhone, called

\section{The Vallisneria.}

This plant consists of a small root, with a few long leaves rising from it, and in the midst of them a stalk of two or three feet in length, but so weak, that it is by no means able to support itself erect. On the top of each stalk is one single flower, in some degree resembling a bunch of jessamine. It appears to be the purpose of nature, and it is absolutely necessary to the well being of the plant, that every part of it should be immersed in water, except just the flower at the top of each stalk. But these flowers must be always kept above the water; and the heat of the sun is requisite to the opening of the seeds contained in a cup at the base of them. Now the Rhone, wherein this plant grows in great abundance, is a river of very uncertain depth, and that in places very near one another. If the seeds of this plant, or the side shoots from the root, produce new ones at different depths, how is the flower to be carried to the top, and only just to the top, of the water in each? The Rhone is also, of all rivers, the most apt to be swelled by sudden floods; in this case, how is the plant that was just flowering in its proper manner at four 
feet depth, to be kept in the necessary state of having the flower above water, when the depth is increased to six? Or how is it to be kept from falling on the surface of the water, and rotting, when the depth decreases, and leaves a foot or two of a naked stalk, which is unable to support itself? All this is provided for by nature, or rather by God the Creator, who, with apparent wisdom and intention, has made the stalk which supports the flower of this plant of such a form and texture, that it all times suits itself to the depth of the water it is in; for the stalks are not straight, but twisted in a spiral form, in the manner of a cork-screw, or rather in the manner of those springs of wire which we see made by wrapz ping the wire round a small stick. By this formation the stalks of this plant have a power of extending or contracting themselves in length, and this so suddenly, that let the rise or fall be ever so quick, the lengthening or shorteniug of the stalks accompany it; and the same formation suits them in a yet easier manner to different depths. By this formation, (the like of which is not seen in any other plant in nature) the flower of the Vallisneria (for so this singular vegetable is called) is kept just at the furface of the water, be the depth what it will, or the changes in depth ever so sudden. By this means the sun has power to ripen the flower, till the seeds are scattered on the surface of the water in perfect ripeness, where they float a little while; 
but when thoroughly wetted, sink and take root at the bottom. To prove to ocular demonstration, what is said of this plant, several of them have been put into vessels of water, some of them with stalks so long, that one half of them was above the surface of the water; others with them so short, that they were immersed several inches under it; but in a few hours they had each adapted the length of their stalks to the depth, and the flower of every one was floating just on the surface.

\section{Dionae Muscipula, or Venus's Fly Trap.}

This is a newly discovered sensative plant. Every one skilled in natural history knows, that the mimosæ, or sensative plants, close their leaves, and bend their joints, upon the least touch. This is astonishing; but no end or design of nature has yet appeared from these surprising motions: they soon recover themselves again, and their leaves are expanded as before. But the plant we are now going to describe shews that nature may have some view towards its nourishment, in forming the upper joint of its leaf, like a machine to catch food. Upon the middle of this lies the bait for the unhappy insect that becomes its prey. Many minute red glands, that cover its inner surface, and which, per- 
haps, discharge some sweet liquor, tempt the poor animal to taste them; and the instant these tender plants are irritated by its feet, the two lobes rise up, grasp it fast, lock the two rows of spines together, and squeeze it to death. And further, lest the strong efforts for life, in the creature thus taken, should serve to disengage it, three small erect spines are fixed near the middle of each lobe among the glands, that effectually put an end to all its struggles. Nor do the lobes ever open again, while the dead animal continues there. But it is nevertheless certain, that the plant cannot distinguish between an animal and a mineral substance; for if we in troduce a straw, or a pin, between the lobes, it will grasp it full as fast as if it were an insect. This plant grows in America, in wet shady places, and flowers in July and August. The largest leaves are about three inches long, and an inch and a half across the lobes: the glands of those exposed to the sun are of a beautiful red colour; but those in the shade are pale, and inclining to green. The roots are squamous, sending forth but few fibres, and are perennial. The leaves are numerous, inclining to bend downwards, and are placed in a circular order; they are jointed and succulent; the lower joint, which is a kind of stalk, is flat, longish, two-edged, and inclining to heart-shaped. In some varieties, they, are serrated on the edges near the top. The up. per joint consists of two lobes, each lobe is of 
a semi-oval form, with their margins furnished with stiff hairs, like eye-brows, which embrace or lock in each other when they close: this they do when they are inwardly irritated. The upper surfaces of these lobes are covered with small red glands, each of which appears, when highly magnified, like a compressed arbutus berry. Among the glands, about the middle of each lobe, are three very small erect spines. When the lobes enclose any substance, they never open again while it continues there. If it can be shoved out, so as not to strain the lobes, they expand again; but if force is used to open them, so strong has nature formed the spring of their fibres, that one of the lobes will generally snap off, rather than yield. The stalk is about six inches bigh, round, smooth, and without leaves, ending in a spike of flowers. The flowers are milk-white, and stand on footstalks, at the bottom of which is a little painted bractea, or flower-leaf.

\section{The Datura, or Highwayman's Plant.}

Among the many remarkable plants growing in Egypt, is a kind of night-shade, named Datura, or Tatura, by the common people, which shoots into the ground with a long, thick, and brushy root, of a very unpleasing favour. The stalk being slender, broad, and round, grows to the height of four or five 
cubits, divided into several branches, on which hang dark brown coloured leaves, deeply indented on each side. The blossom is very sweet scented, and pleasant to the eye, beneath small, above broad, and white without and within; followed by a roundish fruit, enclosed in a prickly shell, full of yellowish seeds.

The seeds, eaten, cause a temporary kind of inebriation, and is commonly used by the Egyptian highwaymen to facilitate their robberies. They mix it up with bread, and have a very subtle way of administering it to those they intend to plunder. They insinuate themselves into the company of merchants, following the caravans, and, under pretence of friendship and conducting them safe, they take their repast together, when they contrive to convey these loaves, instead of bread, which on eating, the unsuspecting travellers become strait besotted, and the highwaymen embrace this opportunity of temporary derangement, to plunder them of their gold, silver, and other rich commodities, and generally escape with their booty.

\section{The Paliurus, or Thorn of Christ.}

This shrub, or tree, is a native of Palestine, Spain, Portugal, and Italy. It will grow to nearly the height of fourteen feet, and is armed with sharp thorns, two of which are at each 
joint, one of which is about half an inch long, straight and upright; the other is scarcely half that length, and bent backward; and between them is the bud for the next year's shoot. June is the time of flowering, and the flowers are succeeded by a small fruit, surrounded by a membrane. This plant is undoubtedly the sort, of which the crown of thorns for our blessed Saviour was composed. The branches are very pliant, and the spines of it are at every joint, strong and sharp. It grows naturally about Jerusalem, as well as in many parts of Judea; and there is no doubt that the barbarous Jews would make choice of it for their cruel purpose. But what farther confirms the truth of these thorns being then used, are the ancient pictures of our blessed Saviour's crucifixion. The thorns of the crown on his head exactly answer to those of this tree; and there is great reason to suppose these were taken from the earliest paintings of the Lord of Life; and even now our modern painters copy from them, and represent the crown as composed of these thorns. These plants, therefore, should principally have, a share in those parts of the plantation that are more peculiarly designed for religious retirement; for they will prove excellent monitors, and conduce to due reflection on gratitude to "Him who hath loved us, and has washed us from our sins," \&c. 


\section{The Rose of Jericho.}

The Rose-shrub of Jericho, so called because it grows in the Plain of Jericho, is a small plant, with a bushy root, about an inch and a half in length. It has a number of stems which diverge from the earth; they are covered with few leaves; but it is loaded with flowers, which appear red when in bud, turn paler as they expand, and at length become white entirely. These flowers have a great resemblance to those of the elder tree, with this difference, that they are entirely destitute of smell. The stems never rise more than four or five inches from the ground. This shrub sheds its leaves and its flowers as it withers. Its branches then bend in the mid. dle, and, becoming entwined with each other at the top, form a kind of globe. This happens during the great heats; but during moist and rainy weather, they again open and expand.

In this country of ignorance and superstimtion people do not judge with a philosophical eye, of the alternate opening and shutting of this plant: it appears to them to be a periodical miracle, which heaven operates in order to make known the events of this world. The inhabitants of the neighbouring cantons come and examine these shrubs when they are about to undertake a journey, to form an alliance, to conclude any affair of importance, 
or on the birth of a son. If the stems of the plants are open they do not doubt of success ; but they account it a bad omen to see them shut, and therefore renounce their project, if it be not too late.

This plant is neither subject to rot nor to wither. It will bear to be transplanted; and thrives, without degenerating, in any kind of soil whatever.

\section{The Arundo-Arenaria, or Bent Star.}

This plant grows in most places near the sea, and is known to the islanders by the name of murah: to the English, by that of bent star, mat grass, or marram. Linnæus calls it arundo-arenaria. The Dutch call it halm. This plant hath stiff and sharp-pointed leaves, growing like a rush, a foot and a half long: the roots both creep and penetrate deeply into their sandy beds : the stalk bears an ear five or six inches long, not unlike rye, the seeds are small, brown, and roundish. By good fortune, no cattle will eat or touch this vegetable, allotted for other purposes, subservient to the use of mankind. The late Benjamin Stillingfleet, Esq. recommended the sowing of this plant on the sandy wilds of Norfolk, that its matted roots might prevent the deluges 'of sand which that country experiences. Wheresoever this plant grows the salutary effects are soon observed to follow. 
A single plant will fix the sand, and gather it into a hillock; these hillocks, by the increase of vegetation, are formed in to larger; till by degrees a barrier is made often against the encroachments of the sea, and might often prevent similar calamities, by the growth being encouraged, as appears from the following melancholy instance.

The estate of Coubin, near Fores, was once worth three hundred pounds a year, but at this time is overwhelmed with sand. This strange inundation was still in motion in 1769 , chiefly when a strong wind prevailed. Its motion is so rapid, that we are assured an apple tree has been so covered with it in one season, that only the very summit appeared. This distress was brought on about ninety years ago, and was occasioned by the cutting down some trees, and pulling up the bent or star, which grew on the sand hills: which at last gave rise to an act of parliament to prohibit the destruction of this useful plant. Vide Act 15 George II. c. 33. Providence hath kindly formed this plant to grow only in pure sand. Mankind was left to make, in after times, an application of it suitable to their wants. The sand hills, on a portion of the Flintshire shores, in the parish of Llanasa, are covered with it naturally, and kept frm in their place, and the Dutch perhaps owe the existence of part at least of their country, to the sowing of it on the niobile solum, their sand banks. 


\section{The Virginian Sumach, or Vinegar Plant.}

This plant grows naturally in almost every part of North America. It hath a woody stem, with many irregular branches, which are generally crooked and deformed. The young branches are covered with a soft, velvet-like down, resembling greatly that of a young stag's horn, both in colour and texture, from whence the common people have given it the name of stag's-horn. The leaves are winged, composed of six or seven pair of oblong, heart-shaped lobes, terminated by an odd one, ending in acute points, hairy on their under side, as is also their midrib. The flowers are produced in close tufts at the end of the branches, and are succeeded by seeds, enclosed in purple, woolly, succulent covers; so that the bunches are of a beautiful purple colour in autumn; and the leaves, before they fall in autumn, change to a purplish colour at first, and before they fall to a feuillemort. This plant, originally a native of North America, has been long cultivated in the North of Germany, and is lately introduced into Russia. It has got the name of the vinegar plant, from the double reason of the young germin of its fruit, when fermented, producing either new or adding to the strength of old weak vinegar, whilst its ripe berries afford an agreeable acid, which might supply the place, 
when necessary, of the citric acid. The powerful astringency of this plant, in all its parts, recommends it as useful in several of the arts. As for example. The ripe berries, bojled with alum, make a good dye for hats. The plant in all its parts may be used as a succedaneum for oak bark in tan. ning, especially the white glove-leather. It will likewise answer to prepare a dye for black, green, and yellow colours; and with martial vitriol it makes a good ink. The milky juice that flows from incisions made in the trunk or branches, makes, when diried, the basis of a varnish, little inferior to the Chinese. Bees are remarkably fond of its flowers; and it affords more honey than any of the flowering shrubs, so that it may prove a useful branch of economy, where rearing these insects is an object. The natives of America use the dried leaves as tobacco.

\section{The Palma Christi, or Castor-oil Plant.}

This plant is a native of America, and of such speedy growth, that in one year it arrives at its full height, which seldom exceeds twenty feet. 'The trunk is subligineous; the pith is large; the leaves broad and palmated; the flower-spike is simple, and thickly set with yellow blossoms, in the shape of a cone; the capsules are triangular and prickly, con- 
taining three smooth, gray, mottled seeds. When the bunches begin to turn black, they are gathered, dried in the sun, and the seeds picked out. They are afterwards put up for use, as wanted, or for exportation.

Castor oil is obtained either by expression or by decoction. The first method is practised in England: the latter in Jamaica. It is common first to parch the nuts or seeds in an iron pot over the fire; but this gives the oil an empyreumatic taste, smell and colour, and it is best prepared in the following manner: A large iron pot or boiler is first made ready, and half filled with water. The nuts are then beaten, in parcels, in deep wooden mortars, and after a quantity is beaten it is thrown into the iron vessel. The fire is then lighted, and the liquor is gently boiled for two hours, and kept constantly stirred. About this time the oil begins to separate, and swims on the top, mixed with a white froth, and is skimmed off till no mure rises. The skimmings are heated in a small iron pot, and strained through a cloth. When cold, it is put up in jars, or bottles, for use.

Castor oil, thus made, is clear and well flavoured, and, if put into proper bottles, will keep sweet for years. The expressed castor oil soon turns rancid, because the mucilagi.* nous and acrid parts of the nut are squeezed out with the oil. On this account the preference is given to well-prepared oil by decoc- 
tion. An English gallon of the seeds yields about two pounds of oil, which is a great proportion.

Before the disturbances in America, the planters imported train oil for lamps and other purposes about sugar works. It is, however, now found, that the castor oil can be procured as cheap as the fish oil of America; and it burns clearer, and has not any offensive smell. This oil, too, is fit for all the purposes of the painter, or for the apothecary, in ointments and plasters, and as a medicine for many internal complaints it is highly valuable, and used with remarkable success. All oils are noxious to insects, but the castor oil kills and expels them, almost immediately.

SINGULAR PROPERTIES OF

\section{The Mimosa, or Sensative Plant.}

The Sensative Plants are well known to possess a kind of motion, by which the leaves and stalks are contracted and fall down upon being slightly touched, or shaken with some degree of violence.

The contraction of the leaves and branches of the Sensative plant, when touched, is a very singular phenomenon. Different hypotheses have been formed by botanists in order to explain it; but we are disposed to believe, that these have generally been deduced, rather 
from analogical reasoning, than from a collec; tion of facts and observations. We shall therefore give an account of all the important facts which we have been able to collect upon this curious subject; and then draw such conclusions as obviously result from ther, without, however, attempting to support any old, or to establish a new hypothesis.

1st. It is difficult to touch the leaf of a healthy sensative plant so delicately that it will not imnediately collapse, the foliola, or little leaves, moving at their base, till they come in contact, and then applying themselves, close together. If the leaf be touched with a little more force, the opposite leaf will exhibit the same appearance. If a little more force be applied, the partial footstalks bend down towards the common footstalk, from which they issue, making with it a more acute angle than before. If the touch be more violent still, all the leaves situated on the same side with the one that has been touched, will instantly collapse, and the partial footstalk will approach the common footstalk to which it is attached, in the same manner as the partial footstalk of the leaf ap. proaches the stem or branch from which it issues; so that the whole plant, from having its branches extended, will immediately appear like a weeping birch.

2. These motions of the plants are formed by means of three distinct and sensible articulations. The first, that of the foliola or lobes 
to the partial footstalk; the second, that of the partial footstalk to the common one; the third, that of the common footstalk to the trunk. The primary motion of all which is the closing of the leaf upon the partial footstalk, which is performed in a similar manner, and by a similar articulation. This, however, is much less visible than the others. These motions are wholly independent of one another, as may be proved by experiment. It appears, that if the partial footstalks are moved, and collapse towards the petioli, or these towards the trunk, the little leaves, whose motion is usually primary to these, should be affected also; yet experiment proves that it is possible to touch the footstalks in such a manner as to affect them only, and make them apply themselves to the trunk, while the leaves feel nothing of the touch; but this cannot be, unless the footstalks are so disposed, as that they can fall to the trunk, without suffering their leaves to touch any part of the plant in their passage, because, if they do, they are immediately affected.

3. Winds and heavy rains make the leaves of the sensative plant contract and close; but no such effect is produced from slight showers.

4. At night, or when exposed to much cold in the day, the leaves meet and close in the same manner as when touched, folding their upper surfaces together, and, in part, over each other, like scales or tiles, se as to expose as little as possible of the upper sur- 
face to the air. The opposite sides of the leaves (foliola) do not come close together in the night; for, when touched, they apply themselves closer together. Dr. Darwin kept a sensative plant in a dark place for some hours after day-break; the leaves and footstalks were collapsed as in its most profound sleep; and, on exposing it to the light, above twenty minutes passed before it was ex pauded.

5. In the month of August, a sensative plant was carried in a pot, out of its usual place, into a dark cave: the motion that it received in the carriage shut up its leaves, and they did not open till twenty-four hours afterwards; at this time they became moderately open; but were afterwards subject to no changes at night or morning, but remained three days and nights with their leaves in the same moderately open state. At the end of this time they were brought out again into the air, and there recovered their natural periodical motions, shutting every night, and opening every morning, as naturally and as strongly, as if the plant had not been in this forced state, and while in the cave, it was observed to be very little less affected with the touch, than when abroad in the open air.

6. The grest heats of summer, when there is open sunshine at noon, affect the plant, in some degree, like cold, causing it to shut up its leaves a little; but never in any very great degree. The plant, however, is least of all affected about nine o'clock in the morning, and 
that is consequently the properest time to make experiments on it. A branch of the sensative plant, cut off, and laid by, retains yet its property of shutting up, and opening in the morning, for some days; and it holds it longer if kept with one end in water, than if left to dry more suddenly.

7. The leaves only of the sensative plant shut up in the night, not the branches; and if it be touched at this time, the branches are affected in the same manner as in the day, shutting up, or approaching to the stalk of the trunk, in the same manner, and often with more force. It is of no consequence what the substance is with which the plant is touched, it answers alike to all; but there may be observed a little spot, distinguishable by its paler colour, in the articulations of its leaves, where the greatest and nicest sensibility is evidently placed.

8. Duhamel having observed, about the 15 th of September, in moderate weather, the natural motion of a branch of the sensative plant, remarked, that, at nine in the morning, it formed with the stem an angle of 100 degrees; at noon, 112 degrees; at three in the afternoon, it returned to 100 , and after touching the branch, the angle was reduced to 90 . Three quarters of an hour after, it had mounted to 112 ; and, at eight at night, it descended again, without being touched, to 90 . The day after, in finer weather, the same branch, at eight in the morning, made an angle of 135 
degrees with the stem; after being touched, the angle was diminished to 80 ; an hour after, it rose again to 135 ; being touched a second time, it descended again to 80 ; an hour and a half after, it had risen to 145 ; and upon being touched a third time, it descended to 135 , and remained in that position till five o'clock in the afternoon, when, being touched 2 fourth time, it fell to 110 .

9. The parts of the plant which have collapsed afterwards unfold themselves, and return to their former expanded state. The time required for that purpose varies, according to the vigour of the plant, the season of the year, the hour of the day, the state of the atmosphere. Sometimes half an hour is requisite, sometimes only ten minutes. 'The order in which the parts recover themselves varies in like manner; sometimes it is the common footstalk, sometimes the rib to which the leaves are attached, and sometimes the leaves themselves are expanded, before the other parts have made any attempt to be reinstated in their former position.

10. If, without shaking the other smaller leaves, we cut off half of a leaf, or lobe, belonging to the last pair, at the extremity, or summit, of a wing, the leaf cut, and its antagonist, that is to say, the first pair, begin to approach each other; then the second, and so on successively, till the lesser leaves, or lobes of that wing, have collapsed in like manner. Frequently, after twelve or fifteen 
seconds, the lobes of the other wings, which were not immediately affected by the stroke, shut; whilst the stalk, and its wing, beginning at the bottom, and proceeding in order to the top, gradually recover themselves. If, instead of one of the lesser extreme leaves, we cut off one belonging to the pair that is next the footstalk, its antagonist shuts, as do the other pairs successively, from the bottom to the top. If all the leaves of one side of a wing be cut off, the opposite leaves are not affected, but remain expanded. With some address, it is possible even to cut off a branch without hurting the leaves, or making them fall. The common footstalk of the winged leaves being cut as far as three-fourths of its diameter, all the parts which hang down collapse, but quickly recover, without appearing to have suffered any considerable violence by the shock. An incision being made into one of the principal branches, to the depth of onehalf the diameter, the branches situated betwixt the section and the root will fall down; those above the incision remain as before, and the lesser leaves continue open: but this direction is soon destroyed, by cutting off one of the lobes at the extremity, as was observed above. Lastly, a whole wing being cut off with precaution, near its insertion into the common footstalk, the other wings are not affected by it, and its own lobes do not shut. No motion ensues from piercing the branch with a needle, or other sharp instrument. 
11. If the end of one of the leaves be burned with the flame of a candle, or by a burning glass, or by touching it with hot iron, it closes up in a moment, and the opposite leat does the same; and, after that, the whole series of leaves on each side of the partial, or little footstalk; then the footstalk itself; then the branch, or common footstalk; all do the same, if the burning has been in a sufficient degree. This proves that there is a very nice communication between all the parts of the plant, by means of which the burning, which only is applied to the extremity of one leaf, diffuses its influence through every part of the shrub. If a drop of aquafortis be carefully laid upon a leaf of the sensative plant, so as not to shake it in the least, the leaf does not begin to move till the acrid liquor corrodes the substance of it; but at that time, not only that particular leaf, but all the leaves placed on the same footstalk, close themselves up. The vapour of burning sulphur has also this effect on many leaves at unce, according as they are more or less exposed to it; but a bottle of very acrid and sulphureous spirit of vitriol, placed under the branches, unstopped, produces no such effect. Wetting the leaves with spirit of wine has been observed also to have no effect, nor the rubbing oil of almonds over them; though this last application destroys many plants.

From the preceding experiments the following conclusions may be fairly drawn: 
First. The contraction of the parts of the sensative plant is occasioned by an external force, and the contraction is in proportion to the force. Secondly. All bodies which can exert any force affect the sensative plant; some by the touch, or by agitation, as the wind, rain, \&c. some by chemical influence, as heat and cold. Thirdly. Touching, or agitating the plant produces a greater effect, than an incision or cutting off a part, or by applying heat or cold.

To explain these curious phenomena, many celebrated naturalists, have undertaken, and written largely on the subject.

\section{The Nuayhas, or Ague Tree.}

This name is given by the Indians to a sort of Bamboo cane, the leaves of which falling into the water, are said to impregnate it with such virtue, that the bathing in it afterwards will cure the ague. They use also a decoction of the leaves to dissolve coagulated blood, giving it internally, and, at the same time rubbing the briised part externally with it. It is said, that this plant bears its flowers only once in its life; that it lives sixty years before those make their appearance; but that when they brgin to shew themselves, it withers away in about a month afterwards, that is, as soon as it has ripened the seed. The length of the stalks, or trunk, are very 
great, for in the gallery of Leyden there is preserved a cane of it twenty-eight feet long; and another, not much shorter, in the Ashmolean Museum, at Oxford, and which is more than eight inches in diameter; yet both these appear to be only parts of the whole trunk, they being nearly as large at one end as at the other.

\section{The Lotus, or Egyptian Water-Lily.}

This plant has heart-shaped, toothed leaves, and peculiar to Egypt. When the river Nile is become full, and all the grounds round it are a perfect sea, there grows a vast number of lilies, in the water, which the Egyptians call lotus, After they have cut them, they dry them in the sun; then, having parched the seed within the lotus, which is most like the poppy, they make bread of it, baking it with fire. The root also of the lotus is eatable, easily becoming sweet, being round, and of the size of an apple. There are two sorts, or varieties, of this plant, growing in the rivulets, and on the sides of the lakes, the one with a white, the other with a bluish, flower. The calyx blows like a large tulip, and diffuses a sweet smell, resembling that of the lily. The first species produces a round root, like that of a potatoe, and the inhabitants of the lake Menzall feed upon it. The. rivulets in the environs of Damietta are 
covered with this majestic flower, which rises upwards of two feet above the water.

\section{The Nelumbo, or Ceylon Lily.}

In the East and West Indies, grows a species of the lily, named by the inhabitants of Ceylon, Nelumbo. The leaves which rest upon the surface of the water are smooth, undivided, perfectly round, thick, target-shaped, and about one foot and a half in diameter. The footstalk of the leaves is prickly, and inserted, not into their base, or margin, as in most plants, but in the centre of the lower disk, or surface. From this centre, upon the upper surface, issue, like rays, a great number of large ribs, or nerves, which towards the circumference, are divided and subdivided into a small number of very minute parts. The flowers are large, flesh-coloured, and consist of numerous petals, disposed, as in the other species of water-lily, in two or more rows. The seed-vessel is shaped like a top, being broad and circular above, narrow and almost pointed below. It is divided into several distinct cells, which form so many large round holes, upon the surface of the fruit, each containing a single seed. With the flower of this plant, which is sacred among the heathens, they adorn the altars of their temples, they paint their gods sitting upon it, and make use of such pictures to 
animate the minds of the pious on their deathbed, and to raise their affections to heaven. The stalks, which are used as a pot-herb, are of wonderful length. The root is very leng, extends itself transversely, is of the thickness of a man's arm, jointed and fibrous, with long intervals between the joints, and the fibres surround the joints in verlicilli, or whirls.

\section{The Lien-hoa, or Chinese Lily.}

The Lien-hoa is highly extolled in China, for its excellent virtues, and ranked, by their physicians, among those plants which are employed in the composition of the liquor of immortality. The seeds are there eaten as we eat filberds in Europe: they are more delicate when green, but harder of digestion. They are preserved in many different ways, with sugar. 'The root of this plant is also admitted by the Chinese to their tables. In whatever manner it be prepared, it is equaliy wholesome. Great quantities of it are pickled with salt and vinegar, which they reserve to eat with their rice. When reduced to powder, it makes excellent soup, with water and milk. The leaves of this plant are much used for wrapping up fruits, fish, salt, provisions, \&c. When dry, the Chinese mix them with their smoaking tobacco, to render it softer and milder. It is to this hour held in great veneration by the Hindoos and Egyptians. 


\section{The Papaver Album, or White Poppy.}

Opium is the juice of the White Poppy, with which the fields of Asia Minor are in many places sown, as ours are with corn. When the heads are ripening, they wound them with an instrument that has five edges, which, on being struck into the head, makes at once five long cuts in it; and from these wounds the opium flows, and is next day taken off by a person who goes round the tield, and put up in a vessel, which he carries, fastened to his girdle. At the same time that this opium is collected, the opposite side of the poppy-head is wounded, and the opium collected from it the next day. They distinguish, however, the produce of the first wounds from that of the succeeding ones; for the first juice afforded by the plant is greatly superior to what is obtained afterwards. After they have collected the opium, they moisten it with a small quantity of water, or honey, and work it a long time upon a flat, hard, and smooth board, with a thick and strong instrument of the same wood, till it becomes of the consistence of pitch; and then work it up with their hands, and form it into cakes, or rolls, for sale. Opium is at present in great esteem, and is one of the most valuable of all the simple medicines.

The best opium in the world is said to come from Patna, on the river Ganges, where 
at least the greatest traffic of it is made, and from whence it is exponted all over India: though in some parts, especially on the $\mathrm{Ma}$ lay coasts, it is prohibited under pain of death, on account of the madness, and murders consequent upon the madness, which are occasioned by it; notwithstanding which severe prohibition, however, it is plentifully smuggled into all those countries. The soil about the Ganges is accounted best for producing the strongest kind of opium ; of which the following remarkable instance is related. "A nabob of these parts, having invited an English factory to an entertainment, a young gentleman. a writer in the Company's service, sauntering about the garden, plucked a poppy, and sucked the head of it. In consequence of this he fell into a profound sleep, of which the nabob being apprised, and likewise informed of the particular bed out of which he had taken the flower, expressed his sorrow; acquainting his friends at the same time, that the poison was too strong to admit of any remedy; which accordingly proved true, and the unfortunate gentleman never awaked.',

\section{The Urceola Elastica, or Indian Rubber Plant.}

This plant is a native of Sumatra, Prince of Wales's Island, \&c. in the Malay Coun. 
rries. The stem is woody, climbing over trees, \&c. to a very great extent. The wood is white, light, and porous. The leaves opposite, and flowers numerous, minute, of a dull greenish colour, and hairy on the outside.

From wounds made in the bark of this plant, there oózes out a milky fluid, which, on exposure to the open air, separates into an elastic coagulum, and watery liquid, apparently of no use after the separation takes place. This coagulum is not only like the American caoutchouc, or Indian rubber, but possesses the same properties.

The chemical properties of this vegetable milk, while fresh, were found by Mr. Hewison, late surgeon on the Prince of Wales's Island, surprisingly to resemble those of animal milk. From its decomposition, in consequence of spontaneous fermentation, or by the addition of acids, a separation takes place between its caseous and serous parts, both of which are very similar to those produced by the samr; processes from animal milk. An oily, butyrous matter is also one of its component parts, which appears on the surface of the gum, so soon as the latter has attained its solid form. He endeavoured to form an extract of this milk so as to approach to the consistence of new butter, by which he hoped to retard its fermentative stage, without depriving it of its useful qualities; but as he had no apparatus for distilling, the surface of the milk, that was exposed to the air, in- 
stantly formed into a solid coat, by which the evaporation was, in a great degree, prevented. He, however, learned, by collecting the thickened milk from the inside of the coats, and depositing it in a jelly pot, that, if excluded from the air, it might be preserved in this state for a considerable length of time; and, even without any preparation, be kipt in bottles, tolerably good, upwards of tweive months.

\section{The Tabacum, or Conmon Tobacco Plant.}

This plant was first discovered in America, by the Spaniards, about the year 1.600 , and by them imported into Europe. It had been used by the inhabitants of A merica long be. fore; and was called, by those of the islands, yoli, and pretux, by the inhabitants of the continent. It was sent into Spain from $T a-$ baco, a province of Yucatan, where it was first discovered, and from whence it takes its common name. Sir Walter Raleigh is generally said to have been the first that introvived it in England, about the year 1585, and who taught his countrymen how to smoke it, of whom we shall presently relate an anecdote, which, we trust, may not be unacceptable to our readers:

There are two species of this plant, which are cultivated for common use, and which are 
distinguished by the names of Oronokoe, and sweet scented tobacco. They differ from each other only in the figure of their leaves: those of the former being longer and narrower than the latter. They are tall herbaceous plants, growing erect, with fine foliage, and rising, with a strong stem, from six to nine feet high. The stalk, near the root, is upwards of an inch diameter, and surrounded with a kind of hairy, or velvet, clammy substance, of a yellowish green colour. The leaves are rather of a deeper green, and grow alternately at the distance of two or three inches from each other. They are oblong, of a spear-shaped oval, and simple; the largest about twenty inches loug, but decreasing in size as they ascend, till they come to be only ten inches long, and about half as broad. 'The face of the leaves is much corrugated, like those of spinage, when full ripe. Before they come to maturity, when they are about five or six inches long, the leaves are generally of a full green, and rather smooth; but as they increase in size, they become rougher, and acquire a yellowish cast. The stem and branches are terminated by large bunches of flowers, col. lected into clusters of a delicate red; the edges, when fill blown, inclining to a pale purple. They continue in succession till the end of the summer, when they are succeeded by seeds of a brown colour, and kidney-sbaped. These are very small, each capsule containing about one thousand: and the whole produce 
of a single plant is reckoned at about three hundred and fifty thousand.

Tobacco is an annual plant, and those who intend to cultivate it ought to be as careful as possible in the choice of the seeds; in which, however, with all their care, they may bc sometimes deceived. The seeds are to be sown about the middle of April, or rather sooner, in a forward season, in a warm, kindly, rich soil, that is not subject to be over-run with weeds. The southern declivity of a hill, or a spot sheltered from the north winds, is the best for tobacco; but, at the same time, the plánts must enjoy a free air ; for without that they will not prosper.

A mong all the productions of foreign climes, introduced into these kingdoms, scarce any has been held in higher estimation, by persons of every rank, than tobacco. In the countries of which it is a native, it is considered by the Indians as the most valuable offering that can be made to the beings they worship. They use it in all their civil and religious cerenionies. When once the spiral wreaths of its smoke ascend from the feathered pipe of peace, the compact that has been just made, is considered as sacred and inviolable. Likewise, when they address their great Father, or his guardian spirits, residing, as they believe, in every extraordinary production of nature, they make liberal offerings to them of this valuable plant, not doubting but that they are thus secured of protection, 
Tobacco is made up into rolls by the inhabitants of the interior parts of America, by means of a machine, called a tobacco wheel. With this machine they spin the leaves, after they are cured, into a twist of any size they thinis fit; and having folded it into rolls, of about twenty pounds each, they lay it by for use. In this state it will keep for several years, and be continually improving, as it always grows milder. The Illinois usually form it into carrots; which is done by laying a number of leaves, when cured, on each other, after the ribs have been taken out, and rolling them round with pack-thread, till they become cemented together. These rolls commonly measure about eighteen or twenty inches in length, and nine round, in the middle part.

Tobacco-smoaking was introduced (as we before observed) in to this country, in the reign of Queen Elizabeth. Sir Walter Raleigh, having imitated the Indians, in smoaking this plant, at length so much delighted in it, that he was unwilling to disuse it, on his return to England, and therefore supplied himself with several hogsheads, which he placed in his own study, and generally indulged himself with smoaking secretly two or three pipes a day. He had a simple fellow, who waited at his study door, to bring him up daily a tankaid of old ale and nutmeg, and he always. laid aside his pipe when he heard this man approaching.- One day, being earnestly en. o 2 
gaged in reading some bouk which amused. him, the fellow abruptly entered, and, surprised at seeing his master enveloped in smoke, (a sight perfectly new to him) the smoke ascending in thick vapours from his mouth and the bowl of the tobacco-pipe, immediatély threw the ale in his master's face, and ran down stairs, and alarmed the family with repeated exclamations, that his master was on fire in the inside, and that if they did not make haste, before they could get up stairs, his master would be burned to ashes.

\section{The Drossera Anglicana, or Sundew.}

This is a very minute, villous plant, usually growing, entangled with moss, on peat bogs; the leaves are curiously fringed with numerous strong, reddish hairs, terminated by small pelucid globules of viscous liquor, which occasion, by the reflection of the sun, that peculiar lustre, from which its name is derived. It is in these hairs that the essential properties of the plant reside; for, if a small insect should fix itself on one of the leaves, these hairs immediately begin to close, one by cne, till the insect is wholly environed by them, and then the leaf in which it is imprisoned, gradually bends inwards, so as to reach the base. In this state the insect is killed by the operation of the acrimonious juice exuding from the ends of the hairs. 
An eminent naturalist mentions the effects of this singular plant, occasioned by the irritation of an ant, which he placed on the centre of one of the leaves, with a pair of pincers. The ant, in endeavouring to escape, was held fast by the viscous juice of the smaller hairs, till the large ones, together with the edges of the leaf, closed in, and imprisoned it. The ant died in fifteen mimutrs ; but this gentleman observes, that the effects followed sooner or later, in different experiments, according to the state of the weather.

\section{The Herica, or Wild Heath.}

This plant is common on lofty barren hills, and though little regarded, miǵht be made to serve many valuable purposes. In the Highlands of Scotland the poor inhabitants make walls for their cottages with alternate layers of heath, and a kind of mortar, made of black earth and straw. They also make beds of it; and their houses are thatched with it. In the Isle of Ilay, ale is made by brewing one part of malt, and two parts of the young tops of heath. Woollen cloth, boiled in alum water, and then in a strong decoction of the tops of heath, comes out a fine orange colour. The stalks and tops will tan leather. Bees extract great quantities of honey from the flowers, which are very beautiful. 


\section{Yorkshire Saniele, or Butterwort.}

If the fresh-gathered leaves of this plant, which grows on boggy land, are put into a strainer, through which warm nilk from the cow is poured, and the milk is set by for a day or two to become accessant, it acquires a consistence and tenacity; the whey does not separate, nor does the cream. In which state it is an extremely grateiul food, and used as such by the inbabitants of Sweden. Half a spoonful of this prepared milk, mixed with fresh warm milk, will convert it to its nature; and this again will change another quantity of fresh milk, and so on ad infinitum. The juice of the leaves is also made great use of by the common people, for destroying vermin in sheep and other animals.

\section{The Trientalis, or Common Chick-ueed.}

This pretty plant is very common in fields, and under hedges. The stalk is single, five or six inches high, and is teminated with five, six, or seven, oval pointed leaves; from the centre of which arise, on long tootstalks, commonly two white starry flowers, each generally consistrig of seven oval and equal petals, and succeeded by a globular, dry berry, covered with a thin, white rind, having one cell, and containing several angular seeds. 
GROMWELL.T-THE WILD PINE. 159

This beantiful plant, the Reverend Dr. Shaw remarks, is an excellent out-of-door barometer. "When the flower (says the Doctor) expands boldly and fully, no rain will happen for lour hours, or upwards; if it continues in that open state, no rain will disturb the summer's day: when it half conceals its miniature flower, the day is generally showery; but if it entirely shuts up, or veils the white flower with its green mantle, let the traveller put on his great coat, and the ploughman, with his beasts of draught, rest from their labour."

\section{Gromwell, or Bastard Alkanet.}

This plant is common in corn fields. The girls in the northern parts of Europe paint their faces with the juice of this root on days of public festivity. The seeds are as hard as bone, and effervesce with acids. The bark of the root tinges wax and oil of a beautiful red, similar to that which is attained from the root of the foreign alkanet sold in the shops.

\section{The Wild Pine.}

This curious plant is a native of Jamaica, and is so contrived, by the great Author of nature; as to be of the greatest use to the inhabitants of that hot climate, where there is 
a scarcity of water; for its leaves are chanm nelled, so as to catch aud convey water down into their reservatories, which reservatories are so made as to hold much water, and to close at top, when full, to hinder its evaporation. And in scarcity of water these reservatories are not only sufficient for the plants themselves, but likewise are very useful to men, birds, and insects, which come in troops to them, and seldom go away without refreshment. Dampier, in his Voyage, says, "The wild pine is a plant so called, because it somewhat resembles the bush that bears the pine; they are commonly supported, or grow from some bunch, knot, or excrescence of the tree, where they take root, and grow upright. The root is short and thick, from whence the leaves rise up in folds, one within another, spreading oft to the top. They are of a good thick substance, ten or twelve inches long; the outside leaves are so compact as to contain the rain water, as it falls; they will hold a pint and a half, or a quart, and this water refreshes the leaves, and nourishes the root. When we find these pines (says our traveller) we stick our knives into the leaves, just above the roots, and that lets out the water, which we catch in our hats, as I have done many limes, to my great relief."

One contrivance of nature in this vegetable is very admirable. The seed has lorg, and many threads of tomentum, not only that it. may be carried every where by the wind, but 
also, that it may, by those threads, when driven through the bonghs, be held fist, and stick to the arus, and extaut parts of trees. So soon as it smouts, althouge it be on the under part of a bough, its leaves and stalk rise perpendiculariy, or straight up; because, if it had any other position, the cistern, or reservatory (before mentioned, by which it is chindy iscurished) made of the hollow leaves, could not hold water, which is necessary for the nourishment, and life of the plant. Many lives, in dearth of water, are preserved by means of this plant.

\section{The Water With.}

The Water With is also a native of Jamaica. It hath a trunk as thick as a man's leg, and in most respects, resembles the common vine. But what renders it remarkable is, that growing on dry hills, in the woods, where no water is to be found, its trunk, if cut in pieces, two or three yards long, and held by either end to the mouth, affords so plentifully a limpid, innocent water, or sap, as gives new life to the droughty traveller, or hunter. For these valuable properties, it is very much célebrated by the inhabitants of the island.

A similar plant, discovered in the woods of Amboyna, is thus described by a celebrated traveller. "I saw, in the woods of this island, a plant, or tree, in substance much 
like to the body of our wy-bare, without sprig or.sprout; the one end fast in the ground, the other fixed to the limb of a great tree. This rope is of firm, solid wood, without any concavity, and yet yieldeth excellent, good, fair, and sweet water, and as fresh as from the fountain; nor doth it herein admit of any distinction or difference, unless that it is more delicate: According to your companies, cut more or less thereof, distributing to every one the quantity of two foot, or thereabouts, and they will have sufficient; for every piece will run to the value of a pint, or nearly, and that in an instant, affording an admirable refreshment to thuse that rravel those high and dry mountains, as myself did find by good experience.

\section{The Myrica Cerifera, or Candlebury Bush.}

In a wet soil, and in the neigbbourhood of the sea, in Pennsylvania, this bush, or tree, thrives remarkably well. The berries grow abundantly on the female shrub, and look as if flour had been strewed upon them. They are gathered late in Autumn, being ripe about that time, and are thrown into a kette, or pot, full of boiling water; by this means their fat melts out, floats on the top of the water, and may be skimmed off into a vessel; which is repeated till there is no tallow left. The 
tallow, as soon as it is congealed, looks like common tallow, or wax, but has a dirty green colour. This tallow is dearer than common tallow, but cheaper than wax. In Philadelphia they pay a shilling, Pennsylvania currency, for a pound of this tallow. From this tallow, they make candles, in many parts of the province, but they usually mix common tallow with it. Candles of this kind do not easily bend, nor melt in summer, as common candles do; they burn better and slower, nor do they cause any smoke, but rather yield an agree. able smell, when they are extinguished. From the wax of this plant, they likewise make a soap, which has an agreeable scent, and is good for shaving, \&c. The wax is likewise used by surgeons and apothecaries, who reckon it exceedingly good for plasters, for many kinds of wounds. The root of the candlebury shrub was formerly made use of by the Indians as a remedy against the toothache; others have been relieved from this pain by applying the peel of the root to the part affected. In Carolina, they not only make candles out of the wax of the berries, but likewise sealing-wax.

\section{The Diica-patustris, or Leatlier Wood Shrub.}

This is a little shrub, which grows on the rising ground, adjoining to the swamps and 
marshes in New Jersey, America. The En. glish call it leather-wood, because its bark is as tough as leather. The French call it bois de plomb, or leaden-wood, because the wood itself is soft and as tough as lead. The bark' of this shrub they make use of for ropes, baskets, \&c. And it is very fit for that purpose, on account of its remarkable strength and toughness, which is equal to that of the limetree bark. The English and the Dutch, in many parts of North America, and the French, in Canada, employ this bark in all cases where we make use of lime-tree bark in Europe. The shrub itself is very tough, and the branches cannot be easily separated, without the help of a knife. Many people make use of the twigs of this useful shrub for fishingrods, \&c.

\section{The Asclepias Syriaca; or C'otton Plant.}

The French call this curious and useful plant le cotonier. It grows abundant in $\mathrm{Ca}$ nada, and other parts of America, on the sides of hills, which lie near rivers, and other situations, as well in dry and open places, as in a rich and loose soil. When the stalk is cut or broken, it emits a lactescent juice, ard for this reason the plant is reckoned in some. degree poisonous. The French in Canada, nevertheless, use its tender shoots in spring, 
preparing them like asparagus; and the use of them is not attended with any bad consequence, as the slender shoots have not yet had time to suck up any thing poisonous. Its flowers are very odoriferous, and, when in season, they fill the woods with their fragrant exhalations, and make it very agreeable travelling through them, especially in the evening. The French, in Canada, make a sugar of the flowers; which, for that purpose, are gathered in the morning, when they are covered all over with dew. This dew is expressed, and by boiling yields a very good brown, palatable, sugar. The pods of this plant, when ripe, contain a kind of wool, which incloses the seed, and resembles cotton, from whence it has got its French name. The poor collect it, and fill their beds with it, especially their children's, instead of feathers. This plant flowers in Canada at the end of June and beginning of July, and the seeds are ripe in the middle of September.

\section{The Rhus Radicans, or Ink Shrub.}

In many parts of America, this shrub grows abundantly, and, like the Ivy with us, has the property of not growing without the support of a tree, wall, or hedge. It frequently reaches the very top of high trees in the woods, and its branches shoot out every where little roots, which fasten upon the tree, 
and, as it were, enter into it. When the stem is cut, it emits a pale brown sap, of a disgreeable scent. This sap is so sharp, that the letters and characters made upon linen - with it, cannot be got out again, but grow blacker the more the cloth is washed. Boys commonly mark their names on their linen with this juice, and if paper is written on with it, the letters never go out, but grow blacker from time to time.

\section{The Kalmai Augusti Folia, or Dwarf Laurel.}

This beautiful little shrub, or tree, is found in great plenty on the sandy heaths and poor grounds in Pennsylvania, and other parts of America, where few other plants grow. Its leaves are green all the winter, and the flowers, which are a real ornament to the woods, grow in bunches, like crowns, and are of a fine lively purple colour; at the bottom is a circle of deep purple, and within it a greyish or whitish colour. These flowers grow as before mentioned, in bunches, round the extremity of the stalk, and make it look like a decorated pyramid. It has little or no smell, and its good properties are hitherto undiscovered. It kills sheep and lesser animals, when they eat of it plentifully, and appears, at present, to be of no other use, than to gratify the traveller's sense of seeing, in traversing these sandy heaths, and dreary parts of the country. 


\section{The Pepper Plant.}

The chief sorts of pepper are two, the one round, and the other long. The round pep. per grows chiefly in some of the Molucco islands, as Java and Sumatra, shooting up high, and is supported as hops are in Europe. The outside of the leaves is of a deep, but the inside of a more pale, green colour. The fruit hangs like currants, only the branches are much bigger and longer. 'The berries, or pepper-corns, are at first green, but grow black of colour, as they grow ripe, which is in the summer months. The berries are gathered and dried in the sun, which makes the outward shell so shrivelled. But when this black shell is taken off, before it is dried in the sun, it makes another sort of pepper, called white pepper, which is sharper, and also pleasanter of taste, than the black, and often used in India, by persons of quality, instead of salt, with their meat. The peeling of this outward black skin is done when the pepper is over ripe, and after it has been steeped in salt water; for, by this infusion the outward skin aforesaid, swells, so that the white pepper corns within may be taken out with little or no trouble, which are afterwards dried again in the sun. Not only the berrics, which are properly called pepper, have a fiery, hot tiste, but also the leaves, and the whole growth, have the same virtue. 
Besides these plants just mentioned, there grows in India a sort of long pepper, called, by the Indians, pimpilim, which is never used about meats, but only in medicine, especially in treacle, and other antidotes against poison; and this appears to be done not without great reason, in consequence of its very great strength, which single quality makes it sell at a dearer rate than the other. This pepper grows in great abundance at Bengal, and is transported from thence into Europe. 'In shape (except the fruit) this plant is like unto that of the round pepper, only it creeps along upon the ground, or runs up against lower poles than those of the other pepper. The leaves of it are also more tender than the other, are of a darker green, and have longer stalks.

\section{The Cannabis Sativa, or Manured Hemp.}

This plant is always sown in a deep, moist, rich soil, such as is found in Holland, Lincolnshire, and the fens of the Isle of Ely, where it is cultivated to great advantage. It has a single, white, woody, fibrous root, with a square, hairy stalk, rough to the touch, and hollow within. It grows two yards high, and has a rind that may be divided into threads. The valuable properties of this useful plant are thus described by an elegant writer. 
66 Europe produces a little plant, whose fruit is an excellent nourishment to several sorts of birds. It affords a kind of bread, good to fatten large cattle, and produces an oil that illuminates innumerable families in the night. The European women generally work off the bark of this plant into those spreading sails, by the aid of which our ships transport their merchandize to the remotest parts of the world, and convey to us whatever we want. The same bark is worked into cables, strong enough to bear the weight and force of anchors. Ropes, packthread, girths, \&c. are likewise made of its materials. And all these are of constant use in navigation, conımerce, husbandry, and domestic affairs. With this very bark, houses are made to shelter our soldiers. It affords us the finest ornaments for our tables, and we form it into a dress, which accommodates us day and night, is perfectly neat and convenient, and contributes as much to the health of our bodies, as the bath to which it now succeeds, and from the trouble and preparation of which, it entirely discharges us. In a word, this bark, according to the different forms given it by Europeans, becomes the most ornamental habit of kings, and furnishes the husbaudman and shephrard with a decent attire, at a very inconsiderable expence. These are the benefits we receive from this valuable plant."

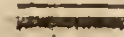




\section{The Zea, (Maize) or Indian Corn.}

The Indians in New England, and many other parts of America, had formerly no other vegetable but maize, or Indian corn, for making their bread. They call it weachin; and in the United States of America, there is much of the bread of the country made of this grain, not of the European Corn. In Italy and Germany, also, there is a species of maize, which is the food of the poor inhabitants.

The ear of the maize yields a much greater quantity of grain than any of our corn ears. There are commonly about eight rows of grain in the ear, often more, if the ground be good. Each of these rows contains at least thirty grains, and one of these gives much more flour than a grain of any of our corn. The grains are usually either white, or yellowish; but sometimes they are red, bluish, greenish, or olive coloured, and sometimes striped and variegated. This sort of grain, though so essentialiy necessary to the natives of the place, is yet liable to many accidents. It does not ripen till the end of Septemher; so that the rains ofter fall heavy upon it while on the stalk, and the birds in general peck it when it is soft and unripe. Nature has, to defend it from these accidents, covered it with a thick busk, which keeps off slight rams very well; but the birds, if not frighted away, often eat 
through it, and devour great quantities of the grain.

There are three or four varieties of maize in different parts of America. That of Virginia is very tall and robust, growing to seven or eight feet high. That of New England is shorter and lower. And the Indians, farther up in the country, have yet a smaller kind in common use. The stalk of the maize is joined like the sugar cane; it is very soft and juicy, and the juice is so sweet and saccharine, that sirup, as sweet as that of sugar, has been often made of it; and things, sweetened with it, have been found not distinguishable from those done with sugar. It has not yet been tried whether it will crystallize into sugar, but in all probability it will.

The Americans plant this corn any time from the beginning of March to the beginning of June; but the best season is the middle of April. The savage Indians, who knew nothing of our account of months, used to guide themselves in the seed time of this useful plant, by the budding of some particular trees of that country, and by the coming up of a sort of fish into their rivers, which they call the alonfe. These things were both so regular, that they were in no danger of mistaking the time.

The manner of planting maize is in rows, at equal distances, every way about five or six feet. They open the earth with a hoe, taking away the surface to three or four inches 
deep, and of the breadth of the hce; they then throw in a little of the finer earth, so as to leave the hoe four inches deep, or thereabouts, and in each of these holes they place four or five grains, at a little distance from one another. If two or three of these grow up, it is very well, as some of them are usually destroyed, either by the birds or other animals.

When the young plants appear, they hoe up the weeds from time to time; and when the stalk gathers some strength, they raise the earth a little about it, and continue this at every hoeing, till it begins to put forth the ears; then they enlarge the hill of earth round the root, to the size of a hop-hill, and after this they leave it, till the time of the harvest, without any further care. When they gather the ears, they either immediately strip off the corn, or else hang up the ears, tied in traces, at distances from one another; for if they are laid near together, they will heat and rot, or else sprout and grow ; but, kept cool and separate, they will remain good all the winter. The best method is to thresh out the corn as soon as the harvest is over, to dry it well on mats in the sun, and then lay it up in holes of the ground, well lined with mats, grass, or the like, and afterwards covered at top with more earth. The most careful of the Indians use this method, and this sort of subterranean granary always proves good.

The uses of this plant, among the Indians, are very many. The great article is the 
making their bread of it; but besides this, the stalks, when cut up before they are too much dried, are an excellent winter lood for cattle; but they usually leave them on the ground, for the cattle to feed on. The husks about the ear are usually separated from the rest, and make a particular sort of fodder, not inferior to our hay. The Indian women have a way of slitting them into narrow parts, and then they weave them artifially into baskets, and many other toys. The original way of eating the grain, among the Iridians, was this : they boiled it whole in water, till it swelled and became tender, and then they fed on it, either alone, or eat it with their fish and venison, instead of bread. After this, they found the way of boiling it into a sort of pudding, after brusing it in a mortar; but the way of reducing it to flour is the best of all. They do this by parching it carefully on the fire, without burning, and then beating it in mortars, and siting it. This flonr they lay up in bags, as their constant provision, and take it out with them when they go to war, eating it either dry or with water. The English have contrived, by mixing it into a stiff paste, either by itself, or with rye or wheat meal, fermenting it with leaven or yeast, and baking it in a hot oven, to make good bread of it. They have likewise found out a method of making good beer, either of the bread, or by malting the grain. 


\section{The Plant Cuce, or Coca.}

Among the plants of the country of Po. payan, in the jurisdiction of Timana, grows the Cuca, or Coca; an herb, so esteemed by the Indians, in some provinces of Peru, that they would part with any kind of provisions, the most valuable metals, gems, or any thing else, rather than want it. It grows on a weak stem, which, for support, twists itself round another stronger vegetable, like the vine. Its leaf is about an inch and a half, or two inches in length; and extremely smooth. The use the Indians make of it, is for chewing, which they do by mixing it with a kind of chalk, or whitish earth, called mambi, and chewing the se together, at first spit out the saliva, which that menducation causes, but afterwards swallow it; and thus move the leaves from one side of the mouth to the other, till their substance be quite drained, and then they are thrown away, and immediately replaced by fresh leaves. This herb is so nutritive and invigorating, that they labour whole days wit out any thing else, and on the want of it, they find a decay in their strength. They also add, that it preserves the teeth sound, and fortifies the stomach.

In the southern countries of Peru, great quantities of it are produced, being cultivated by the Indians; but that which grows wild, in the neighbourhood of Cusco, is accounted 
the best of any. It makes no small article in trade, particularly vast quantities of it are carried to the mine towns, that the owners of the mines may have wherewithal to furnish the Indians, who otherwise could not be brought to work, or would not have strength to go through with it. 'This cuca is exactly the same with the betel of the East Indies. The plant, the leaf, the manner of using it, and its qualities, are all the same; and the eastern nations are no less fond of their betel, than the Indians of Peru and Popayar are of their coca; but in the other parts of the province of Quito, as it is not produced, so neither is it used.

\section{The Carica, or Papaw.}

In the West Indies, this plant rises with a thick, soft, herbaceous stem, to the height of eighteen or twenty feet, naked till within two or three feet of the top. The leaves come out on every side, upon very long footstalks. Those which are situated undermost are almost horizontal, but those on the top are erect. These leaves, in full grown plants, are very large and divided into many lobes deeply sinuated. The stem of the plant, and also the footstalks of the leaves, are hollow. The flowers of the male plant are produced from between the leaves on the upper part of the plant. They have footstalks near two feet 
long; at the end of which the flowers stand in loose clusters, each having a separate short footstalk: these are of a pure white, and have an agreeable odour. The flowers of the female papaya also come out from between the leaves, towards the upper part of the plant, upon very short footstalks, sitting close to the stem: they are large and bell-shaped, composed of six petals, and are commonly yellow; when these fall away, the germin swells to a large fleshy fruit, of the size of a small melon. These fruits are of different forms; some angular, and compressed at both ends; others oval, or globular; and some pyramidical. The fruit, and all the other parts of the tree, abound with a milky acrid juice, which is applied for killing of ring-worms. When the roundish fruit are nearly ripe, the inhabitants of India boil and eat them with their meat, as we do turnips. They have somewhat the flavour of a pompion. Previous to boiling, they soak them for some time in salt and water, to extract the corrosive juice; unless the meat they are to be boiled with, should be very salt and old, and then this juice being in them will make it as tender as a chicken. But they mostly pickle the long fruit, and thus they make no bad succedaneum for mango. The buds of the female flowers are gathered and made in to a sweetmeat; and the inhabitants are such good ma. nagers of the produce of this tree, that they boil the shells of the ripe fruit into a repast, 
and the insides are eaten with sugar, in the manner of melons. The stem being hollow has given birth to a proverb in the West India Islands, where, in speaking of a dissembling person, they say, "6 he is as hollow as a popo." When they are grown to a large size, they make a noble appearance, with their strong upright stems, garnished on every side near the top with large shining leaves, spreading out near three feet all round the stem: the flowers of the male sort coming out in clusters on every side, and the fruit of the female growing round the stalks, between the leaves, are so different from any thing of Eu. ropean production, as well to entitle these plants to a place in the gardens of the curious.

\section{The Ricinus Minor, or Cassada Plant,}

OF WHICH IS MADE THE BREAD OF THE WEST INDIES.

This most curious plant is a native of the West Indies, and in general use for provision by all the inhabitants, especially in the hotter parts. It has a long tuberous root, about the size of a man's fist, with fibres drawing its nourishment, and full of a wheyish, veriomous juice. The stalks are white, crooked, brittle, having a very large pith, and several knobs sticking out on every side like warts, being the remainder of the leaves' footstalks, which are dropped off. It usually rises six or 
seven feet high, and has a smooth white bark; the branches, which come out on every side towards the top, are crooked, and have, on every part near their top leaves irregularly placed, something like the leaves of hemp or lupins. The flowers are pendulous, hanging down from the top of the twigs, by stalks branched three or four inches, on the ends of which four or five hang together by small footstalks. They are of a pale colour, with yellow stamina in the midale, which is followed by fruit about the bigness of a hazel nut, covered with a thin green skin, having six crests, or ledges, on its surface, and containing, in separate shells, three oblong grey seeds, spotted with black spots.

It is planted every where about the island; but more especially in the low lands, where it seldom rains, as it endures the want of rain better than any other of the vegetables of which bread is made, in those parts. It is ripe in twelve months after planting, and ready to pull up for use; the longer it is planted the heavier is the bread made of it, and, as it is sold by weight, the more profitable. But the new is pleasanter for use.

But what is very remarkable in this plant is, that the root is one of the strongest poisons; though, when properly prepared, it becomes the most nutritive bread. Some suppose that the poison is in the juice of the root; however this may be, the Indians always prepare it by boiling it over the fire. It is poisonous, 
not only to men, but to all sorts of cattle, unless they are used to it. Swine that are used to it have been known to drink of the juice running from the press very freely, without injury, while others, not accustomed to it, have been poisoned. It takes two years to ripen, and the bread made of it will keep two years. They plant it in raised heaps, nine feet square, planting therein twelve pieces: and they have a tradition, that one Boitius, a wise old man, finding it on a river's brink, brought it to his garden, and after several trials, by which some were killed, he came to prepare it right. The juice, though unboiled, is so strong a poison, when boiled, is pleasanter and more innocent than whey. The inhabitants make the cassada or cazabi bread by taking off the rind of the root, with shells, grating and putting it in to bags, made of tree-bark, pressing it and putting it over the fire. It swells prodigiously, from whence there is a law in India, that it is never to be put on table without wine or water, lest people should be choaked with its swelling. It has no taste, but great nourishment, and does not surfeit. It is called by a variety of names, as yuca, manyoc, manipuera. \&c. If dipped in sugared water, it is more pleasant, and if a little toasted afterwards, it eats yet better. People who feed altogether on this, live as long, and in as good health, as they who feed on any other sort of bread.

How wonderfully does the great Governor

$$
\text { Q } 2
$$


of the Universe provide for all his creatures! holding out a nourishment of this kind to so many thousands, where it would be difficult for them to procure sufficient supplies of wheat or rice. But how amazing is it, that a plant, thus poisonous in itself, should, by a little human care and industry, be rendered thus nutritive and salutary: but there is nothing in the works of God which doth not stimulate human industry and care.

\section{The Quercus, or Cork Tree.}

To take the bark off from this tree, they make an incision from the top to the bottom of the tree, and at each extremity another round the tree, perpendicularly to the first. When stripped from the tree, which does not therefore die, the bark is piled up in a pond or ditch, and loaded with heavy stones to flatten it, and reduce it into tables: hence it is taken to be dried; and when sufficiently dry, but in bales for carriage. If care be not taken to strip the bark, it splits and peels off itself, being pushed up by another bark, formed underneath.

The bark of cork, as well as the acorn, are of some use in medicine, being both reputed astringents, after being burnt, and powdered, when used externally; but the chief employ of the former is, to put in shoes, slippers, \&c. and to stop bottles. The Spaniards burn it, 
to make that kind of light black we call Spanish bluck, used by painters. Ciups made of cork are said to be good for hectical persons to drink out of. The Lgyptians made coffins of cork, which being lined with a resinous composition, preserve dead bodies uncofrupted. The Spaniards line stone walls with it, which not only renders them very warm, but corrects the moisture of the air.

\section{The Red Fir Tree.}

The Red Fir Tree, which grows on the mountains in Norway, is so rich in turpentine, as to be almost incorruptible. Some of the houses belonging to the Norway peasants, built of this timber, are supposed to be above four hundred years standing. In Guldbransdale, the house is still to be seen standing, in which King Olaf lodged five nights, above seven huudred years ago, when he travelledround the kingdom to convert the people to the Christian faith. Even one hundred years after the trunk of the fir tree has been cut down the pea. sants burn the roots for tar, which is a very profitable commodity. In the fens, the resin of the fir tree is by nature transformed into a substance which may be called Norway frankincense. The buds, or pine apples, of this tree, boiled in stale beer, make an excellent medicine for the scurvy; less unpleasant to the taste, though as efficacious, as tar water. 


\section{The Scotch Fir Tree.}

This tree is so called from its being a native of different parts of Scotland. It flourishes best in a poor sandy soil. In groves the trunk becomes tall and naked; in open situations, branched; on rocks and bogs it seldom grows to a large size; in black soil it becomes diseased; and in chalky land it dies. Sometimes it will thrive near running, but never stagnant, waters. The roots spread near the surface of the earth, except the central root, which grows perpendicularly downwards; and if this be broken off, or interrupted in its passage by rocks, the stem ceases to shoot upwards, and the tree ever remains a dwarf. This tree furnishes us with the best red, or yellow deal. Its bark will tan leather. The northern nations make bread of this tree, in the following manner. They chuse a tree whose trunk is even, (for these contain the least'rosin,) and strip off the bark in the spring, when it peels most easily. This they first dry gently in the shade, then in greater heat, and reduce it to powder: with this powder they mix a small quantity of meal, and with water knead it into bread. This they eat in common. The young fruit distilled, affords a fragrant essential oil. 


\section{The Xylo Aloes, or Aloe-wood Tree.}

The famous aloe-wood is the product of a tree growing in China and some of the Indian islands. The Calambac is the finest and most resimous of all the woods we are acquainted with. It is of a light spongy texture, very porous, and its pores so filled up with a soft and fragrant resin, that the whole may be pressed and dented by the fingers like wax, or moulded about, by chewing in the mouth, in the manner of mastich. 'This wood, laid on the fire, melts in great parts, like resin, and burns away in a few moments with a bright flame and perfumed smell. Its scent, while in the mass, is very fragrant and agreeable. It is so variable in its colour, that some have divided it into three kinds; the one variegated with black and purple; the second with the same black, but with yellow instead of purple; and the third yellow alone, like the yolk of an egg. This last is the least scented of the three. The variation, however, is owing to the trunk of the tree being itself of three different colours: and the heart of it is the valuable sort first described. The drug from this tree is esteemed a cordial, and frequently made use of in medicine, and a very fragrant oil may be procured from it by distil. lation. 


\section{The Nux Moschata, or the Nutmeg Tree.}

The trees that bear nutmegs are natives of the Spice Islands, belonging to the Dutch. They are in shape something like our pear trees, and have an ash-coloured bark, with a spongy wood. The flowers, or blossoms, are yellowish, with five leaves, not unlike those of cherries; to these succeed the fruit, hanging to a long pedicle. It is something like a walnut, and the kernel, or nutmeg, is covered with three coats, the first of which is fleshy, soft, and juicy; about as thick as a man's finger, but villous and red, and variegated with yellow, gold colour, and purple spots, like a peach. When it is ripe, it gapes spontaneously, and is of an austere taste. The nutmeg is very firm and compact, and yet is very easily pounded in a mortar. It is wrinkled without, and is somewhat of an ash colour, but within is variegated with a whitish yellow and a bay colour, running in veins without any regularity. Under the first coat, or cover, there is another recticular covering, or rather divided into several parts, which is of an oily clammy consistence, and as it were cartilaginous, but thin, and of an agreeable aromatic smell, and of an acrid aromatic taste, with a sort of bitterness. It is of a saffron colour, and is what we call mace. Between. the clefts of this, there is a third covering, 
which is a hard, woody, thin shell, of a dusky reddish colour, and brittle, and in this the nutmeg is contained. It is soft at first, but grows dry and hard in time. The taste and smell is too well known to need a description. Nutmegs abound with essential oil, which may be gained by distillation, and every pound will yield an ounce: besides which, there is another oil, which will swim on the surface of the water, and is thick, like suet, but has little virtue. Every sixteen ounces of nutmegs will yield three ounces and two drachms of oil, by expression, of the consistence of suet, and has both the smell and taste of the nutmeg. The principal use of nutmegs is as a spice. They are, however, sometimes used with success to promote digestion, discuss the wind, and other complaints : but the immoderate use of them is very bad, for they will affect the head, and produce sleepy diseases, which have been found by experience in the East Indies.

\section{-Manna Calabre, or Manna Tree.}

In Calabria and Sicily are two sorts of ash trees, from the boughs and leaves of which, manna is found in the summer months, unless prevented by rain. Sometimes the inhabitants make incisions in the bark of these trees, and the manna that issues from thence is called by the Calabrians forzato, whereas 
the other is named manna di frondi, and manna di corpo. When the weather is dry, it flows from the trunk and large boughs of these trees spontaneously, from the twentieth of June to the end of July, and from nonn till evening, in the form of a limpid fluid, which concretes into various grumes, and grows white and dry. They gather it the next day, scraping it off with wooden knives, if the weather is fair; but if it should chance to rain, the manna is lost. When July is past, they make incisions in the bark of these trees, and from noon till evening a liquid flows out, which concretes into thicker grumes, which are sumetimes very large; and requires a day or two to bring it to a proper consistence: this is redder than the former, and is sometimes blackish, on account of the earth and other filth mixed therewith.

The Calabrian manna is sometimes in grains, sometimes in tears, and sometimes in grumes, or small masses; it is brittle and whitish, while fresh, and somewhat transparent; but in time grows reddish, and in moist weather turos to the consistence of honey; it is as sweet as sugar, with a kind of an acidity. That is the best which is white or yellowish, light, and concreted into grains or grumes, in the shape of icicles; but that which is fat, like honey, or blackish and dirty, is not gond; for sometimes this is counterfeited with coarse sugar, honey, and a little scammony; likewise that which is white, opaque, solid, heavy, 
and not in the shape of icicles, is bad, because it is nothing but sugar and manna boiled together. This counterfeit sort may easily be distinguished from the true, by its density, weight, opacity, and taste.

The virtues of this valuable gum are well known from its various uses in medicine, which are too numerous to be here inserted. It is very scarce, on account of the difficulty of gathering it, and is held in great estimation, not only by the Calabrians, but by most civilized nations.

\section{Cortex Peruvianus; the Peruvian, or Jesuit's Bark.}

This tree grows in South America; and particularly in Peru, from whence it is named. It is highly esteemed in all parts of the world, where known, for its medicinal virtues. The bark, as it is generally sent to England, is from the sixth part of an inch to the fourth in thickness, is rough on the outside, of a brownish colour, and sometimes covered with a hoary moss; it is smooth within, a little resinous, and of a reddish, rusty colour, with an intensely bitterish taste, and somewhat astringent. Sometimes it is brought in large pieces, three or four inches in length, or up. waris, an inch broad, and not rolled up, because it is taken from the trunk of the tree; sometimes it is in tubes, like cinnamon, and 
marked with shallow circular chaps, or fissures: this is taken from the slender branches; and there is likewise a lesser sort, which is yellowish within and hoary without, which is obtained from the roots, and is in high esteem in different parts of Spain.

\section{Lignum Nephriticum, or Nephritic Wood.}

This wood is commonly brought from Campeachy, in the Bay of Honduras, and is not only famed for its medicinal virtues, but remarkable for the following singular properties. It is of a whitish or pale yellow colour, and is solid and heavy, with a subacrid, and a little bitterish taste; the bark is blackish, and the heart red, or brownish. When this wood is macerated in water for half an hour, it turns it of the colour of an opal, that is, a mixture of blue and yellow, but not united; for in one light it appears blue, and in another yellow. When the tincture of this wood is put into a glass vessel, and placed between the eye and the light, it appears to be of a gold colour; but if the eye is between the light and the vessel, it then seems to be blue. 


\section{The Miracula Natura, or Nepenthes.}

This wonderful plant is a native of Ceylon, and exceeds most others in singularity. The root is thick and brown, with long fibres of a reddish colour. The stem is two feet high, round and firm, and in many parts tinged with a faint purple. The leaves have no footstalks; they are oblong, moderately broad, highly ribbed, and furnished each with a kind of vessel at its extremity. The leaf itself, which is narrow at the base, grows broader towards the middle, and thence decreases gradually; but where it might be expected to terminate, the long point is continued in a kind of horn. 'This hangs down for a considerable length, swelling. very gradually in thickness, and from this lowest part turns up again, expanding into a hollow vessel, three inches long and half an inch in diameter, terminating in a large opening, which is covered with a kind of lid, all of one piece, and ending in a narrow slender tail. Such is the amazing structure of this leaf and its appendage. The flowers terminate the stalk, in considerable numbers. They are placed on short footstalks, and their colour, when in perfection, is yellow or greenish, and sometimes of a white or red colour. What makes this plant have a still more conspicuous ap. pearance is the cup, for there are no petals. This is formed of a single piece, but is divided 
deeply into four oval segments. These stand wide expanded, and mimic so many petals, by their colouring as well as form; but they remain to defend the fruit. In the centre rises a short style, siniple in form, and terminated by an obtuse top; and upon its summit are placed four filaments, so very short, that they are only distinguished by their buttons. The seed vessel is columnar, oblong, angulated, and marked by four ridges. These shew the joinings of four valves, of which it is composed, and it opens in four places, and the seeds are numerous and light. The singular appendages which are continued from the extremities of the leaves, are so many vessels containing a clear, wholesome, and well-tasted water; which has saved the lives of many, perishing in these hot and dry climes with thirst. These vessels, from the beginning, turn upwards, that they may hold the liquor; at first their colour is a whitish green, afterwards they become yellow, and in the end purple. The little piece falls over them very close, while small; but when they are of full bigness, and replete with water, they gape; and in the end the weight of the liquor bears down the vessel ; it runs out, and then the part fades. The fluid contained in these strange vessels is water, little or nothing altered by the plant; and the vess ls themselves are the diluted extremites of secretory glands. Things which appear most wonderful become familiar when a continued observation leads 
the way to understand them. Glands of this kind are very common in plants; though rarely so conspicuous. This wonderful plant grows in thick forests, where its long fibres supply it well with water, and where no sun comes to exhale it. Here they swell with the increasing liquor; and furnish a supply, designed by Providence, for the preservation of perhaps more than the human species. The quantity produced on a single plant is sufincient to quench the thirst of the most despairing traveller; and, by the marks of teeth upon the faded vessels, it is evident beasts often supply their wants at the same plenteous source.

\section{Noli-me-tangere, or Touch me'not.}

This plant is very common to be met with in summer time, under hedges, and is frequently cultivated in gardens, for its curious properties. It has a root that runs level with the ground, and sends forth a stalk to the height of a foot and a half, which is tender, of a bright green colour, smooth, shining; light, branched, geniculated by intervals, with tuberosities that look like the knots of the gout. 'The leaves are placed alternately, and are somewhat like French mercury, but they are bigger, and deeply dentated on the edges. From the places where the leaves join to the stalk, there proceed long pedicles, that bend R 2 
down to the ground, which are divided in to three or four branches, on which hang small flowers, with four unequal petals, supported by two green leaves; but the flower is yellow, representing a kind of sea monster, with a small body, and a slender, short, crooked, pointed tail, like an ox's horn, sprinkled with deep red spots; the mouth is wide, and in the middle there are several stamina, of a whitish colour. They are succeeded by long; slender, knotted fruit, of a whitish green, streaked with green lines, bending to the ground. They open as they grow ripe, and when the wind blows a little stronger than ordinary, or by the least touch, they shoot out their seeds, at the same time writhing themselves like worms: the seeds are either ash-coloured, brown, or red. Those that are not used to this plant, are always startled when the seeds burst out in the manner above described, and from its not bearing to be touched, without this effect, it is called nolime-tangere, that is, touch me not. It grows wild in some places, and flowers in June, and it is also propagated in gardens, for the diversion it affords, and delights most in moist, shady places.

\section{Orchis Latifolia, or Dog's Stones.}

This plant has a root composed of two bulbs, or fleshy tubercles, in the shape of 
large olives. The stalk rises near the height of a cubit, and has long pyramidical flowers. at the top, which are large and beautiful, whitish within, and spriskled with purple spots, but are reddish on the outside, and represent a man in armour, without bands or feet. The leaves are big, long, and broad, and are roundish at first, when the rise out of the earth in November. They flower in May. There are several sorts of these plants, the under part of whose flower represents several shapes, as a naked man, a butterfly, a drone, a pigeon, an ape, a lizard, and a parrot, and all these grow wild, in several parts of England, but deserve a place in every good garden, as botanical curiosities.

\section{The Great American Aloe.}

In America, and many parts of the West Indies, of which this wonderful plant is a native, it grows to a most enormous size; and the general opinion is that it blows but once in an hundred years, after which it gradually decays. An eminent naturalist and physician thus describes the valuable properties of this remarkable exotic.

"This plant alone (if human desires knew any bounds) would supply almost all the necessaries of life. It is sufficient for fencing fields and gardens: the leaves are good thatch; the stalks will serve for beams. The fibrous, or nerrous part, supplies the uses of flax, 
hemp, or cotton, to make thread or cloth; the prickles are good for pins, needles, nails, bodkins, and piercers, to make holes in the ears. The Indians likewise use them (in their idolatrous worship) to do penance to their bodies; neither are they unfit instruments for war. If this plant be lopt, or the trunk cut off, there issue forth, forty or fifty arrobas (each of which is thirty-two pounds) of liquor from each plant, out of which is made wine, vinegar, honey and sugar. The liquor is sweet of itself, and drinkuble. It grows by boiling thicker, turning first to sirup, and then to sugar. The natives mix water with the juice, and some orange and molon seeds, adding likewise some intoxicating ingredicnts, with which they drink to excess. Vinegar is made by mixing the sugar with water, and exposing it nine days to the sun. The juice is highly celebrated for its virtues in many internal complaints. The toasted leaf and the juice squeezed out with a little nitre, takes away newly made scars, if anointed therewith. The leaves and trunk, when buked, are very good eating, and taste much like candied citron chips. The leaves also, if roasted, are trequentiy applied as a remedy for convulsions. An ingenious witer, after expatiating largely on the virtues of this plant, thus concludes: "In a word, a whole faxily may be supplied with food and habitation, rainent, fand he arght have said with physic,) by an aloe.'" 


\section{The Bamboe, or Bambou,}

Is a native plant of the Indies, which mulriplies very much by its root, from which springs a branchy tuft, after the manner of the European reeds. It is of the largest kind of cane, and decreases gradually to the top, where it bears a blossom like our reeds.

The bamboo cane grows naturally almost every where within the tropical regions; it is common in many parts of Asia, as China, Cochin-China, Tonquin, Cambodia, Japan Ceylon, the Peninsula of Irdia, and the islands. This useful plant has been long introduced into the West Indies. There are some fine specimens of bamboo in the botanical garden at Liverpool. Scarcely any plant serves for more useful purposes than the bamboo, where it grows naturally. In the East Indies great use is made of it in building, and the houses of the meaner people are almost entirely composed of it. Bridges are also made of it, masts for their sailing vessels, boxes, cups, baskets, mats, and a great variety of other utensils and furniture. Paper is also made from it, by bruising and steeping it in water, and thus forming it into a pulp. It is the common fence for gardens and fields, and is frequently used as pipes for conveying water. The leaves are generally put round the chests of tea which are sent to kuropo from China, as package, fastened together so 
as to form a kind of mat. The tops of the tender shoots are frequently pickled in the West Indies. In the cavities of the bamboo is found, at certain seasons, a concrete white substance, which the Arabian physicians hold in high estimation.

\section{Bole-Hill Trees.}

A plantation of sycamores, encircling a school.house and play-ground, on a barren eminence, facing the High Moors of Derbyshire on the one hand, and on the other overlooking a richly cultivated, well wooded, and mountainous district, (near the seat of a gentleman, where the writer spent many pleasant hours,) gave rise to the following beautiful lines, which we introduce as a poetic finale to the preceding descriptions.

- Now peace to his ashes who planted yon trees

That welcome my wandering eye!

In lofty luxuriance they wave with the breeze,

And resemble a grove in the sky:

On the brow of the mountain, all barren and bleak,

They fourish in grandeur sublime;

Adorning its bald and majestical peak,

Like the lock on the forehead of Time,

2

A land-mark they rise. To the stranger forlorn, All night on the wild heath delay'd, 
'Tis rapture to spy the young beauties of morn,

Unveiling behind their dark shade:

The homeward-bound busioandman joys to behold,

On the line of the grey evening scene,

'Their branches yet gleaming with purple and gold,

And the sun-set expiring hetween.

3

The maidens that gather the fruit of the moor,

As weary and fainting they roam,

Through the blue dazzling distance of moonlight explore

The trees that remind them of home:

The clildren that dwell in the valley suspend

Their sports, and in extacy gaze,

When they see the broad moon from the mountain ascend,

And the school-house and grove in a blaze,

4

Ah ! sweet to my soul is the beautiful grove,

Awakening remembrance most dear;

When lonely in anguish and exile I rove,

Wherever its glories appear.

It gladiens my spirit, it soothes from afar,

With tranquil and tender delight;

It shines through my heart like a hope-burning star

Alone in the valley of night.

It tells me of moments of innocent bliss,

For ever and ever gone o'er;

Like the light of a smile, like the balm of a kiss,

They were-but they will be no more.

Yet wherefore of pleasures departed complain,

That leave such enjoyment behind?

Though the sun of theirsweetness be sunk in the main,

Their twilight still rests on the mind. 
6

Then peace to his ashes that planted yon trees!

Supreme o'er the landscape they rise,

With simple and lovely magnificence please

All bosoms, and ravish all eyes;

Nor marble, nor brass, could emblazon his fame,

Like his own sylvan trophies, that wave

In graceful memorial, and whisper his name,

And scatter their leaves on his grave.

7

Ah! thus when I sleep in the desolate tomb,

May the laurels I planted endure,

On the mountain of high immortality bloom,

Midst lightning and tempest secure!

Then ages unborn shall their verdure admire,

And nations sit under their shade,

While their spirit in secret shall move on my lyre,

Aloft in their branches displayed.

8

Hence, dream of vain glory ! - the light drop of dew

That glows in the violet's eye,

In the sun-beams of morn, to a fugitive view,

May rival a star of the sky:

But the violet is pluckt, and the drw.drop is flown,

The star unextinguished shall shine:

Then mine be the laurels of virtue alone,

And the glory of Paradise mine!

T H E E N D. 


\section{N D E X .}

A.

PAE.

Anacardium, or Cashew Nut Trec

Alligatol Pear tree

Acer Rubrum, or Red Maple

Arundo Arenaria, or Bent Star

126

Ague tree: Nuayhas

139

Alkanet Bastard. Gromwell

153

Asclepias Syriaca, or Cotton plant

158

Aurantia Malus. Orange tree

Aloe-wood tree. Xyló

Aloe, great American

B.

Baobab tree

Banian ditto

Beech ditto

Balsam of Tolu. Toluifera

Beaver tree. Magnolia Glauca

Besom ditto. Thuyæ

Bent Star. Arundo Arenaria

Butterwort. Yurkshire Saniele

Bark tree. Cortex Peruvianus 


\section{N D X.}

FA.GE.

Bamboe, ol Bambou 189

Bole-Hill Trees

C.

Cottun tree

Cucoa ditto

Coffee ditto

Cashew Nut tree. Anacardium

Cabbage Palm. Oleracea

Chesnut tree-the largest in the world

Chesnut tree, valuable properties of

Cinnamomum. Cinnanon

Camphora, or Camphor tree"

Cantchouc, India Rubber, or Syringe tres

Caryophyllus, or Clove tree

Cerbera, or Devil tree

Caratonia (Carob tree) or St. John's Bread

ib.

Cercis, or Judas tree

Chamaerops, or Palmetto tree

Cedar tree (white) or Juniper 78

Cedar tree (red) or Juniper

Citreum, Citrum, or Citron tree

Christ's Thorn. Paliurus

Castor Oil plant. Palma Christi

Ceylon Lily. Nelumbo

Chinese ditto. Lien-hoa

Chick-weed, Common. Trientalis

Candlebury Bush. Myrica-Cerifera 
$P A G$.

Corn, Indian, Zea, ol' Maize 264

Cuca, or Coca plaut 168

Carica, or Papaw plant 169

Cassada plant. Ricinus Minor 171

Caunabis Sativa, or Manured Hemp 162

Cork tree. Quercus 1.74

Cortex Feruvianus, or Bark tree

D.

Devil tree. Cerbera

Dionæ Muscipula, or Venus's Fly-trap 120

Datura, or Highwayman's Plant

Drossera Anglicana, or Sundew plant 150.

Dirca Patustris, or Leather-wood shrub 157.

Dwarf Laurel, or Kalmai Augusti-folia 160

Dog's Stones. Orchis Latifo'ia 186

Q.

Ebony tree 26

Egyptian Water Lily. Lotus

F.

Fountain tree.

Fir tree, Red 175.

Fil tree, Scotch 176

G.

Gunx tree of Dominica

Guava, or Sensative tree

Gromwell, or Bastaid Alkanet

H.

Herbs, wonderful propertien of 
INDEX.

PAGE.

Highwayman's Plant. Datura

Herica, or Wild Heath

151

Hemp, Manured. Canuabis Sativa

I.

India Rubber, Caontchouc, or Syringe tree

John, St. his Bread. Caratonia. Carob tree

Judas tree, Cercis

Jake tree, or Sour Sack

Juniper, or White Cedar tree

Juniper, or Red Cedar tree

Jericho, Rose of

India Rubber plant. Urceola Elastica

Ink shrub. Rhus Radicaus

159

Indial Corn, Zea, or Maize

K.

Kooker-boom, or Quiver tree

Kalmai Angusti-folia, or Dwarf Laurel

L.

Liriodendron, or Tulip tree

Lime, or Linden tree, Tilia

Lemon tree. Malus Limunia

Liquid Ambar, or Sweet Gum tree

Lotus, or Egyptian Water Lily

Lien-hoa, or Chinese Lily

Leather-wood shrub, Dirca Patustris

Lignum Nephriticum, or Nephritic Wood

M.

Magney, or Mati tree 
Maple Sugar tree

Magnolia Glauca, or Beaver trec

Malus Limonia, or Lemon tree

Mimosa, or Sensative plant

Myrica Cerifera, or Candlebury bush

Manna Calabræ, or Manna tree

Miracula Natura, or Nepenthes

Maize, or Indian Corn. Zea.

Nuayhas, or Ague tree

Nelumbo, or Ceylon Lily

Nutmeg tree. Nux Moschata

Nephritic Wood. Lignum Nephriticum

Nepenthes. Miracula Naturx

Noli-me-tangere, or Touch me not

O.

Oleracæ, or Cabbage Palm tree

Olea Europea, or Common Olive tree

Orange tree. Aurantia Malus

Oak trees, Description of remarkable one:

Langley Oak

Lucomb ditto

ib.

Damery's ditto

Wallace ditto

Hern's ditto

Queen Elizabeth's ditto

Fairlop ditto

Shire ditto 
Oak tree, Chaucer's

Magdalen Oak

Boddington ditto. 102

Shelton ditto 104

Royal, or King Charles' ditto 105

Sir Philip Sydney's ditto 109

Beauty, Stately, and Majesty 110

Orehis Latifolia, or Dog's Stones

P.

Poison tree. Upas

Plaue tree, remarkable Instance of one

Persea, or Alligator Pear tree

Poison Ash. Rhus Vernix

Palmetto tree. Chamaerops

Plantain tree, or White Fig

Plants and Herbs, wouderful properties of

Paliurus, or Thorn of Christ

Palma Cliristi, or Castor-oil plant

Papaver Album, or White Poppy

Pine, Wild, curious properties of

Pepper plant

Papaw, Popo, or Carica

Peruvianus Cortex, or Jesuits' Bark tree

Q.

Quiver tree or Kooker-boom

Quercus, or Cork trce

$\mathrm{R}$.

Rhus Vernix, or Poison Ash 


\section{IN DEX.}

PA GE.

Red Janiper, or Cedar tree 80

Red Maple tree. Acer Rubrum

83

Rose of Jericho

125

Ricinus Minor, or Casada plant of the Wost Indies

171

Rhus Radicans, or Ink shrub

159

Red Fir tree

S.

Sugar Maple tree

Sissafras tree

St. John's Bread. Cillitunia. Carob trec

Sour Sack, or Jake tree

Sweet Gum, or Liquid Amber tree

Sensative tree, Gruava

Sour Sop tree

Swietenia Mahagoni, or Mabogauy tiee

Sensative plant. Mimosa.

Sundew. Drossera Anglicana

Scutch Fir tree

T.

Tallow tree, remarkable properties of,

Tea tree

Tulip tree. Liriodendron

Toluifera, or Balsam of Tolu tree

Thuyæ, or Besom tree

Thorn of Christ. Paliurus

Tobacico plant. Tabacum

Trientalis. Common Chick-weed

Touch me not. Noli-me-tangere 
U. V 。

Upas, or Poison tree

Vallisneria, or Water plant

Venus's Fly Tiap. Dionæ Muscipula

Vinegar plant. Virginian Sumach

Urceola Elastica, or Indian Rubber plant

W.

Water tree, or Fountain, in Americá

White Fig tree, or Plantain

Wintera Aromatica, or Winter Cinnamon

White Cedar, or $J$ uniper tree 78

Water Lily, Egyptian. Lotus

White Poppy. Papaver Album

Wild Heath. Herica

Wild Pine

Water With, or -Water plant

Wonderful properties of Plańts and Herbs

Wonderful Contrivance of Nature for the Preservation of a plant

$\mathbf{x}$.

Xylo Aloes, or Aloe-wood tree

Y.

Yorkshire Saniele, or Butterwort

$z$.

Zea, Maize, or Indian Corn 

an $\quad 9=$

wa 